\title{
SECOND GENERATION ADVANCED REBURNING FOR HIGH EFFICIENCY NOx CONTROL
}

\author{
Quarterly Report No. 6 for Period \\ January 1 - March 31, 1997 \\ Prepared by: \\ Vladimir M. Zamansky, Peter M. Maly, Mark S. Sheldon, \\ David Moyeda, William C. Gardiner, Jr., and Vitaly V. Lissianski
}

April 30, 1997

DOE Contract No. DE-AC22-95PC95251

Phase I

Submitted by:

Energy and Environmental Research Corporation

18 Mason, Irvine, CA 92618 
Disclaimer

This report was prepared as an account of work sponsored by an agency of the United States Government. Neither the United States nor any agency thereof, nor any of their employees, makes any warranty, express or implied, or assumes any legal liability or responsibility for the accuracy, completeness, or usefulness of any information, apparatus, product, or process disclosed, or represents that its use would not infringe privately owned rights. Reference herein to any specific commercial product, process, or service by trade name, trademark, manufacturer, or otherwise does not necessarily constitute or imply its endorsement, recommendation, or favoring by the United States Government or any agency thereof. The views and opinions of authors expressed herein do not necessarily state or reflect those of the United States Government or any agency thereof. 


\begin{abstract}
This project is designed to develop a family of novel $\mathrm{NO}_{\mathrm{x}}$ control technologies, called Second Generation Advanced Reburning which has the potential to achieve 90+\% $\mathrm{NO}_{\mathrm{x}}$ control in coal fired boilers at a significantly lower cost than SCR. The sixth reporting period (January 1 - March 31, 1997) included both experimental and modeling activities. New kinetic experimental data for hightemperature decomposition of sodium carbonate were obtained in a flow reactor at the University of Texas in Austin. Pilot scale combustion tests in a 1.0 MMBtu/hr Boiler Simulator Facility were continued with firing coal and using natural gas as reburn fuel. The results demonstrate that over $90 \%$ $\mathrm{NO}$ control is achievable by injecting one or two N-agents with sodium promoters into the reburning zone and with the overfire air. Advanced reburning technologies does not cause significant byproduct emissions. The AR kinetic model was updated to include chemical reactions of sodium carbonate decomposition. Modeling was conducted on evaluation of the effect of sodium on process kinetics in the reburning zone. This study revealed that increasing or decreasing radical concentrations in the presence of sodium can significantly affect the reactions responsible for NO reduction under fuel-rich conditions. The effect of mixing time on performance with sodium was also evaluated. Initial activities on engineering design methodology for second generation AR improvements are described.
\end{abstract}




\section{TABLE OF CONTENTS}

$\underline{\text { Section }}$

Page

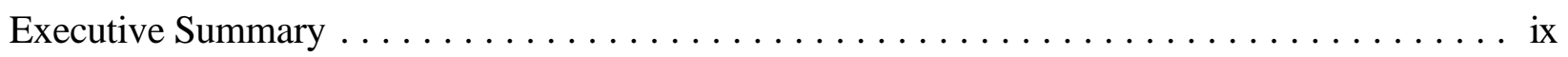

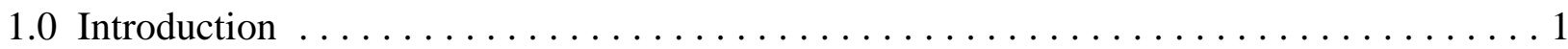

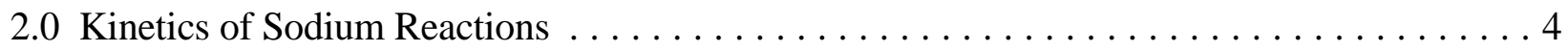

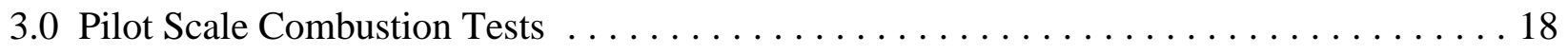

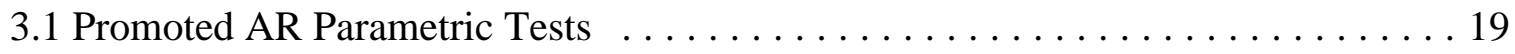

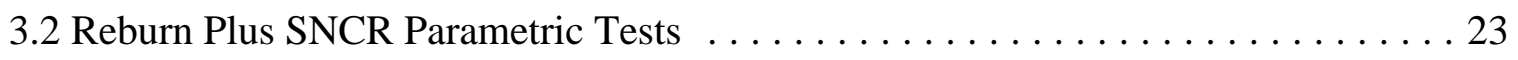

3.3 MIAR Parametric Tests . . ............................ 27

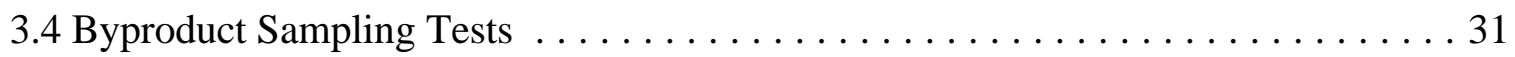

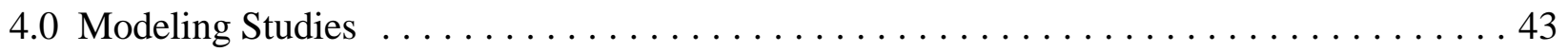

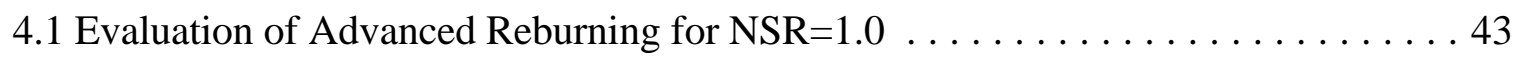

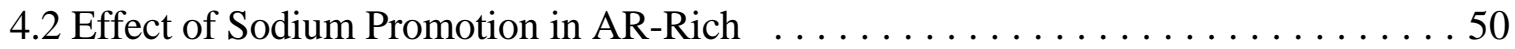

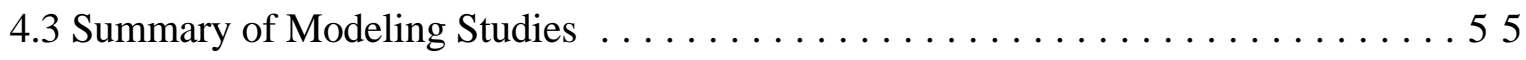

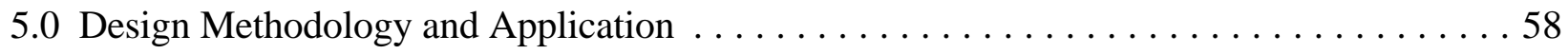

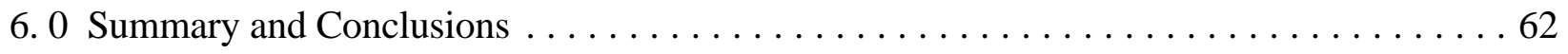

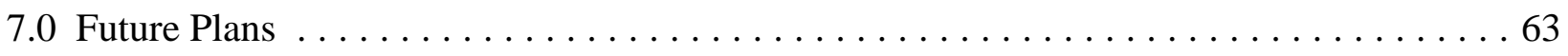

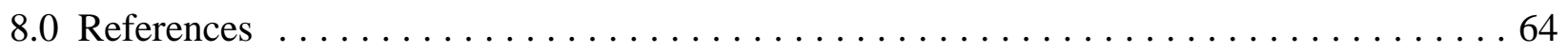




\section{LIST OF FIGURES}

Figure $\quad$ Page

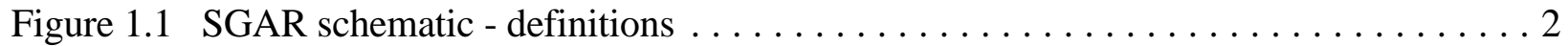

Figure 2.1. Dependence of $\mathrm{Na}_{2} \mathrm{CO}_{3}$ to $\mathrm{CO}_{2}$ conversion according to equation (2.1) $\ldots \ldots$

Figure 2.2. Comparison between experimental and calculated equilibrium conversions of $\mathrm{Na}_{2} \mathrm{CO}_{3}$ to

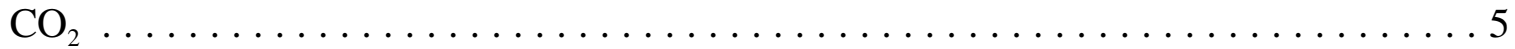

Figure 2.3. Sensitivity spectrum for decomposition of $\mathrm{Na}_{2} \mathrm{CO}_{3} \ldots \ldots \ldots \ldots$

Figure 2.4. Rate coefficient inferred for $\mathrm{Na}_{2} \mathrm{CO}_{3} \rightarrow \mathrm{Na}_{2} \mathrm{O}+\mathrm{CO}_{2} \ldots \ldots \ldots \ldots \ldots$

Figure 2.5. Rate coefficient inferred for $\mathrm{Na}_{2} \mathrm{O}+\mathrm{CO}_{2} \rightarrow \mathrm{Na}_{2} \mathrm{CO}_{3} \ldots \ldots \ldots \ldots$

Figure 2.6. Comparison of experimental (symbols) and calculated (lines) $\mathrm{Na}_{2} \mathrm{CO}_{3}$ conversion profiles

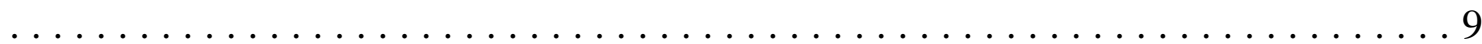

Figure 2.7. Time histories of ion currents at $m / z=44$ and 106 and total ion current $\ldots \ldots 12$

Figure 2.8. Mass spectrum at $62 \mathrm{~s}$ on the $\mathrm{x}$-axis of Figure $2.7 \ldots \ldots \ldots \ldots \ldots \ldots$

Figure 2.9. Mass spectrum at the time $m / z=23$ reaches its maximum $\ldots \ldots \ldots 13$

Figure 2.10. Mass spectrum at the time $m / z=23$ reaches its maximum in thermal ionization mode

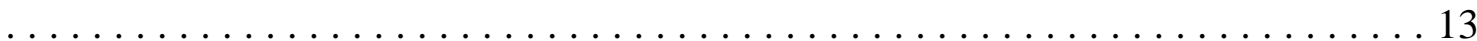

Figure 2.11. Time histories of ions with $m / z=23\left(\mathrm{Na}^{+}\right), 44\left(\mathrm{CO}_{2}^{+}\right), 53\left(\mathrm{Na}_{2} \mathrm{CO}_{3}^{++}\right), 106\left(\mathrm{Na}_{2} \mathrm{CO}_{3}^{+}\right)$, $129\left(\mathrm{Na}_{3} \mathrm{CO}_{3}^{+}\right)$, and total ion current $\ldots \ldots \ldots \ldots \ldots \ldots \ldots \ldots \ldots \ldots \ldots \ldots \ldots \ldots \ldots \ldots \ldots \ldots$

Figure 2.12. Time histories of $\mathrm{Ag}^{+}$(109) and total ion current for experiments with $\mathrm{Ag}$ wire . 14

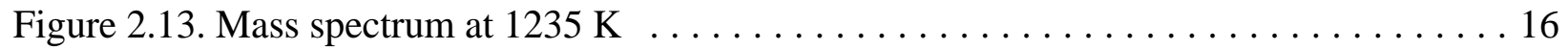

Figure 2.14. Time histories of ions with $m / z=23\left(\mathrm{Na}^{+}\right)$and $109\left(\mathrm{Ag}^{+}\right)$, and total ion current . 16

Figure 2.15. Mass spectrum corresponding to the moment of burnout of Ag wire . . . . . 17

Figure 3.1. AR-Lean tests: effect of N-agent/OFA injection temperature upon performance . 20

Figure 3.2. AR-Rich tests: effect of $\mathrm{N}$-agent injection temperature upon performance . . . . . 21

Figure 3.3. AR-Rich tests: effect of OFA injection temperature upon performance $\ldots \ldots \ldots 22$

Figure 3.4. AR-Rich tests: effect of sodium promoter concentration upon performance . . . . 24

Figure 3.5. Reburning+SNCR tests: effect of additive injection temperature upon performance .25

Figure 3.6. AR-Rich + SNCR tests: effect of second additive injection temperature upon 


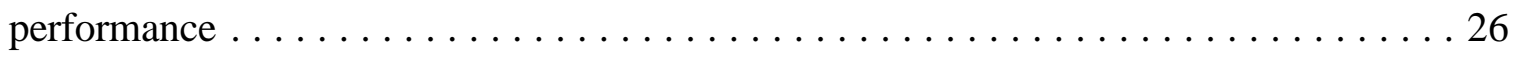

Figure 3.7. MIAR tests: effect of first additive injection temperature upon

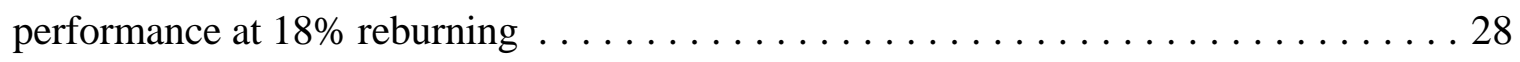

Figure 3.8. MIAR tests: effect of first additive injection temperature upon performance at $9 \%$ reburning . . . . . . . . . . . . . . . . . . . 29

Figure 3.9. MIAR tests: effect of second additive injection temperature upon

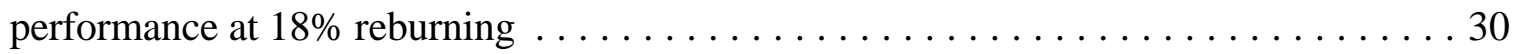

Figure 3.10. MIAR tests: effect of second additive injection temperature upon

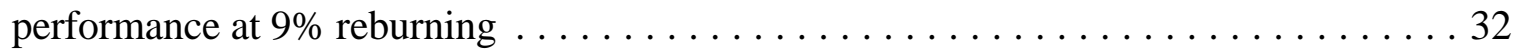

Figure 3.11. $\mathrm{CO}$ and $\mathrm{N}_{2} \mathrm{O}$ emissions for $\mathrm{AR}$ technologies $\ldots \ldots \ldots \ldots \ldots \ldots \ldots \ldots$

Figure 3.12. $\mathrm{NH}_{3}$ and $\mathrm{HCN}$ emissions for $\mathrm{AR}$ technologies $\ldots \ldots \ldots \ldots \ldots \ldots$

Figure 3.13. $\mathrm{SO}_{3}$ emissions for AR technologies $\ldots \ldots \ldots \ldots \ldots \ldots \ldots \ldots \ldots \ldots \ldots \ldots$

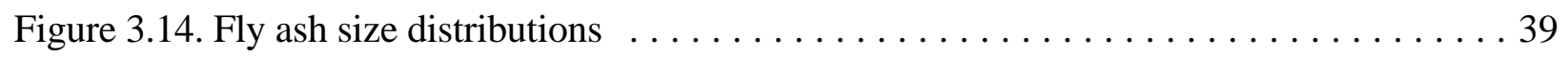

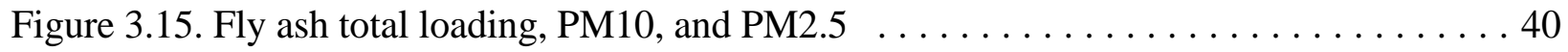

Figure 3.16. Carbon in ash results $\ldots \ldots \ldots \ldots \ldots \ldots \ldots \ldots \ldots \ldots \ldots \ldots \ldots \ldots \ldots \ldots \ldots \ldots \ldots$

Figure 4.1. AR-Rich $\mathrm{NO}$ emissions, for $\mathrm{SR}_{2}=0.90$ and $\mathrm{NH}_{3}$ added to $\mathrm{NSR}=1 \ldots \ldots 6$

Figure 4.2. AR-Rich $\mathrm{NO}$ emissions, for $\mathrm{SR}_{2}=0.99$ and $\mathrm{NH}_{3}$ added to $\mathrm{NSR}=1 \ldots \ldots 7$

Figure 4.3. AR-Lean $\mathrm{NO}$ emissions, for $\mathrm{SR}_{2}=0.99$ and $\mathrm{NH}_{3}$ added at the same time as burnout air,

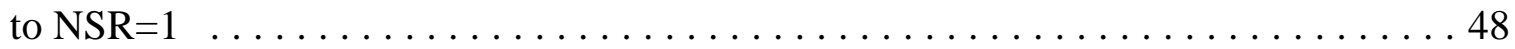

Figure 4.4. AR-Lean $\mathrm{NO}$ emissions, for $\mathrm{SR}_{2}=0.99$ and $\mathrm{NH}_{3}$ added $0.1 \mathrm{~s}$ after burnout air, to $\mathrm{NSR}=1$

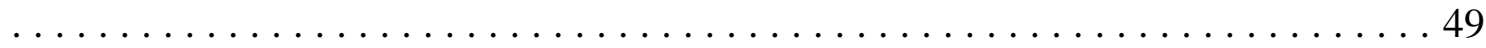

Figure 4.5. Promoted AR-Rich kinetic curves from the point of $\mathrm{NH}_{3}(\mathrm{NSR}=1)$ and $50 \mathrm{ppm} \mathrm{Na}_{2} \mathrm{CO}_{3}$ injection $(100 \mathrm{~ms}$ after reburn fuel $)$, with instantaneous mixing . . . . . . . . 52

Figure 4.6. Unpromoted AR-Rich kinetic curves from the point of $\mathrm{NH}_{3}(\mathrm{NSR}=1)$ injection (100 ms after reburn fuel), with instantaneous mixing $\ldots \ldots \ldots \ldots \ldots \ldots \ldots \ldots \ldots \ldots \ldots \ldots \ldots \ldots$

Figure 4.7. Promoted AR-Rich kinetic curves from the point of $\mathrm{NH}_{3}(\mathrm{NSR}=1)$ and $50 \mathrm{ppm} \mathrm{Na}_{2} \mathrm{CO}_{3}$ injection $(100 \mathrm{~ms}$ after reburn fuel), with $30 \mathrm{~ms}$ mixing $\ldots \ldots \ldots \ldots \ldots \ldots$

Figure 4.8. Unpromoted AR-Rich kinetic curves from the point of $\mathrm{NH}_{3}(\mathrm{NSR}=1)$ injection $(100 \mathrm{~ms}$ after reburn fuel), with 30 ms mixing $\ldots \ldots \ldots \ldots \ldots \ldots \ldots \ldots \ldots \ldots \ldots \ldots \ldots \ldots \ldots \ldots$ 
Figure 4.9. Promoted AR-Rich kinetic curves from the point of $\mathrm{NH}_{3}(\mathrm{NSR}=1)$ and $50 \mathrm{ppm} \mathrm{Na}_{2} \mathrm{CO}_{3}$ injection $(100 \mathrm{~ms}$ after reburn fuel), with $300 \mathrm{~ms}$ mixing . . . . . . . . . . 54

Figure 4.10. Unpromoted AR-Rich kinetic curves from the point of $\mathrm{NH}_{3}(\mathrm{NSR}=1)$ injection $(100 \mathrm{~ms}$

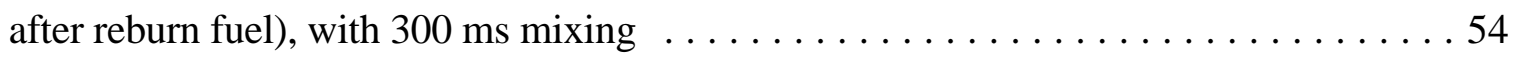

Figure 4.11. NO and Total Fixed Nitrogen before burnout for AR-Rich, $\mathrm{NH}_{3}$ added to NSR=1.0, with and without $50 \mathrm{ppm} \mathrm{Na}_{2} \mathrm{CO}_{3}$ promoter $\ldots \ldots \ldots \ldots \ldots \ldots \ldots \ldots \ldots \ldots \ldots \ldots \ldots \ldots$

Figure 4.12. NO and Total Fixed Nitrogen before burnout for AR-Rich, 800 ppm $\mathrm{NH}_{3}$ added (NSR approximately 1.5), with and without $50 \mathrm{ppm} \mathrm{Na}_{2} \mathrm{CO}_{3}$ promoter $\ldots \ldots \ldots \ldots 6$

Figure 5.1. EER's general methodology for application of reburning and advanced reburning to

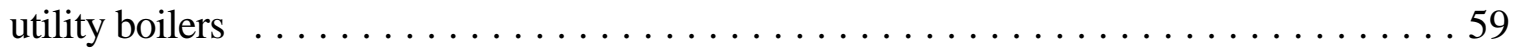




\section{LIST OF TABLES}

Table

Page

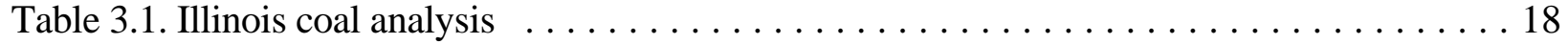

Table 3.2. Byproduct sampling conditions and results $\ldots \ldots \ldots \ldots \ldots \ldots \ldots \ldots \ldots \ldots \ldots \ldots$ 


\section{EXECUTIVE SUMMARY}

This project is designed to develop a family of novel $\mathrm{NO}_{\mathrm{x}}$ control technologies, called Second Generation Advanced Reburning, which has the potential to achieve 90+\% $\mathrm{NO}_{\mathrm{x}}$ control in coal fired boilers at a significantly lower cost than SCR. The sixth reporting period (January 1 - March 31, 1996) included both experimental and modeling activities.

New kinetic experimental data for high-temperature decomposition of sodium carbonate (Task 1.2) were obtained in a flow reactor at the University of Texas in Austin. These data show that decomposition of $\mathrm{Na}_{2} \mathrm{CO}_{3}$ from 900 to $1190 \mathrm{~K}$ can be described in terms of three chemical reactions:

$$
\begin{aligned}
& \mathrm{Na}_{2} \mathrm{CO}_{3} \rightarrow \mathrm{Na}_{2} \mathrm{O}+\mathrm{CO}_{2} \\
& \mathrm{Na}_{2} \mathrm{O}+\mathrm{CO}_{2} \rightarrow \mathrm{Na}_{2} \mathrm{CO}_{3} \\
& \mathrm{Na}_{2} \mathrm{O}+\mathrm{H}_{2} \mathrm{O}<=>2 \mathrm{NaOH}
\end{aligned}
$$

The rate coefficients of the first two reactions were defined to describe the measured rate of $\mathrm{Na}_{2} \mathrm{CO}_{3}$ decomposition, while the rate coefficient of the third rapid step was estimated from kinetic data for the similar reaction of $\mathrm{CaO}$.

Mass spectrometric analysis of products of $\mathrm{Na}_{2} \mathrm{CO}_{3}$ decomposition confirms that the primary gas-phase products of decomposition are $\mathrm{Na}, \mathrm{NaOH}$ and $\mathrm{CO}_{2}$. Experiments with temperature control show formation of $\mathrm{Na}$ atoms at temperature $1235 \mathrm{~K}$.

The BSF parametric pilot scale tests (Task 1.4) were completed during this reporting period. The results demonstrated that the AR technologies are able to provide effective $\mathrm{NO}_{\mathrm{x}}$ control for a high-sulfur coal fired combustor. Sodium was found to significantly promote performance when added at $150 \mathrm{ppm}$, which can be a manageable level for utility boilers. Maximum NO reductions achieved by the promoted AR technologies were $84 \%$ for AR-Lean, $93 \%$ for AR-Rich, $94 \%$ for reburning plus SNCR, and $95 \%$ for MIAR.

A comparative byproduct emission study was conducted to compare the emissions from different variants of AR with commercial technologies (reburning and SNCR). For each technology sampling included: $\mathrm{CO}, \mathrm{SO}_{2}, \mathrm{~N}_{2} \mathrm{O}$, total hydrocarbons, $\mathrm{NH}_{3}, \mathrm{HCN}, \mathrm{SO}_{3}$, fly ash mass loading and size distribution, PM10, PM2.5, and carbon in ash. AR technologies do not generate significant byproduct emissions in comparison with basic reburning and SNCR processes under similar conditions. In most cases, byproduct emissions were found to be lower for the AR technologies.

Modeling (Task 1.5) demonstrated that optimization of the amount of $\mathrm{N}$-agent is important to AR system performance. The quantity must be adequate for the degree of NO reduction but more is not necessarily better. The amount of $\mathrm{N}$-agent and mixing time both affect the net NO reduction.

Modeling predicts that sodium promotion can improve AR-Rich performance by sustaining the radical pool when it is needed. This effect is most pronounced in systems with long characteristic mixing times, as is typical in full-scale industrial applications. Thus, promoted advanced reburning shows promise for commercial implementation.

A detailed plan was prepared for updating EER's basic methodology for design and scale up of AR to utility boilers to include the second generation improvements (Task 1.6).

The main activities of the next quarter will include continuation of the experimental and modeling studies on identification of sodium promotion mechanisms under reburning and burnout conditions. Main results on developing engineering design methodology of the second generation AR processes will be obtained, including economic and market analysis of controlling NO emissions. 


\subsection{Introduction}

This project is designed to develop a family of novel $\mathrm{NO}_{\mathrm{x}}$ control technologies, called Second Generation Advanced Reburning (SGAR), which has the potential to achieve $90+\% \mathrm{NO}_{\mathrm{x}}$ control in coal fired boilers at a significantly lower cost than SCR.

Phase I consists of six tasks:

Task 1.1 Project Coordination and Reporting/Deliverables

Task 1.2 Kinetics of $\mathrm{Na}_{2} \mathrm{CO}_{3}$ Reactions with Flue Gas Components

Task $1.30 .1 \times 10^{6} \mathrm{Btu} / \mathrm{hr}$ Optimization Studies

Task $1.41 .0 \times 10^{6} \mathrm{Btu} / \mathrm{hr}$ Process Development Tests

Task 1.5 Mechanism Development and Modeling

Task 1.6 Design Methodology and Application

During the period (October 1, 1995 - December 30, 1996), flow system experiments were conducted at the University of Texas in Austin on experimental evaluation of sodium carbonate kinetics (Task 1.2). The bench-scale $0.1 \mathrm{MMBtu} / \mathrm{hr}$ combustion tests were completed on different variants of the AR technology (Task 1.3). The pilot-scale combustor, 1.0 MMBtu/hr Boiler Simulator Facility (BSF), was prepared for the test program and natural gas and coal firing experiments were conducted (Task 1.4). This Task is currently completed. A C-H-O-N-Na-S-Cl chemical mechanism for description of the process chemistry was selected, and interaction of ammonia with NO in the reburning and overfire air (OFA) zones was modelled under different conditions (Task 1.5). The effect of various additives to promote $\mathrm{NO}-\mathrm{NH}_{3}$ interaction in the reburning zone was also evaluated by modeling. Thermodynamic data on sodium speciation under typical flue gas conditions were obtained.

The sixth reporting period (January 1 - March 31, 1997) included both experimental and modeling activities. Kinetic rate coefficients were obtained on reactions of sodium carbonate decomposition and sodium oxide interaction with water (Task 1.2) at the University of Texas in Austin (UT). Mass 
spectrometric analysis of $\mathrm{Na}_{2} \mathrm{CO}_{3}$ decomposition confirmed that the primary gas phase products are $\mathrm{Na}, \mathrm{NaOH}$, and $\mathrm{CO}_{2}$. The BSF tests (Task 1.4) were completed. The results have been reduced and are reported below. The C-H-O-N-Na kinetic model was used to evaluate the effect of sodium under reburning and burnout conditions (Task 1.5). This analysis revealed the most important elementary reactions of sodium which are responsible for formation/removal of active species and promotion/inhibition of NO control. The effect of mixing times on performance of AR-Lean and ARRich in the presence of sodium was also evaluated by using a one-dimensional flame code. Initial activities on updating engineering design methodology to include the second generation improvements are reported. As in previous quarterly reports, Figure 1.1 summarizes the nomenclature for the various regions of the Second Generation Advanced Reburning (SGAR) process.

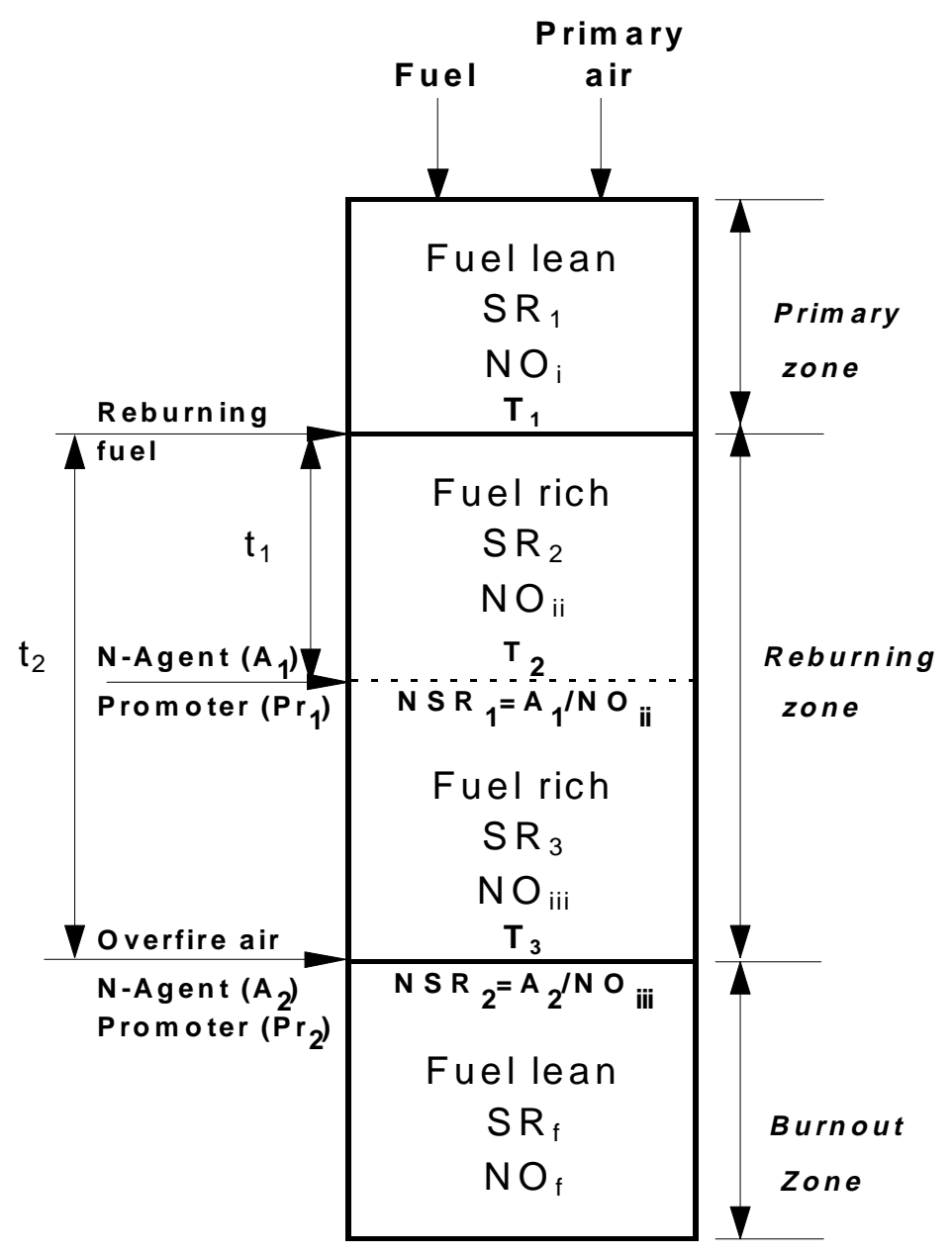

Figure 1.1 SGAR schematic-definitions. 
The region upstream of the reburning fuel injection is referred to as the "primary zone". The primary zone Stoichiometric Ratio $\left(\mathrm{SR}_{1}\right)$ is maintained at $\mathrm{SR}_{1}=1.1$ for all tests and the initial NO concentration in this zone is referred to by a single subscript "i". The region between the reburning fuel and overfire air (OFA) injection is referred to as the "reburning zone". The reburning fuel is injected at a temperature of $T_{1}$. The first $\mathrm{N}$-agent $\left(\mathrm{A}_{1}\right)$ is introduced into the reburn zone at $\mathrm{T}_{2}$ with a Nitrogen Stoichiometric molar Ratio $\mathrm{NSR}_{1}=\mathrm{A}_{1} / \mathrm{NO}_{\mathrm{ii}}$. This zone is divided into two fuel rich zones with stoichiometries $\mathrm{SR}_{2}$ and $\mathrm{SR}_{3}$. NO concentration upstream of the first $\mathrm{N}$-agent injection is referred to as "ii". NO reduction from $\mathrm{NO}_{\mathrm{i}}$ to $\mathrm{NO}_{\mathrm{ii}}$ is caused by reburning only. The first $\mathrm{N}$-agent is injected with or without promoters $\left(\operatorname{Pr}_{1}\right)$ with a $t_{1}$ delay time after RF injection. NO concentration downstream of the $\mathrm{A}_{1}$ injection is called $\mathrm{NO}_{\mathrm{iii}}$, and $\mathrm{NO}$ reduction from $\mathrm{NO}_{\mathrm{ii}}$ to $\mathrm{NO}_{\mathrm{iii}}$ is caused by the first $\mathrm{N}$-agent. Overfire air is injected at $\mathrm{T}_{3}$ with a $\mathrm{t}_{2}$ delay time after RF injection. OFA is a carrier gas for injecting the second $\mathrm{N}$-agent $\left(\mathrm{A}_{2}\right)$ which is injected with or without promoters $\left(\operatorname{Pr}_{2}\right) . \mathrm{A}_{2}$ is injected with $\mathrm{NSR}_{2}=\mathrm{A}_{2} \mathrm{NO}$. Tiir he downstream region is referred to as the "burnout zone". Stoichiometric ratio in this zone is $\mathrm{SR}_{\mathrm{f}}$, and the final $\mathrm{NO}$ concentration is $\mathrm{NO}_{\mathrm{f}}$. 


\subsection{Kinetics of Sodium Reactions}

This section was prepared by W.C. Gardiner and V. Lissianski of the University of Texas at Austin.

General objective of the work for 1/97 - 3/97:

Kinetic modeling of the $\mathrm{Na}_{2} \mathrm{CO}_{3}$ decomposition. Experimental study of $\mathrm{Na}_{2} \mathrm{CO}_{3}$ decomposition in flow system. Mass spectrometric study of products of $\mathrm{Na}_{2} \mathrm{CO}{ }_{3}$ decomposition as a function of temperature.

Summary of activity through March 31, 1997.

Activity during the period January 1 through March 31 concentrated on two directions: Computer modeling of $\mathrm{Na}_{2} \mathrm{CO}_{3}$ decomposition and experiments on determination of rate and products of $\mathrm{Na}_{2} \mathrm{CO}_{3}$ decomposition. Significant additional efforts were given to mass spectrometric study of $\mathrm{Na}_{2} \mathrm{CO}_{3}$ decomposition as a function of temperature.

As described in the previous report (Zamansky et al., Section 2, January 1997), $\mathrm{Na}_{2} \mathrm{CO}_{3}$ decomposition at temperatures lower than $2000 \mathrm{~K}$ is not a spontaneous process in the ordinary thermochemical sense. It was noted, however, that if the amount of $\mathrm{Na}_{2} \mathrm{CO}_{3}$ introduced is very small, it still can decompose significantly or even completely since the final pressure of $\mathrm{CO}_{2}$ is less than its equilibrium value at flue-gas temperatures. Since in some of our experiments the measured $\mathrm{CO}_{2}$ pressures were lower than equilibrium values, we concluded that $\mathrm{Na}_{2} \mathrm{CO}_{3}$ might decompose either completely or partially into gas phase products on the time scale of the experiments. Figure 2.1 illustrates this idea by showing how $\mathrm{Na}_{2} \mathrm{CO}_{3}$ to $\mathrm{CO}_{2}$ conversion (based on equation 2.1) at chemical and phase equilibrium at a total pressure of 1 atmosphere depends on temperature at initial $\mathrm{Na}_{2} \mathrm{CO}_{3}$ concentrations of 100, 300 and 500 ppm, typical concentrations used in our flow system experiments and proposed for pollution control in flue gas. The assumed amount of $\mathrm{H}_{2} \mathrm{O}$ in the mixture is $20 \%$, the rest is $\mathrm{N}_{2}$.

$$
\mathrm{Na}_{2} \mathrm{CO}_{3}+\mathrm{H}_{2} \mathrm{O} \Leftrightarrow>2 \mathrm{NaOH}+\mathrm{CO}_{2}
$$




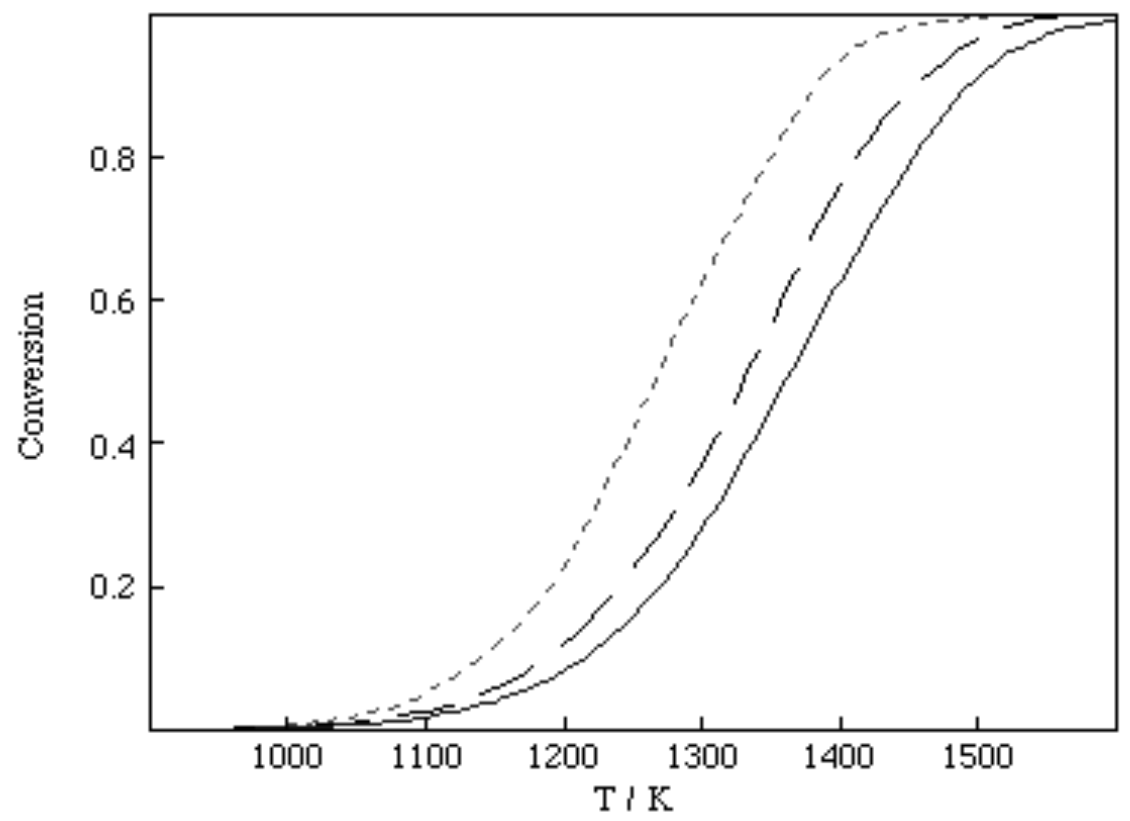

Figure 2.1. Dependence of $\mathrm{Na}_{2} \mathrm{CO}_{3}$ to $\mathrm{CO}_{2}$ conversion according to equation (2.1). Solid line corresponds to an initial $\mathrm{Na}_{2} \mathrm{CO}_{3}$ concentration of $500 \mathrm{ppm}$ in the gas phase, the dashed line to 300 ppm, and the dotted line to $100 \mathrm{ppm}$.

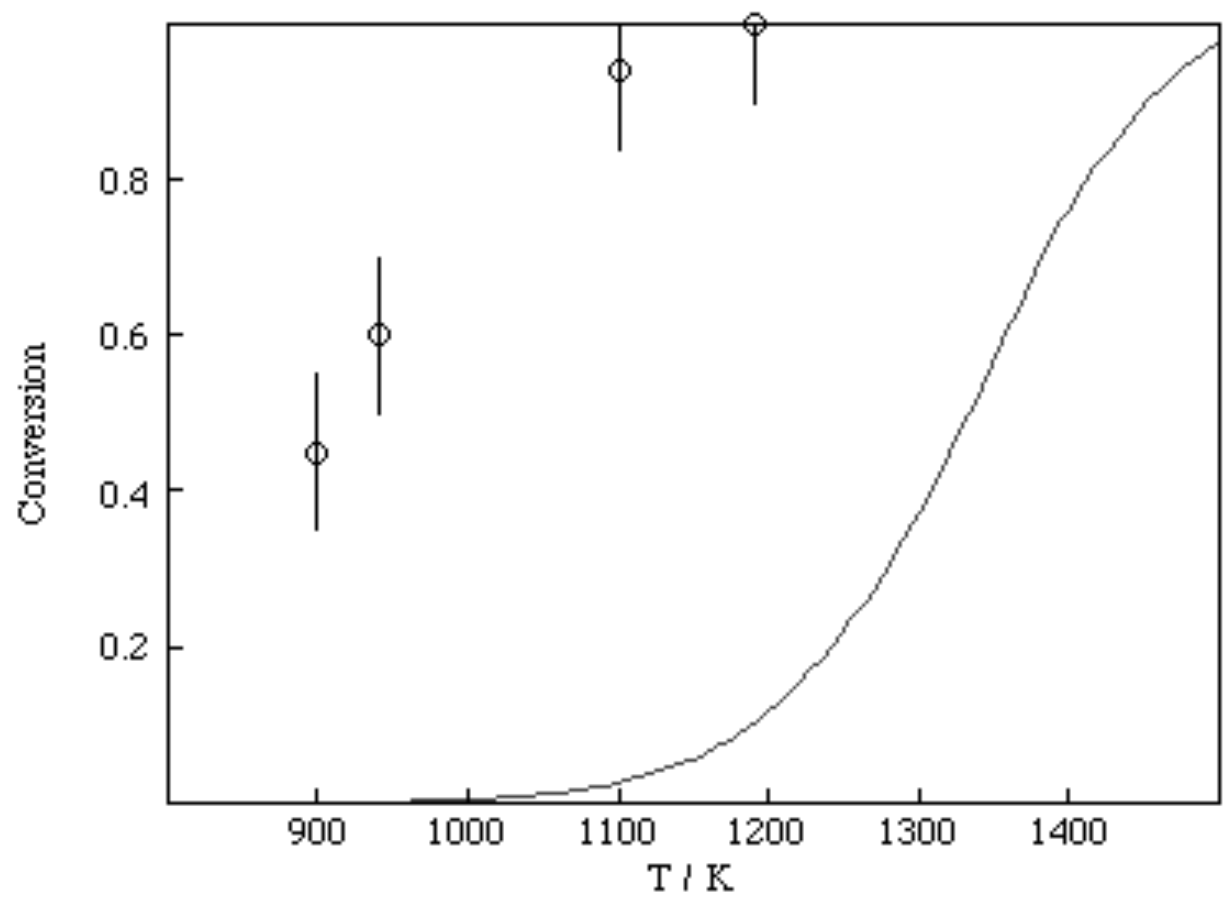

Figure 2.2. Comparison between experimental and calculated equilibrium conversions of $\mathrm{Na}_{2} \mathrm{CO}_{3}$ to $\mathrm{CO}_{2}$. The initial concentration of $\mathrm{Na}_{2} \mathrm{CO}_{3}$ was $300 \mathrm{ppm}$. 
Conversion in Figure 2.1 is defined as the concentration ratio $\left[\mathrm{CO}_{2}\right] /\left[\mathrm{Na}_{2} \mathrm{CO}_{3}\right]_{0}$, where $\left[\mathrm{Na}_{2} \mathrm{CO}_{3}\right]_{0}$ is the initial concentration of sodium carbonate. The calculations were performed using the NASA program CET89 (Feitelberg, 1994), which calculates chemical equilibrium compositions taking into account both gaseous and condensed-phase reactants and products. It is clear from Figure 2.1 that significant decomposition of $\mathrm{Na}_{2} \mathrm{CO}_{3}$ occurs in the temperature range from 1000 to $1500 \mathrm{~K}$ even though reaction (2.1) is not spontaneous at these temperatures in the ordinary thermochemical sense. The dependence of conversion on the initial amount of $\mathrm{Na}_{2} \mathrm{CO}_{3}$ is evident - as the initial concentration decreases, fractional conversion of $\mathrm{Na}_{2} \mathrm{CO}_{3}$ to $\mathrm{CO}_{2}$ is more complete. The calculations for conditions typical of the experiments thus confirm that significant fractional decomposition of $\mathrm{Na}_{2} \mathrm{CO}_{3}$ is thermochemically favored beginning at temperatures slightly above $1000 \mathrm{~K}$.

The experiments (Zamansky et al., Section 2, January 1997), however, show significant $\mathrm{Na}_{2} \mathrm{CO}_{3}$ decomposition also at temperatures below $1000 \mathrm{~K}$. Figure 2.2 shows a comparison between calculated equilibrium conversions and those derived from experimental profiles at long residence times. It clearly indicates that at the conditions of our experiments the $\mathrm{Na}_{2} \mathrm{CO}_{3}$ decomposition reaction is not equilibrated and must be affected by one or more physical processes, for example by diffusion of $\mathrm{CO}_{2}$ from or to the reactor wall or solid/liquid particles of $\mathrm{Na}_{2} \mathrm{CO}_{3}$ and $\mathrm{NaOH}$ participating in reaction (2.1). It also means that reaction (2.1) actually oversimplifies a complex process that involves steps of chemical interaction, diffusion of gaseous $\mathrm{CO}_{2}$ and possibly other processes. For the conditions of our experiments it can be thought of for analysis purposes as comprising opposed irreversible steps

$$
\begin{aligned}
& \mathrm{Na}_{2} \mathrm{CO}_{3}+\mathrm{H}_{2} \mathrm{O} \rightarrow 2 \mathrm{NaOH}+\mathrm{CO}_{2} \\
& 2 \mathrm{NaOH}+\mathrm{CO}_{2} \rightarrow \mathrm{Na}_{2} \mathrm{CO}_{3}+\mathrm{H}_{2} \mathrm{O}
\end{aligned}
$$

occurring in the directions indicated. An alternative model of $\mathrm{Na}_{2} \mathrm{CO}_{3}$ decomposition is

$$
\mathrm{Na}_{2} \mathrm{CO}_{3}<=>\mathrm{Na}_{2} \mathrm{O}+\mathrm{CO}_{2}
$$

that can also proceed in irreversible steps 


$$
\begin{aligned}
& \mathrm{Na}_{2} \mathrm{CO}_{3} \rightarrow \mathrm{Na}_{2} \mathrm{O}+\mathrm{CO}_{2} \\
& \mathrm{Na}_{2} \mathrm{O}+\mathrm{CO}_{2} \rightarrow \mathrm{Na}_{2} \mathrm{CO}_{3}
\end{aligned}
$$

which in presence of water can be followed by $\mathrm{NaOH}$ formation

$$
\mathrm{Na}_{2} \mathrm{O}+\mathrm{H}_{2} \mathrm{O}<=>2 \mathrm{NaOH}
$$

making the ultimate effect of model (2.4) identical to model (2.1).

To model irreversible $\mathrm{Na}_{2} \mathrm{CO}_{3}$ conversion, we used reactions (2.5-2.7) with reactions (2.5) and (2.6) being irreversible and reaction (2.7) being possible in both directions. The rate coefficient of reaction (2.7) was estimated as that of

$$
\mathrm{CaO}+\mathrm{H}_{2} \mathrm{O}<=>\mathrm{Ca}(\mathrm{OH})_{2},
$$

measured by Cotton and Jenkins, 1971 to be $9.18 \times 10^{12} \exp (-3120 / \mathrm{RT})$. Estimates show that the characteristic lifetime of $\mathrm{CaO}$ in the reaction $(2.8)$ at $1000 \mathrm{~K}, 1$ atm and $20 \% \mathrm{H}_{2} \mathrm{O}$ is less than $1 \mu \mathrm{s}$, much less than the characteristic time of our experiments. This suggests that for the conditions of our experiments $\mathrm{Na}_{2} \mathrm{O}$ is practically instantaneously converted to $\mathrm{NaOH}$, and thus the value of the rate coefficient of reaction (2.7) is not really important. All calculations were made using the Chemkin-II modeling program (Kee et al., 1992) under constant pressure and temperature constraints. Thermochemical data for all species but $\mathrm{Na}_{2} \mathrm{O}$ were taken from Zamansky et al., January 1997; thermochemical data for $\mathrm{Na}_{2} \mathrm{O}$ were taken from the NASA database (McBride et al., 1993).

Sensitivity calculations (Figure 2.3) show that the rate coefficient of reaction (2.5) affects both initial and equilibrium conversions of $\mathrm{Na}_{2} \mathrm{CO}_{3}$ to $\mathrm{CO}_{2}$, while that of reaction (2.6) mainly affects the equilibrium value. The rate coefficients of reactions (2.5) and (2.6) were adjusted for the conditions of our experiments $\left(0.03 \% \mathrm{Na}_{2} \mathrm{CO}_{3}+20.00 \% \mathrm{H}_{2} \mathrm{O}+79.97 \% \mathrm{~N}_{2}\right.$ at $\left.1 \mathrm{~atm}\right)$. The rate coefficient of reaction (2.5) was varied to match the initial part of the profiles at 900, 940, 1040, 1100 and 1190 $\mathrm{K}$, while the rate coefficient of reaction (2.6) was changed until the final calculated conversion was 


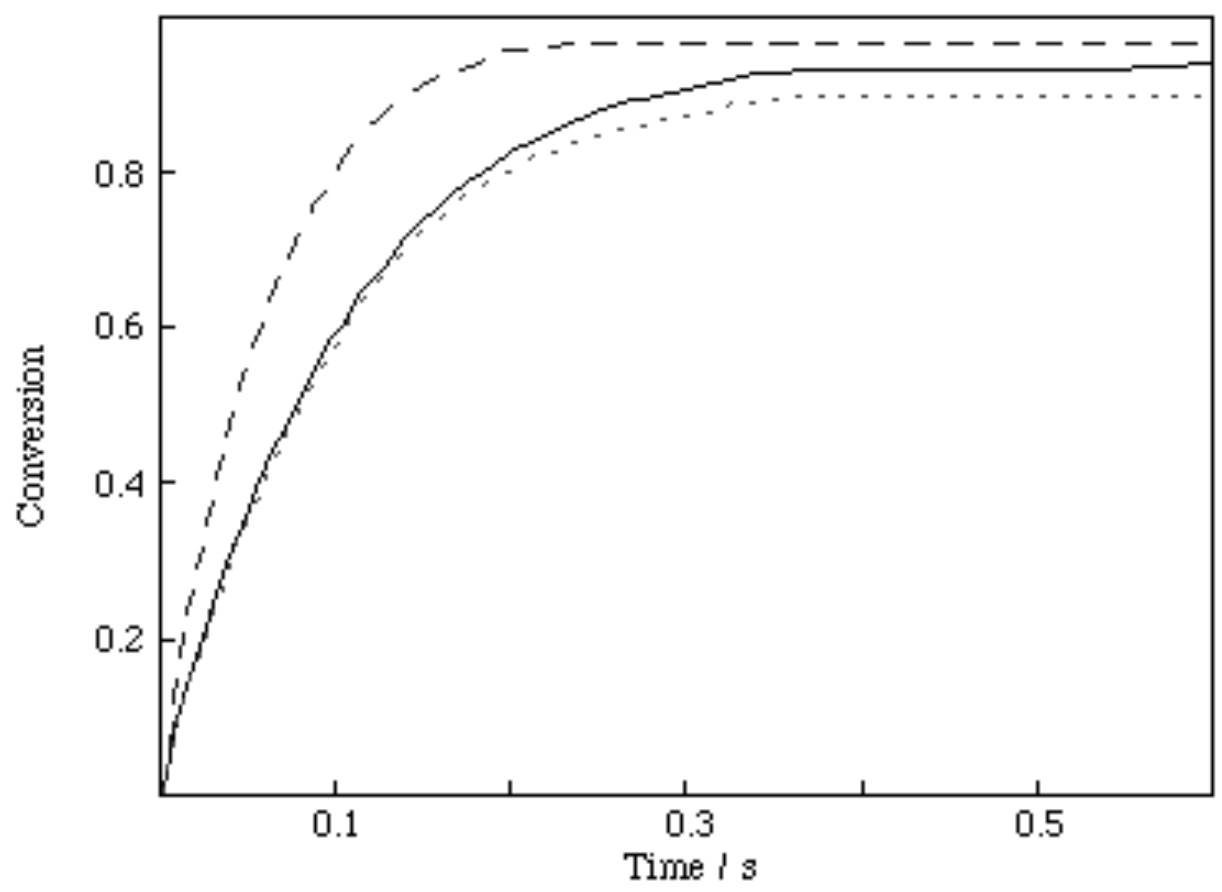

Figure 2.3. Sensitivity spectrum for decomposition of $\mathrm{Na}_{2} \mathrm{CO}_{3}$. The dashed line represents calculations with a doubled rate coefficient of reaction (2.5), the dotted line a doubled rate coefficient of the reaction (2.6).

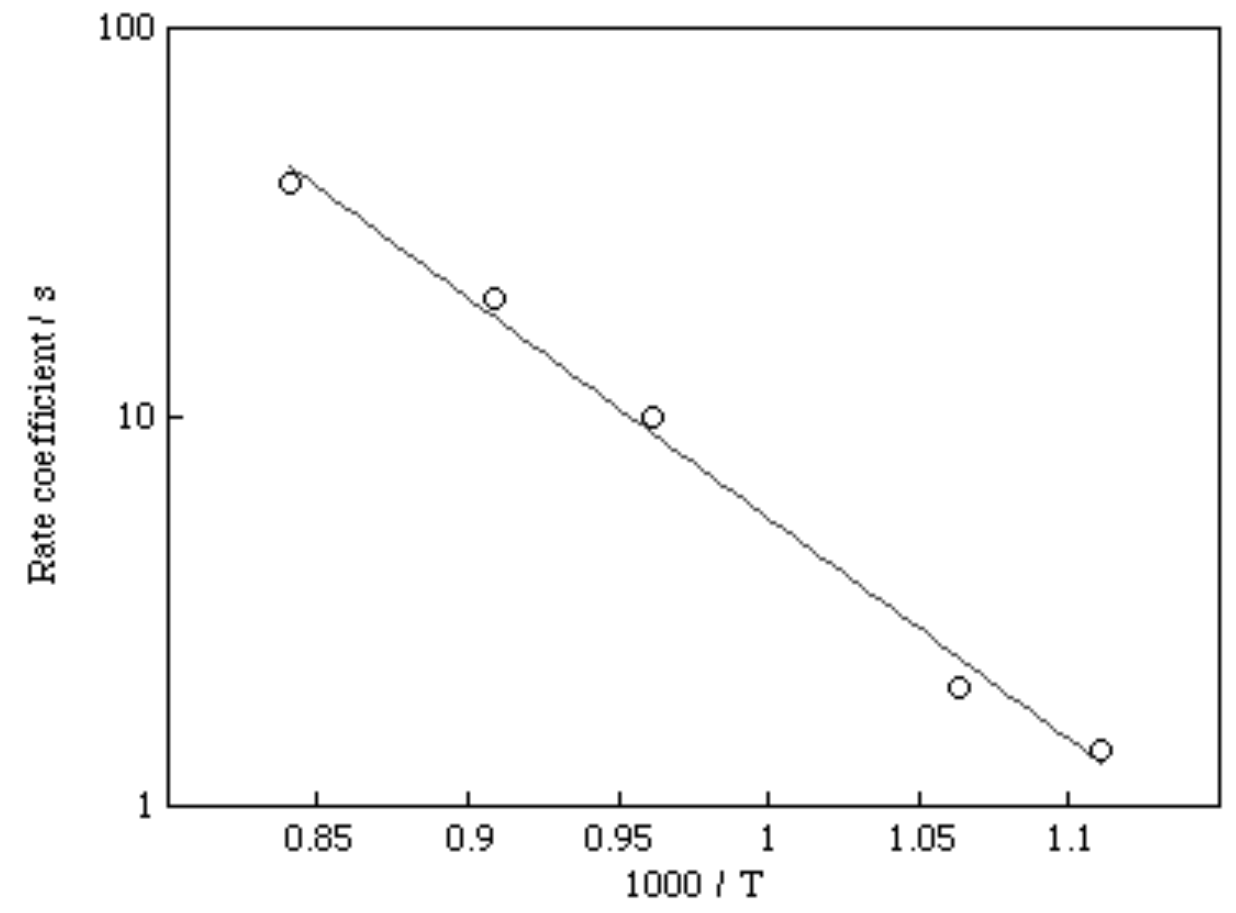

Figure 2.4. Rate coefficient inferred for $\mathrm{Na}_{2} \mathrm{CO}_{3} \rightarrow \mathrm{Na}_{2} \mathrm{O}+\mathrm{CO}_{2}(2.5)$. 


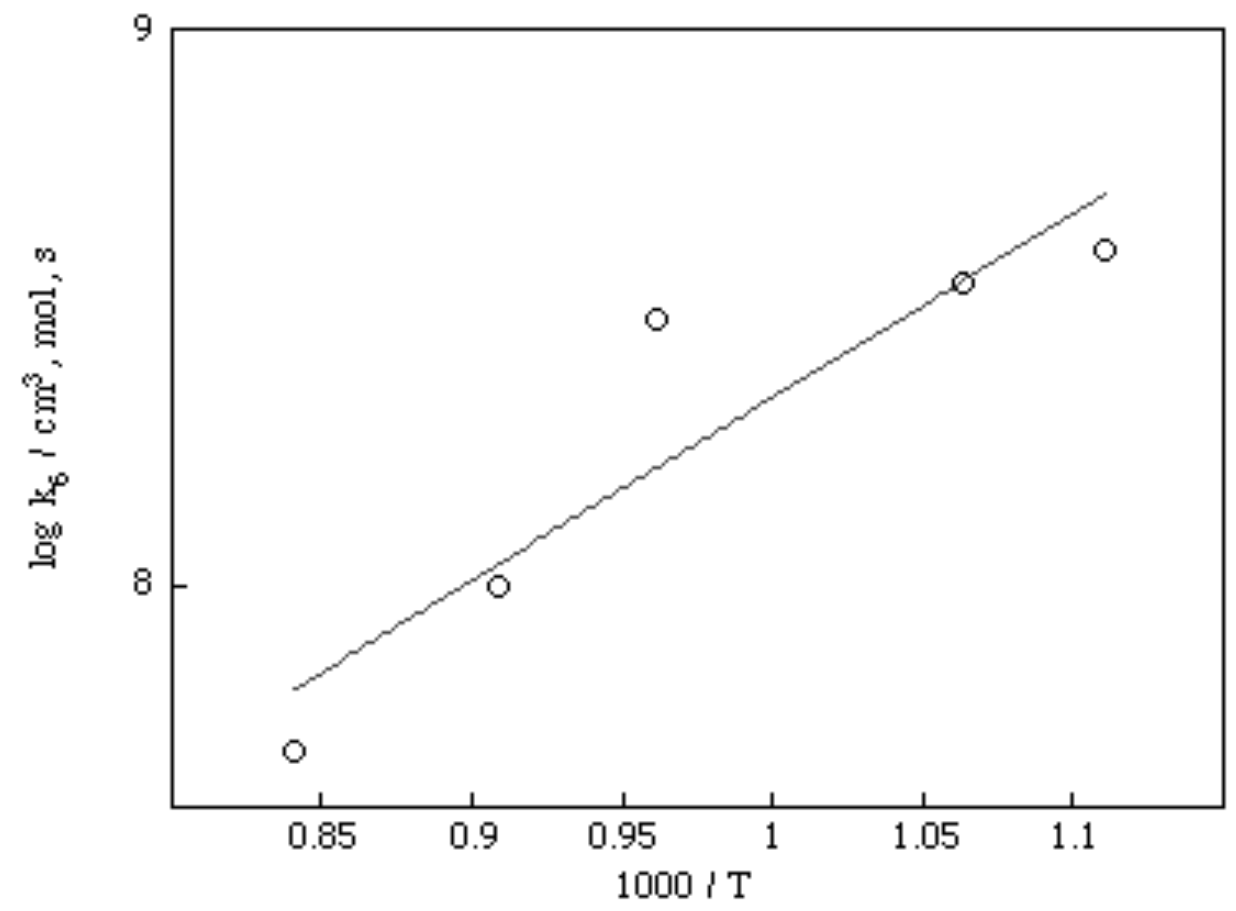

Figure 2.5. Rate coefficient inferred for $\mathrm{Na}_{2} \mathrm{O}+\mathrm{CO}_{2} \rightarrow \mathrm{Na}_{2} \mathrm{CO}_{3}(2.6)$.

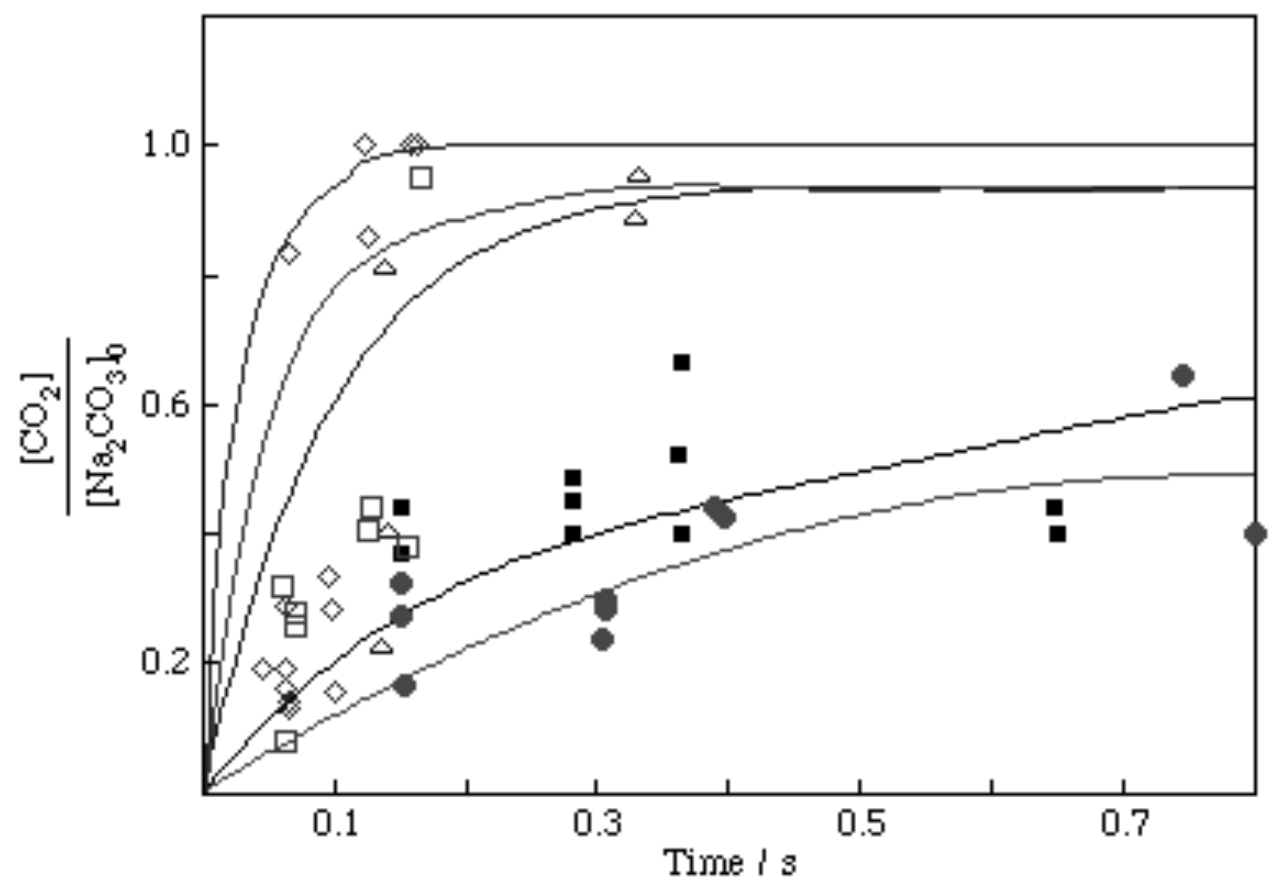

Figure 2.6. Comparison of experimental (symbols) and calculated (lines) $\mathrm{Na}_{2} \mathrm{CO}_{3}$ conversion profiles. Mixture $0.03 \% \mathrm{Na}_{2} \mathrm{CO}_{3}+20.00 \% \mathrm{H}_{2} \mathrm{O}+79.97 \% \mathrm{~N}_{2}, \mathrm{P}=1 \mathrm{~atm} .900 \mathrm{~K}, \boldsymbol{\square} 940 \mathrm{~K}, \Delta 1040$ $\mathrm{K}, \square 1100 \mathrm{~K}, \diamond 1190 \mathrm{~K}$. 
equal to the experimental value. Figures 2.4 and 2.5 show the dependence of rate coefficient of reactions (2.5) and (2.6) on temperature as derived from matching the experimental conversion profiles. The rate coefficient of reaction (2.6) follows a simple Arrhenius dependence, while that of reaction (2.7) decreases with temperature, possibly due to limitation of the reaction rate by $\mathrm{CO}_{2}$ transport. Least square fits to all data give next expressions for $k_{5}$ and $k_{6}$

$$
\begin{aligned}
& k_{5}=2.54 \times 10^{6} \exp (-13040 / \mathrm{T}) \\
& k_{6}=1.11 \times 10^{5} \exp (7580 / \mathrm{T})
\end{aligned}
$$

The total uncertainties (TU) in rate coefficient of reactions (2.5) and (2.6) were determined through the formula

$$
\mathrm{TU}_{\mathrm{i}}=\left(\left(\alpha_{\mathrm{i}} \mathrm{x} \mathrm{U}_{\exp }\right)^{2}+\mathrm{U}^{\mathrm{f}} \mathrm{i}^{2}\right)^{0.5}
$$

where $U_{\text {exp }}$ is the uncertainty of the experimental data (20\%), $\alpha_{i}$ is the sensitivity of the rate coefficient of the reaction (i) to the experimental data, and $\mathrm{U}_{\mathrm{i}}^{\mathrm{i}}$ is the uncertainty associated with the least square fit to all data points for the rate coefficient of reaction (i). Sensitivity coefficients $\alpha_{i}$ were defined as $\alpha_{\mathrm{i}}=1.4 \ln \left(C / C_{0}\right)$, where $C$ and $C_{0}$ are computed conversions for doubled and for reference values of the rate coefficient of the reaction (i), and are equal to 0.46 for reaction (2.5) and 0.1 for reaction (2.6). The values of $\mathrm{Uf}_{\mathrm{i}}$ were found to be 10 and $25 \%$ for $k_{5}$ and $k_{6}$. Based on these data, values of $\mathrm{TU}_{5}$ and $\mathrm{TU}_{6}$ were calculated to be 14 and $25 \%$.

Figure 2.6 shows a comparison between experimental and calculated conversion profiles based on the above expressions. At higher temperatures complete decomposition of $\mathrm{Na}_{2} \mathrm{CO}_{3}$ occurs within 0.2 $\mathrm{s}$, while at low temperatures conversion at long times reaches a maximum value and then stays constant. Taking into account the significant scatter of the experimental data, the agreement between measured and calculated profiles is good.

The irreversible model can not be considered as based on true elementary reactions, however, for these are inherently reversible and eventually equilibrate. We use it as a provisional guide to understanding the times scales involved in the decomposition process, and expect that as the 
gas-phase chemistry begins to be understood in some detail the real origins of the "effective irreversibility" in terms of physical rather than chemical processes will also become evident.

We continued mass spectrometric exploration of the products of $\mathrm{Na}_{2} \mathrm{CO}_{3}$ thermal decomposition using a Finnigan MAT TSQ 70 mass spectrometer in thermal, electron bombardment and chemical ionization modes. Small amounts of aqueous $\mathrm{Na}_{2} \mathrm{CO}_{3}$ solution were heated on a nichrome wire until the water evaporated and the solid or liquid $\mathrm{Na}_{2} \mathrm{CO}_{3}$ started to decompose. In electron ionization mode, used in most experiments, the gas phase was bombarded at electron ionization (EI) energies of 70, 25, 12 volts. In chemical ionization mode (CI), the gas pressure in the ion source is increased to typically $10^{-3}$ mbar of $\mathrm{CH}_{4}$; the dominant initial $\mathrm{CH}_{4}{ }^{+}$ions collide with molecules $\mathrm{M}$ and transfer a proton to give $\mathrm{MH}^{+}$ions with little excess initial energy and therefore little tendency to fragment. Thus, whereas EI spectra contain peaks corresponding to both molecular and fragment ions, CI spectra are simpler, mostly having only quasimolecular ion peaks. Both EI and CI modes were used in our experiments.

Figure 2.7 shows time histories of ions with mass/charge $(\mathrm{m} / z)$ ratios $44\left(\right.$ mostly $\left.\mathrm{CO}_{2}^{+}\right)$and 106 $\left(\mathrm{Na}_{2} \mathrm{CO}_{3}^{+}\right)$and total ion current for $\mathrm{EI}=70 \mathrm{eV}$. The temperature during the run rises from room temperature ( 0 on the $\mathrm{x}$-axis) to the final temperature, which corresponds to red hot nichrome and thus total loss of carbonate from the wire. The first peak on the total ion current curve corresponds to the temperature at which all water evaporates. Peak heights are on a relative scale assuming the height of the largest one (in this case $m / z=44$ ) to be 100. Figure 2.8 shows all detected ions for the moment when $m / z=44$ reaches its maximum value (62 on the X-axis). It reveals the presence of $\mathrm{H}_{2} \mathrm{O}^{+}$ (18), $\mathrm{Na}^{+}(23), \mathrm{CO}_{2}^{+}(44)$, very small amounts of $\mathrm{NaOH}^{+}$(40) and $\mathrm{Na}_{2} \mathrm{CO}_{3}{ }^{+}$(106). The peak with $\mathrm{m} / z$ $=28$ corresponds to $\mathrm{CO}^{+}$and $\mathrm{N}_{2}{ }^{+}$present as residual gas; the other peaks are difficult to identify. As the EI energy decreases (Figure 2.9) the contribution of $\mathrm{Na}^{+}$becomes more prominent compared to other ions because of its very low ionization energy: Figure 2.10 show a mass spectrometric analysis with $\mathrm{EI}=0$, i.e., with all ions arising from thermal ionization of $\mathrm{Na}_{2} \mathrm{CO}_{3}$ on the wire. This mass spectrum shows $\mathrm{Na}^{+}(23)$ and a species with $\mathrm{m} / z=129\left(\mathrm{Na}_{3} \mathrm{CO}_{3}^{+}\right)$. (The species with $\mathrm{m} / z=39$ corresponds a background peak, probably $\mathrm{K}^{+}(39)$, and always appear in analyses with low EI). 


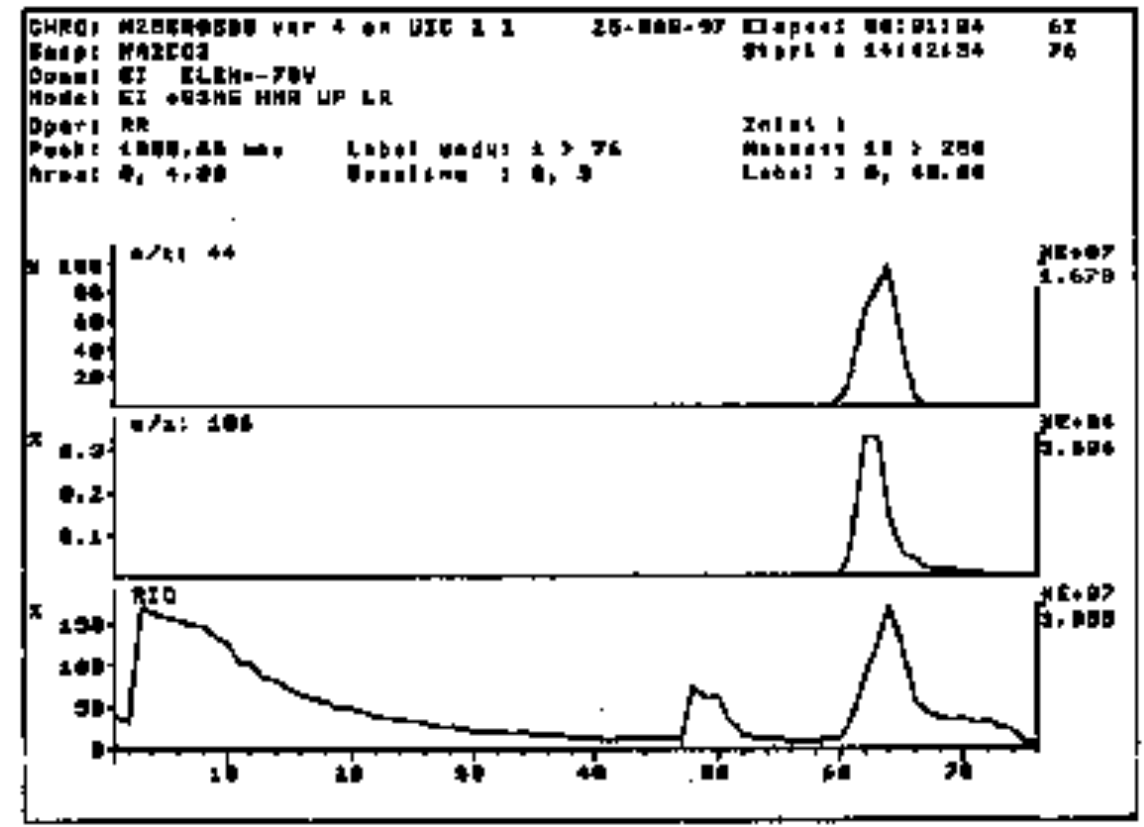

Figure 2.7. Time histories of ion currents at $m / z=44$ and 106 and total ion current. EI $=70$ $\mathrm{eV}$, nichrome wire. The $\mathrm{x}$-axis gives the heating time in seconds.

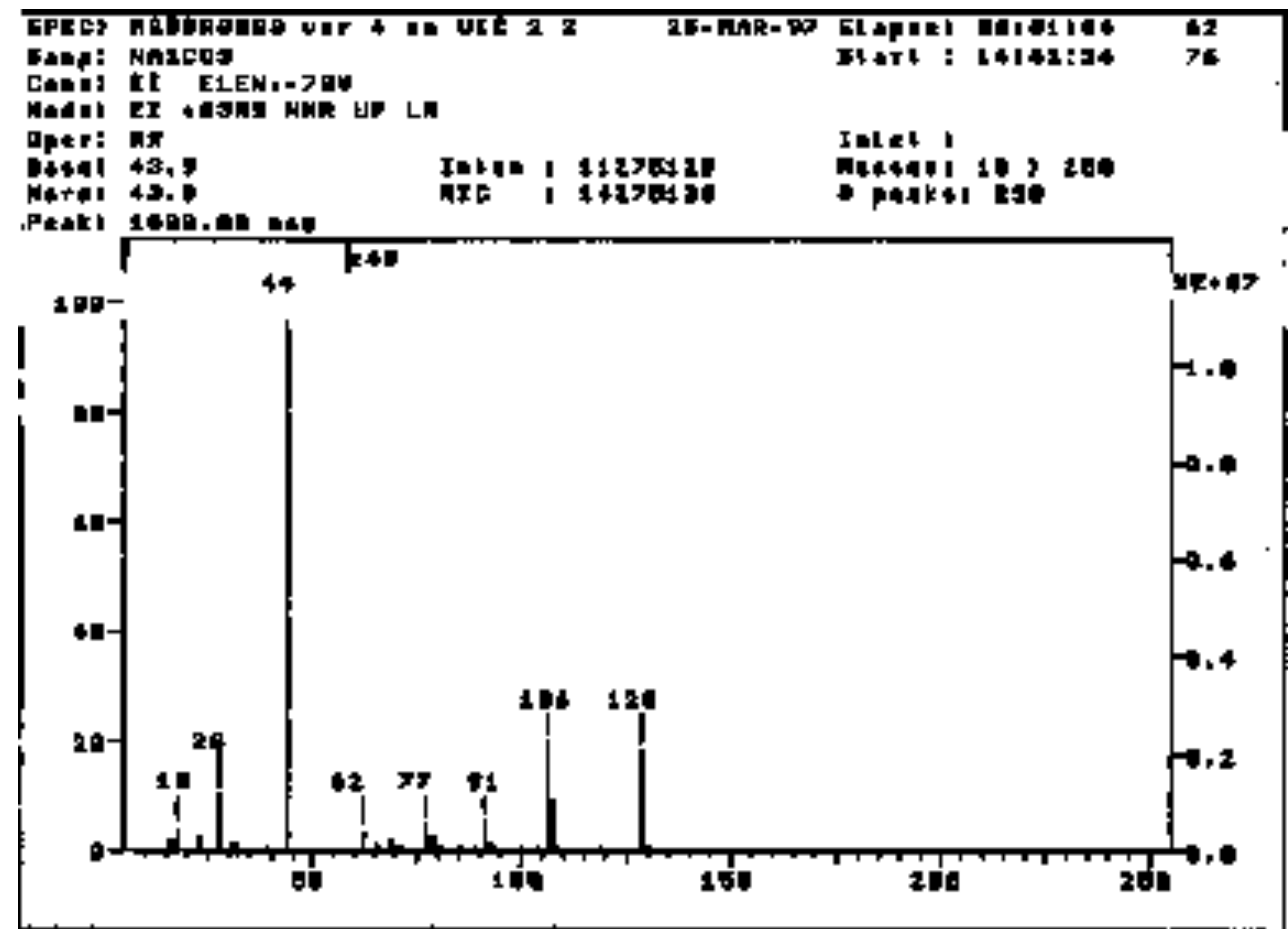

Figure 2.8. Mass spectrum at $62 \mathrm{~s}$ on the $\mathrm{x}$-axis of Figure 2.7. $\mathrm{m} / \mathrm{z}=18$ corresponds to $\mathrm{H}_{2} \mathrm{O}^{+}$, $28 \mathrm{CO}^{+}$to $44 \mathrm{CO}_{2}{ }^{+}$to $62 \mathrm{Na}_{2} \mathrm{O}^{+}$to $106 \mathrm{Na}_{2} \mathrm{CO}_{3}{ }^{+}$and 128 to $\mathrm{Na}_{3} \mathrm{CO}_{3}{ }^{+}$. 


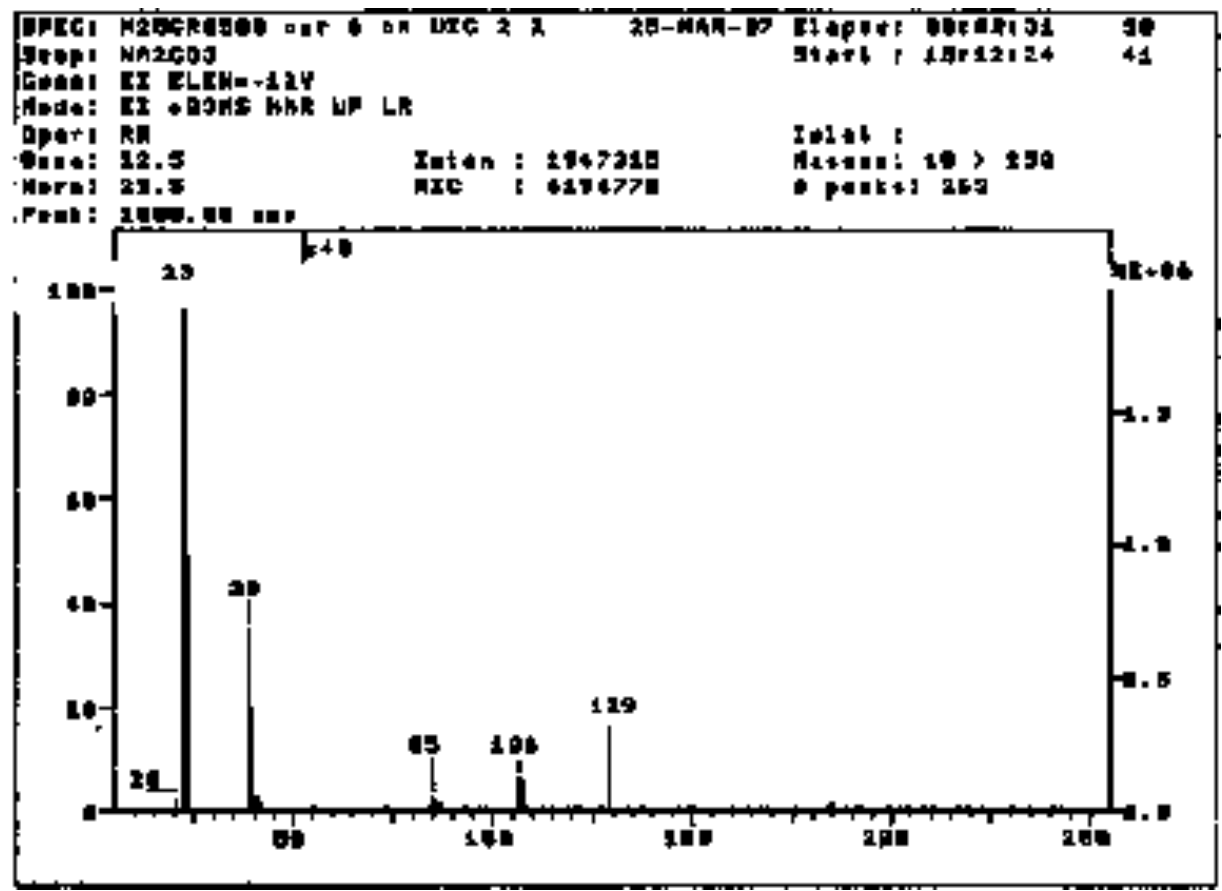

Figure 2.9. Mass spectrum at the time $m / z=23$ reaches its maximum. $\mathrm{EI}=12 \mathrm{eV}$.

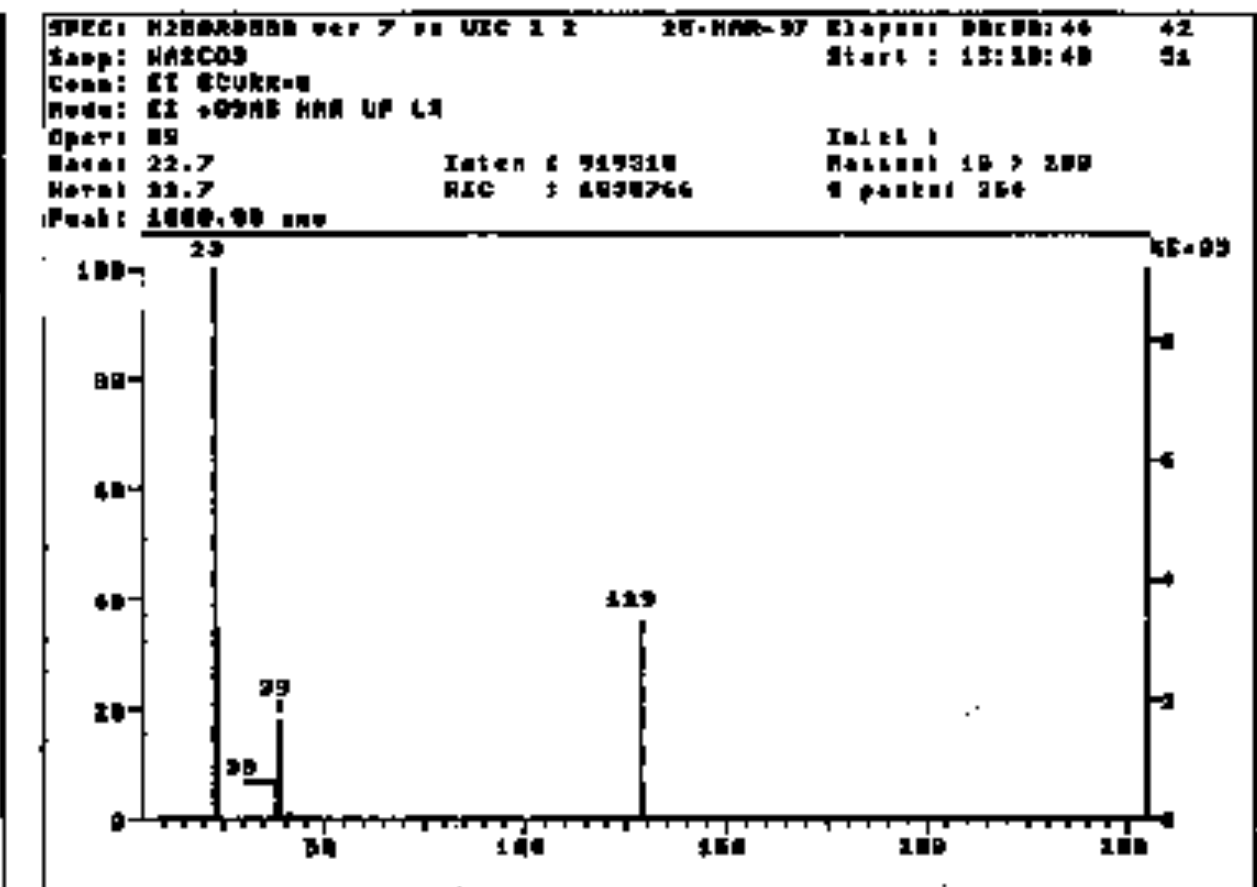

Figure 2.10. Mass spectrum at the time $m / z=23$ reaches its maximum in thermal ionization mode. 


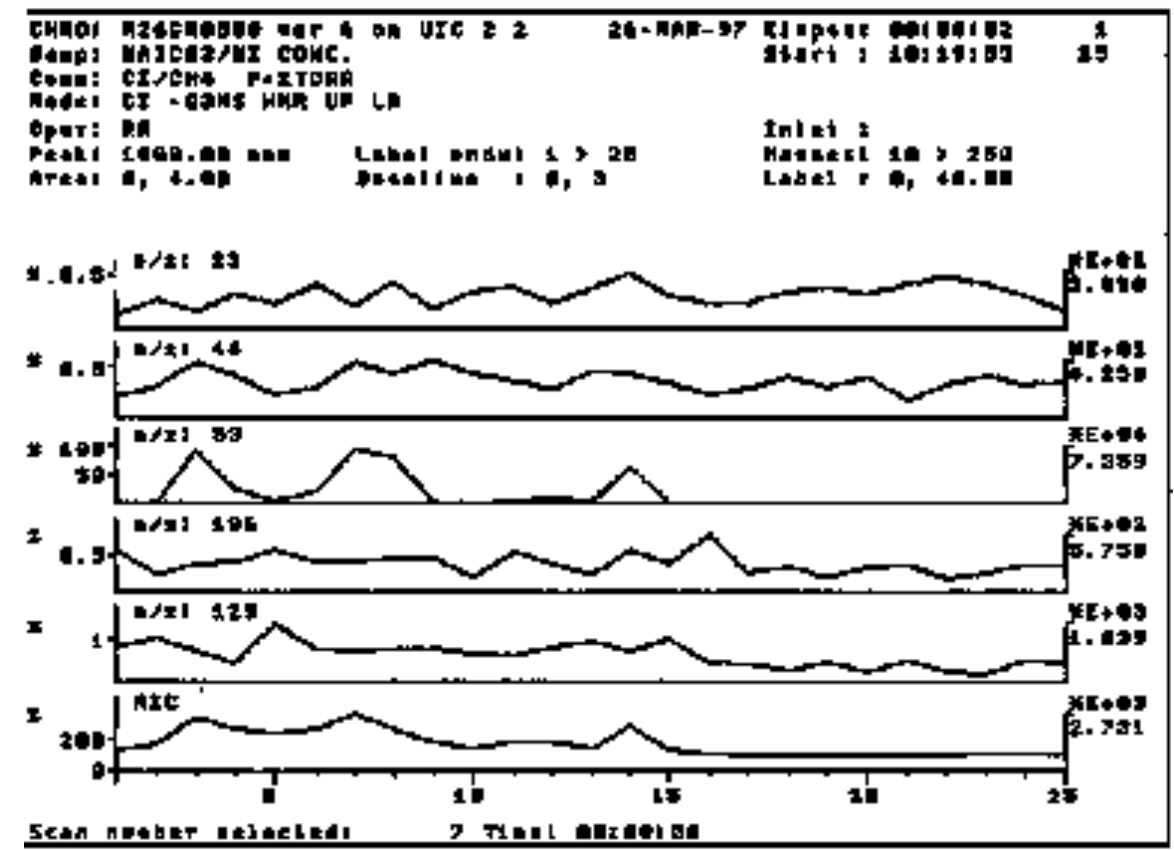

Figure 2.11. Time histories of ions with $m / z=23\left(\mathrm{Na}^{+}\right), 44\left(\mathrm{CO}_{2}^{+}\right), 53\left(\mathrm{Na} \mathrm{CO}_{3}^{++}\right), 106$ $\left(\mathrm{Na}_{2} \mathrm{CO}_{3}^{+}\right), 129\left(\mathrm{Na}_{3} \mathrm{CO}_{3}^{+}\right)$, and total ion current. Chemical ionization mode, nichrome wire.

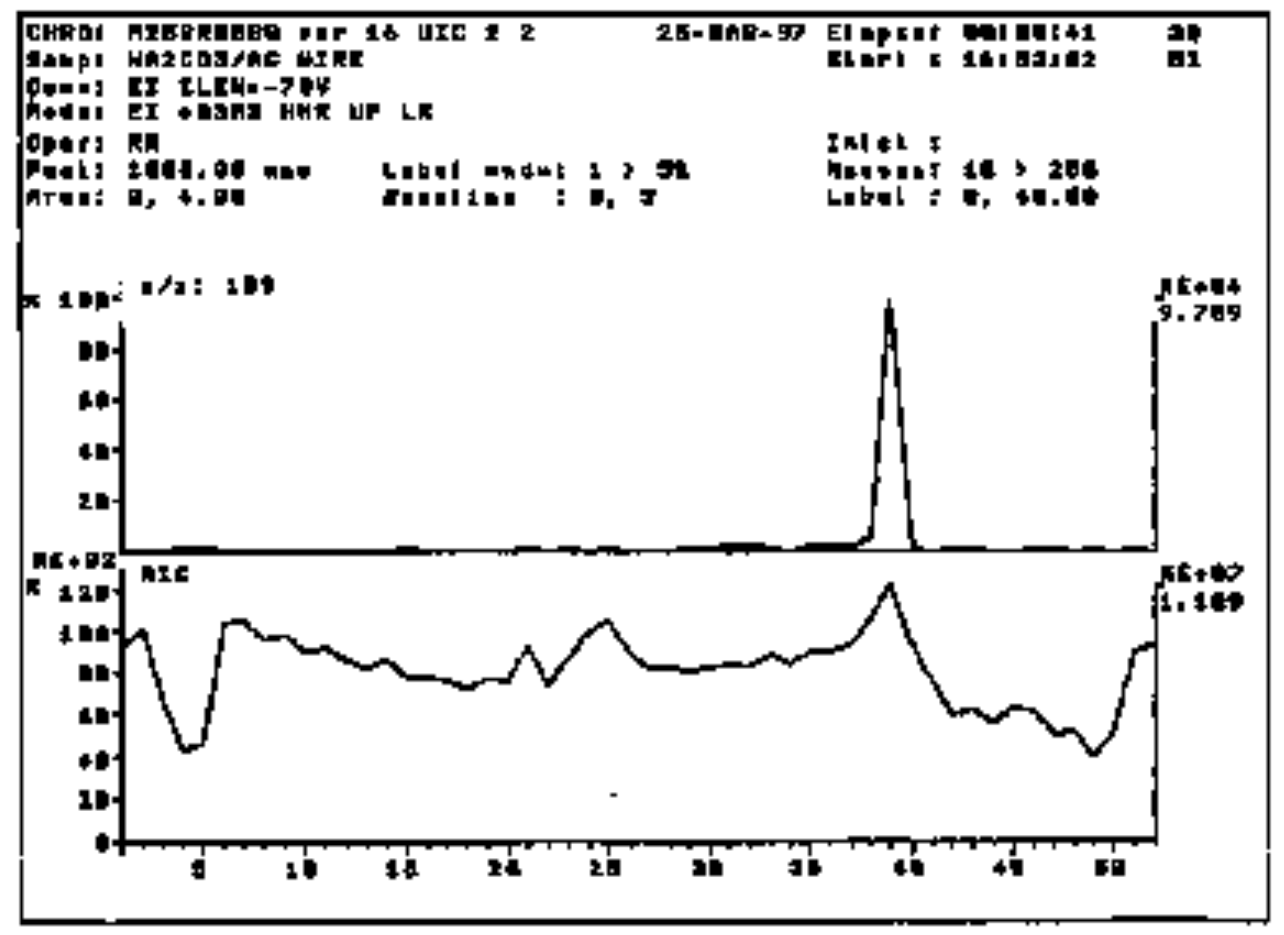

Figure 2.12. Time histories of $\mathrm{Ag}^{+}$(109) and total ion current for experiments with $\mathrm{Ag}$ wire. $\mathrm{EI}=70 \mathrm{eV}$. Time $39 \mathrm{~s}$ corresponds to $1235 \mathrm{~K}$. 
Figure 2.11 shows results of mass spectrometric analysis of an $\mathrm{Na}_{2} \mathrm{CO}_{3}$ sample in chemical ionization mode. The product distribution $\left(\mathrm{Na}^{+}, \mathrm{CO}_{2}^{+}, \mathrm{Na}_{2} \mathrm{CO}_{3}^{+}\right)$is the same as in electron ionization mode with a few new species; among them $m / z=53$ in greatest amount.

A general disadvantage of mass spectrometric measurements is that they do not provide continuous recording of the sample temperature, and it is impossible to correlate mass spectra with the temperature at which active species are formed and/or decomposition of $\mathrm{Na}_{2} \mathrm{CO}_{3}$ occurs. It is possible, however, to correlate some moments on the time scale with corresponding temperatures when in place of standard nichrome wire, which melts at very high temperature, wire made from a metal with lower melting temperature is used. The moment when such a wire melts is detected as a maximum in the total ion current and corresponds to the melting temperature of the metal. Since Ag has melting point of $1235 \mathrm{~K}$, within the temperature range of our interest, we conducted some experiments using Ag wire instead of nichrome. These were done in EI mode with an ionization energy of $70 \mathrm{eV}$ and in thermal ionization mode $(\mathrm{EI}=0)$. The time of $\mathrm{Ag}$ occurrence in the mass spectrum (Figure 2.12) (which also corresponds to the maximum in total current) corresponds to the moment of time when temperature of the wire is $1235 \mathrm{~K}(39 \mathrm{~s})$. The mass spectrum (Figure 2.13) at this temperature shows $\mathrm{CO}_{2}^{+}(44), \mathrm{NaOH}^{+}(40), \mathrm{Na}_{2} \mathrm{CO}_{3}^{+}$(106) and many other species. Some of them are easily identifiable $\left(\mathrm{H}_{2} \mathrm{O}^{+}\right.$and $\left.\mathrm{N}_{2}{ }^{+}\right)$, while secure identification of others requires additional (i.e., high-resolution) analysis. Figure 2.13 does not indicate the presence of $\mathrm{Na}$ atoms. To find out if $\mathrm{Na}$ atoms are present in the system at $1235 \mathrm{~K}$ we repeated experiments with an $\mathrm{Ag}$ wire in thermal ionization mode (Figures 2.14 and 2.15). Figure 14 shows that one of the maximums in $\mathrm{Ag}^{+}(109)$ concentration corresponds to the maximum in total ion current (22 s on x-axis) at the temperature $1235 \mathrm{~K}$. The mass spectrum (Figure 2.15) at this temperature shows $\mathrm{Na}^{+}(23)$ and species with $\mathrm{m} / z$ $=39$ and 129 . 


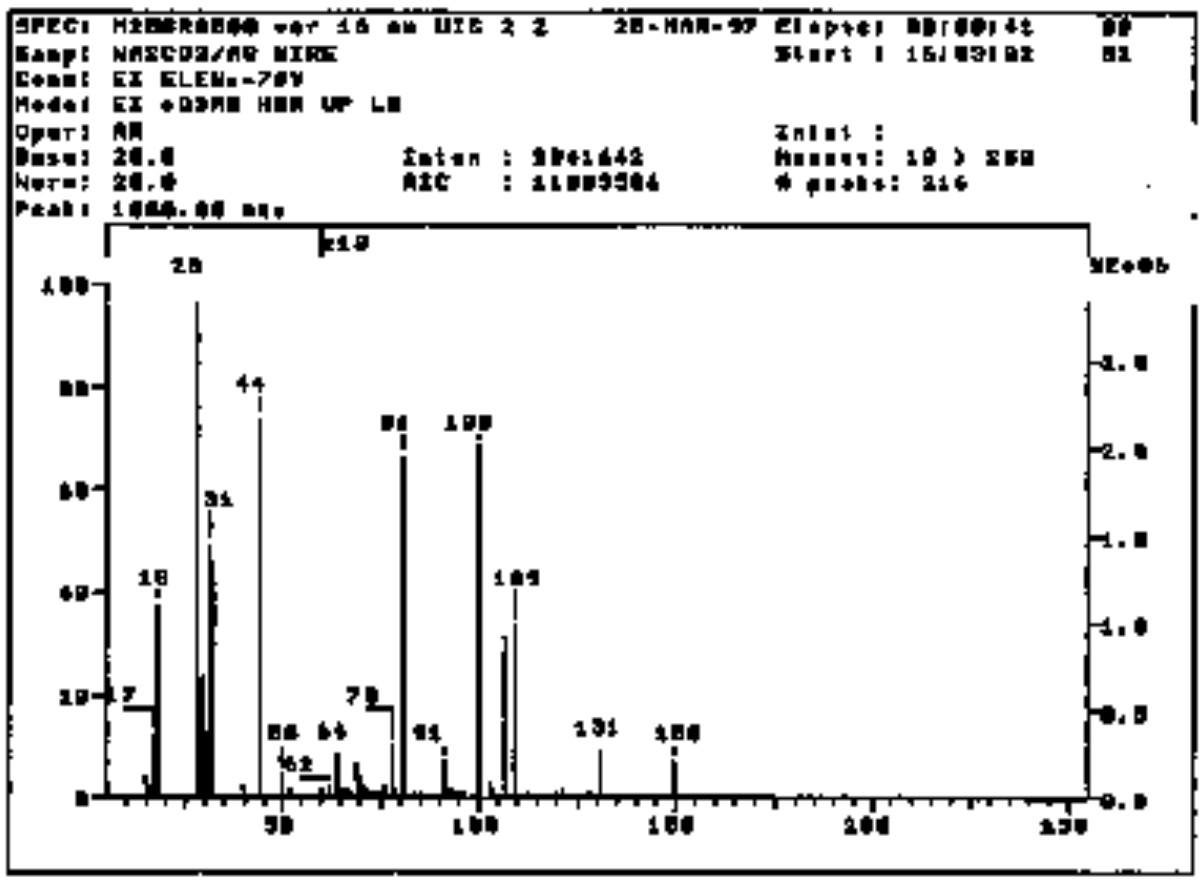

Figure 2.13. Mass spectrum at $1235 \mathrm{~K} . \mathrm{EI}=70 \mathrm{eV}$.

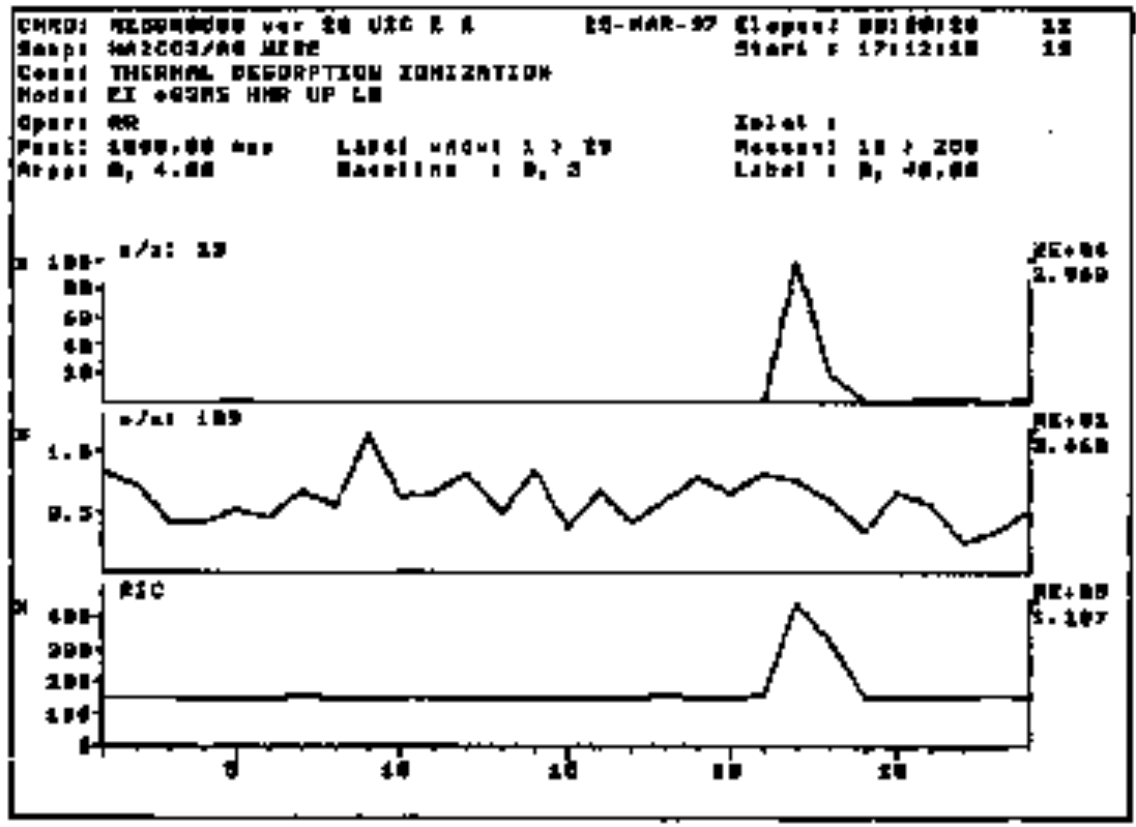

Figure 2.14. Time histories of ions with $\mathrm{m} / z=23\left(\mathrm{Na}^{+}\right)$and $109\left(\mathrm{Ag}^{+}\right)$, and total ion current through the detector for thermal ionization mode. 


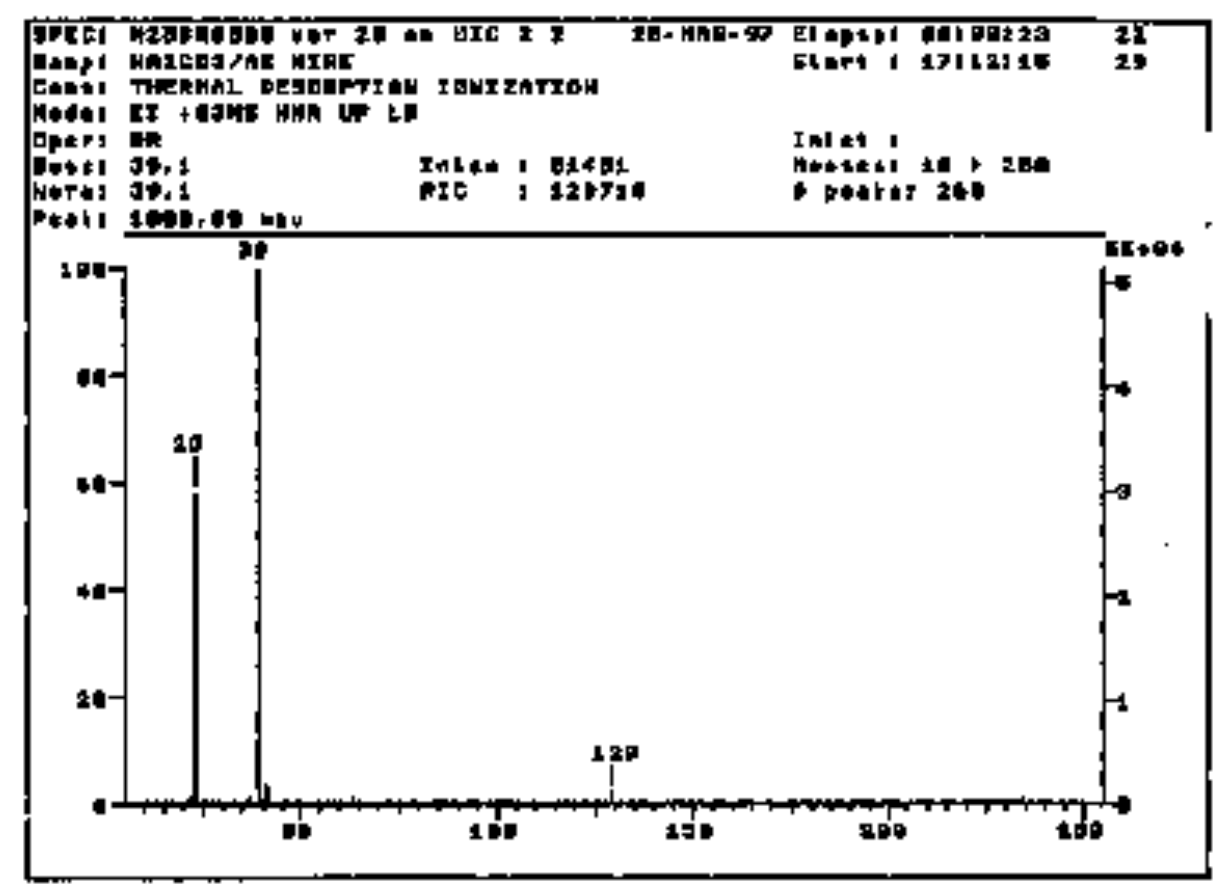

Figure 2.15. Mass spectrum corresponding to the moment of burnout of Ag wire for thermal ionization mode.

\section{Conclusions of Section 2:}

1. Decomposition of $\mathrm{Na}_{2} \mathrm{CO}_{3}$ from 900 to $1190 \mathrm{~K}$ can be described kinetically in terms of two irreversible (2.5) and (2.6) and one reversible (2.7) chemical reactions. The necessary rate coefficients $k_{5}$ and $k_{6}$ were adjusted to describe the measured rate of $\mathrm{Na}_{2} \mathrm{CO}_{3}$ decomposition, while the rate coefficient of reaction (2.7) was estimated from kinetic data for the similar reaction of $\mathrm{CaO}$.

2. Mass spectrometric analysis of products of $\mathrm{Na}_{2} \mathrm{CO}_{3}$ decomposition confirms that the primary gas-phase products of decomposition are $\mathrm{Na}, \mathrm{NaOH}$ and $\mathrm{CO}_{2}$. Experiments with temperature control show formation of $\mathrm{Na}$ atoms at temperature $1235 \mathrm{~K}$. 


\subsection{Pilot Scale Combustion Tests}

Pilot scale test work was conducted in EER's Boiler Simulation Facility (BSF), which has a firing capacity of 1.0 MMBtu/hr. BSF equipment, temperature profiles, and sampling and analytical methods were described in detail in a previous quarterly report (Zamansky and Maly, October, 1996).

Test work in the current reporting period focused on applying the promoted advanced reburning technologies to coal firing. For all tests, high sulfur bituminous Illinois coal was used as the primary fuel and natural gas was used as the reburn fuel. Table 3.1 presents Illinois coal analytical data. The main burner firing rate was $0.7 \mathrm{MMBtu} / \mathrm{hr}$. Stoichiometric ratios in the main and burnout regions were 1.10 and 1.15, respectively. Reburn zone stoichiometries of 0.99 and 0.90 were tested. Urea was used as the $\mathrm{N}$-agent and $\mathrm{Na}_{2} \mathrm{CO}_{3}$ was used as the promoter. The $\mathrm{N}$-agent/NO stoichiometric ratio (NSR) was 1.5. The initial uncontrolled NO concentration was 1000 ppm.

Table 3.1. Illinois coal analysis.

\begin{tabular}{|l|l|c|cc|}
\hline \multicolumn{1}{|c|}{ Parameter } & Units & \multicolumn{2}{|c|}{ As received } & Dry basis \\
\hline Proximate & Moisture & $\%$ & 6.39 & --- \\
& Ash & $\%$ & 8.99 & 9.60 \\
& Volatiles & $\%$ & 38.52 & 41.15 \\
& Fixed Carbon & $\%$ & 46.10 & 49.25 \\
& Total & $\%$ & 100.00 & 100.00 \\
& Calorific Value & Btu/lb & 10494 & 11210 \\
\hline \multirow{6}{*}{ Ultimate } & & & & \\
& Moisture & $\%$ & 6.39 & --- \\
& Carbon & $\%$ & 62.23 & 66.48 \\
& Hydrogen & $\%$ & 3.86 & 4.12 \\
& Nitrogen & $\%$ & 1.22 & 1.30 \\
& Sulfur & $\%$ & 2.91 & 3.11 \\
& Ash & $\%$ & 8.99 & 9.60 \\
& Oxygen & & 14.40 & 15.39 \\
& Total & $\%$ & 100.00 & 100.00 \\
\hline
\end{tabular}


The combustion studies involved both parametric performance tests to optimize NOx control and a series of emissions sampling tests to characterize byproduct levels. The parametric tests were divided into three series: promoted $\mathrm{AR}$, promoted $\mathrm{AR}$ plus $\mathrm{SNCR}$, and multiple injection $\mathrm{AR}$ (MIAR). Performance and byproduct test results are described below.

\subsection{Promoted AR Parametric Tests}

The first series of tests involved promoted AR, with $\mathrm{N}$-agent injected in both lean and rich modes (i.e. AR-Lean and AR-Rich). For the AR-Lean tests, the N-agent was co-injected along with the OFA. The reburn zone SR was 0.99, corresponding to 9\% reburning. Figure 3.1 shows NO reduction as a function of the $\mathrm{N}$-agent/OFA injection temperature. Reburning alone gave $48 \% \mathrm{NO}$ reduction. For both the promoted and unpromoted cases, optimum performance was obtained at 1900 F. Maximum NO reduction was 78\% with no promoter and $84 \%$ with 150 ppm of Na. Sodium exhibited a greater promotional effect at the lower injection temperatures. The sodium concentration of $150 \mathrm{ppm}$ in the flue gas was selected based on performance and boiler operational considerations, as discussed in more detail below.

AR-Rich tests were conducted in which $\mathrm{N}$-agent and promoter were injected into the fuel rich reburning zone upstream of the OFA, which was added at 1900 F. Figure 3.2 shows NO reduction as a function of the $\mathrm{N}$-agent injection temperature. Performance increased with decreasing injection temperature, with greatest NO reduction obtained at $2000 \mathrm{~F}$. Maximum NO control was $86 \%$ with no promoter and $93 \%$ with $150 \mathrm{ppm}$ sodium. The incremental benefit provided by the sodium promoter appeared to increase with decreasing temperature.

AR-Rich tests were then conducted in which the OFA injection temperature was varied, with the $\mathrm{N}$-agent injection temperature held constant at $2300 \mathrm{~F}$. This temperature is well above the optimum, but is of interest for boilers that have limited access at lower temperatures for liquid injectors. As shown in Figure 3.3, performance increased with decreasing OFA temperature. Sodium provided an incremental increase in NO reduction of about 6 percentage points at each temperature. 
Firing Rate: 705,000 Btu/Hr

Main Fuel : Illinois Coal

9\% Nat.Gas Reburn

$\mathrm{SR} 1=1.10, \mathrm{SR} 2=0.99, \mathrm{SR} 3=1.15$

NO level: 1000 ppm @0\%O2 dry

Additive co-injected with OFA, NSR=1.5

- Reburning
$\Delta$ Reburning+ Urea
$\Delta$ Reburning+ Urea/Na 150 ppm

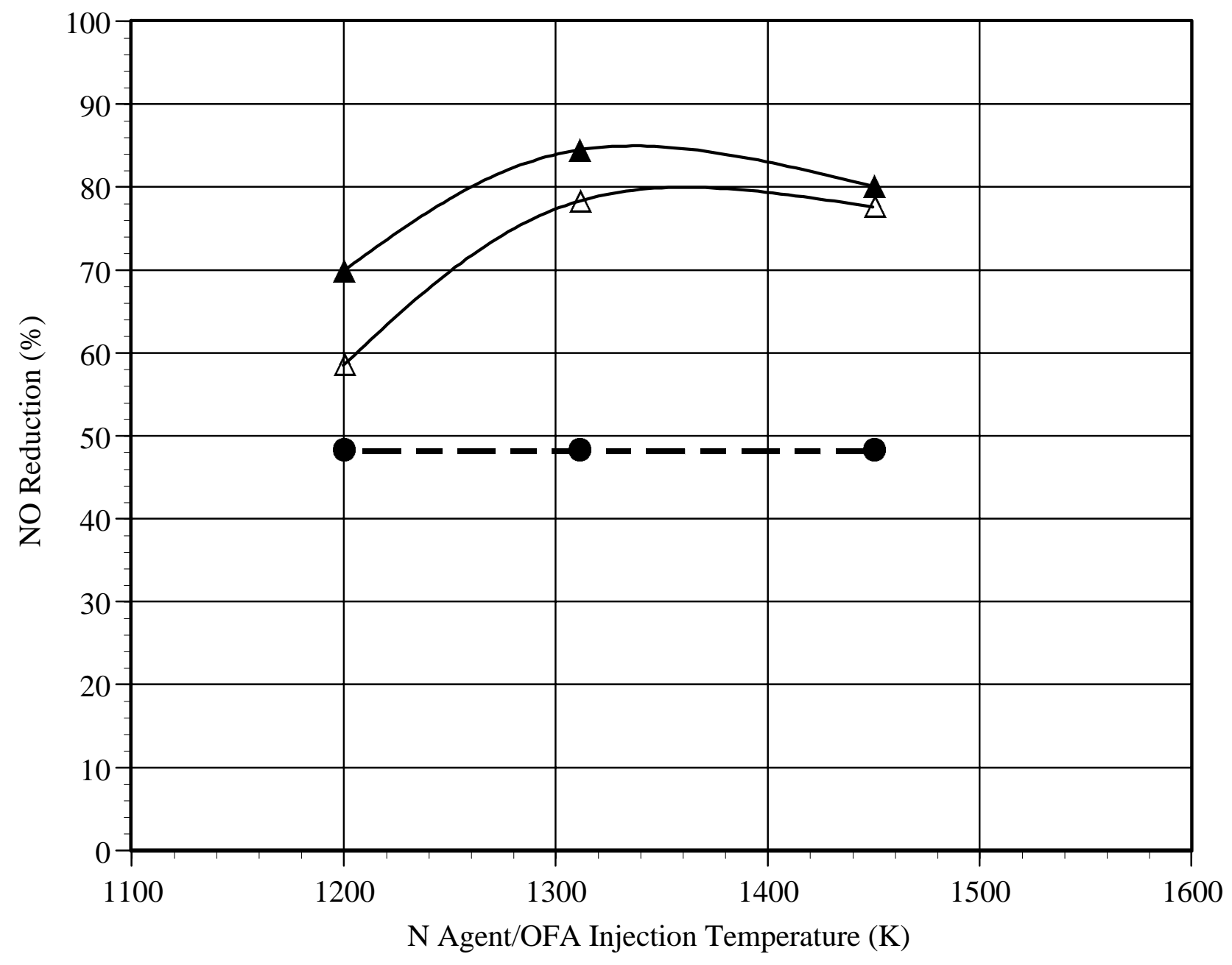

Figure 3.1. AR-Lean tests: effect of N-agent/OFA injection temperature upon performance. 
Firing Rate: 705,000 Btu/Hr

Main Fuel : Illinois Coal

9\% Nat.Gas Reburn

$\mathrm{SR} 1=1.10, \mathrm{SR} 2=0.99, \mathrm{SR} 3=1.15$

NO level: 1000 ppm @0\%O2 dry

OFA injected at $1310 \mathrm{~K}, \mathrm{NSR}=1.5$

- Reburning

$\Delta$ Reburning+ Urea

A Reburning+ Urea/Na $150 \mathrm{ppm}$

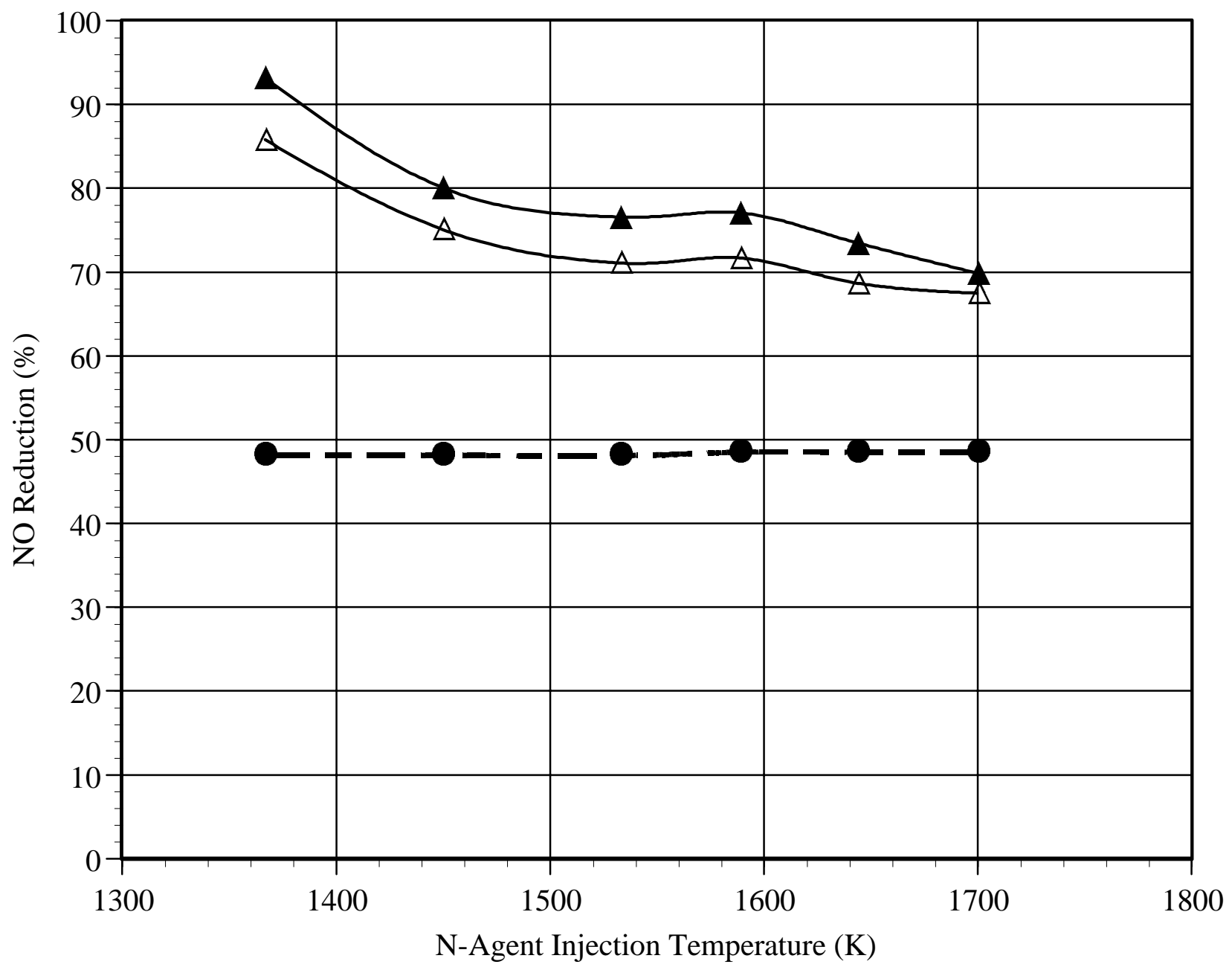

Figure 3.2. AR-Rich tests: effect of $\mathrm{N}$-agent injection temperature upon performance. 
Firing Rate: 705,000 Btu/Hr

Main Fuel : Illinois Coal

9\% Nat.Gas Reburn

$\mathrm{SR} 1=1.10, \mathrm{SR} 2=0.99, \mathrm{SR} 3=1.15$

NO level: 1000 ppm @0\%O2 dry

Additive injected at $1530 \mathrm{~K}, \mathrm{NSR}=1.5$
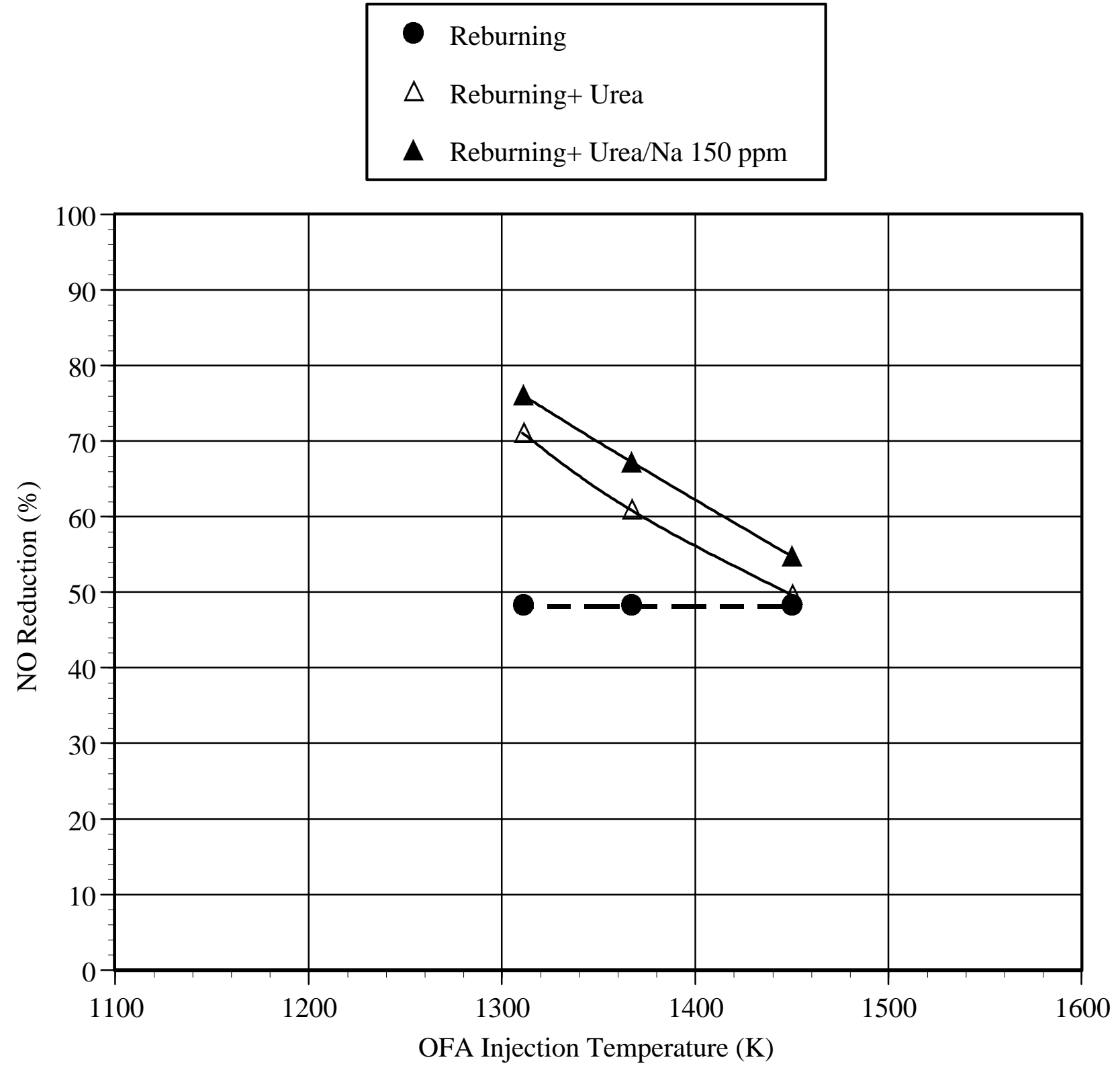

Figure 3.3. AR-Rich tests: effect of OFA injection temperature upon performance. 
Previous test work showed that with natural gas as the main fuel, small amounts of sodium promoter (less than $30 \mathrm{ppm}$ ) can dramatically improve AR performance (Zamansky and Maly, October, 1996). However, with coal as the main fuel, ash and $\mathrm{SO}_{2}$ can partially deactivate the sodium, requiring that more $\mathrm{Na}$ be added to obtain promotion. Illinois coal AR-Rich tests were conducted in which the sodium promoter concentration was varied from 0 to $2000 \mathrm{ppm}$. Reburn zone SR was 0.99, additives were injected at $2150 \mathrm{~F}$, and OFA was injected at $2000 \mathrm{~F}$. As shown in Figure 3.4, NO reduction increased from $63 \%$ at $0 \mathrm{ppm}$ sodium to $86 \%$ at $2000 \mathrm{ppm}$ sodium. The main drawback of high sodium level is the potential for increased boiler fouling. A sodium concentration of $150 \mathrm{ppm}$ was selected for most of the test work as a concentration providing significant promotion while being low enough to minimize fouling effects. As shown in Figure 3.4, this level of sodium addition can also provide a small degree of $\mathrm{SO}_{2}$ control by reaction to form sodium sulfate.

\subsection{Reburn Plus SNCR Parametric Tests}

The second series of Illinois coal tests involved reburning plus SNCR. N-agent was injected into the fuel-lean furnace gas downstream of the OFA. Figure 3.5 shows results of tests conducted at $9 \%$ reburning with OFA at $2300 \mathrm{~F}$. Reburning alone gave $40 \%$ NO reduction. This is relatively low due to the high OFA temperature and corresponding short reburn zone residence time. $\mathrm{N}$-agent injection temperature was varied from 1700 to $1950 \mathrm{~F}$. Optimum performance obtained at $1800 \mathrm{~F}$. Maximum NO reduction was $88 \%$ with no promoter and $94 \%$ with 150 ppm sodium.

Tests were then conducted involving AR-Rich plus SNCR. The first N-agent was injected at 2400 $\mathrm{F}$ and OFA was added at $2300 \mathrm{~F}$. The second $\mathrm{N}$-agent injection temperature was varied from 1760 to $2050 \mathrm{~F}$. Four conditions were run, including no promoter, sodium addition to the first $\mathrm{N}$-agent alone, sodium addition to the second $\mathrm{N}$-agent alone, and sodium addition to both $\mathrm{N}$-agents. As shown in Figure 3.6, performance increased with increasing second $\mathrm{N}$-agent injection temperature. Adding $150 \mathrm{ppm}$ sodium to both $\mathrm{N}$-agents increased NO reduction by 4 to 6 percentage points at each temperature. Maximum NO reductions, obtained at $2050 \mathrm{~F}$, were $88 \%$ with no promoter and 93\% with sodium added to both $\mathrm{N}$-agents. 
Firing Rate: 705,000 Btu/Hr

Main Fuel : Illinois Coal

9\% Nat.Gas Reburn

$\mathrm{SR} 1=1.10, \mathrm{SR} 2=0.99, \mathrm{SR} 3=1.15$

NO level: 1000 ppm @0\%O2 dry

Additive injected at $1450 \mathrm{~K}$, OFA injected at $1370 \mathrm{~K}$

$\mathrm{NSR}=1.5$

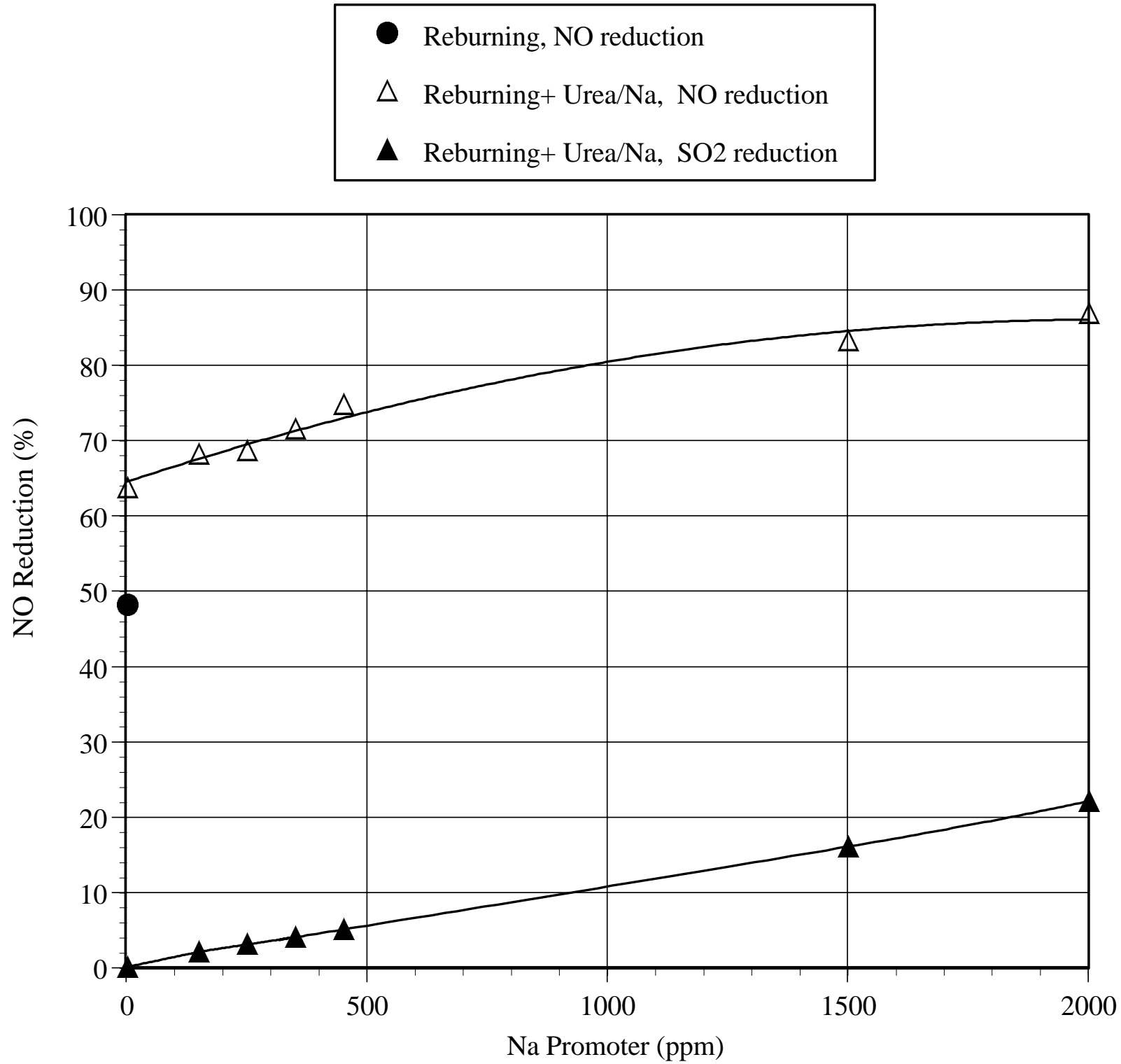

Figure 3.4. AR-Rich tests: effect of sodium promoter concentration upon performance. 
Firing Rate: 705,000 Btu/Hr

Main Fuel : Illinois Coal

9\% Nat.Gas Reburn

$\mathrm{SR} 1=1.10, \mathrm{SR} 2=0.99, \mathrm{SR} 3=1.15$

NO level: 1000 ppm @0\%O2 dry

OFA injected at $1530 \mathrm{~K}$

$\mathrm{NSR}=1.5$

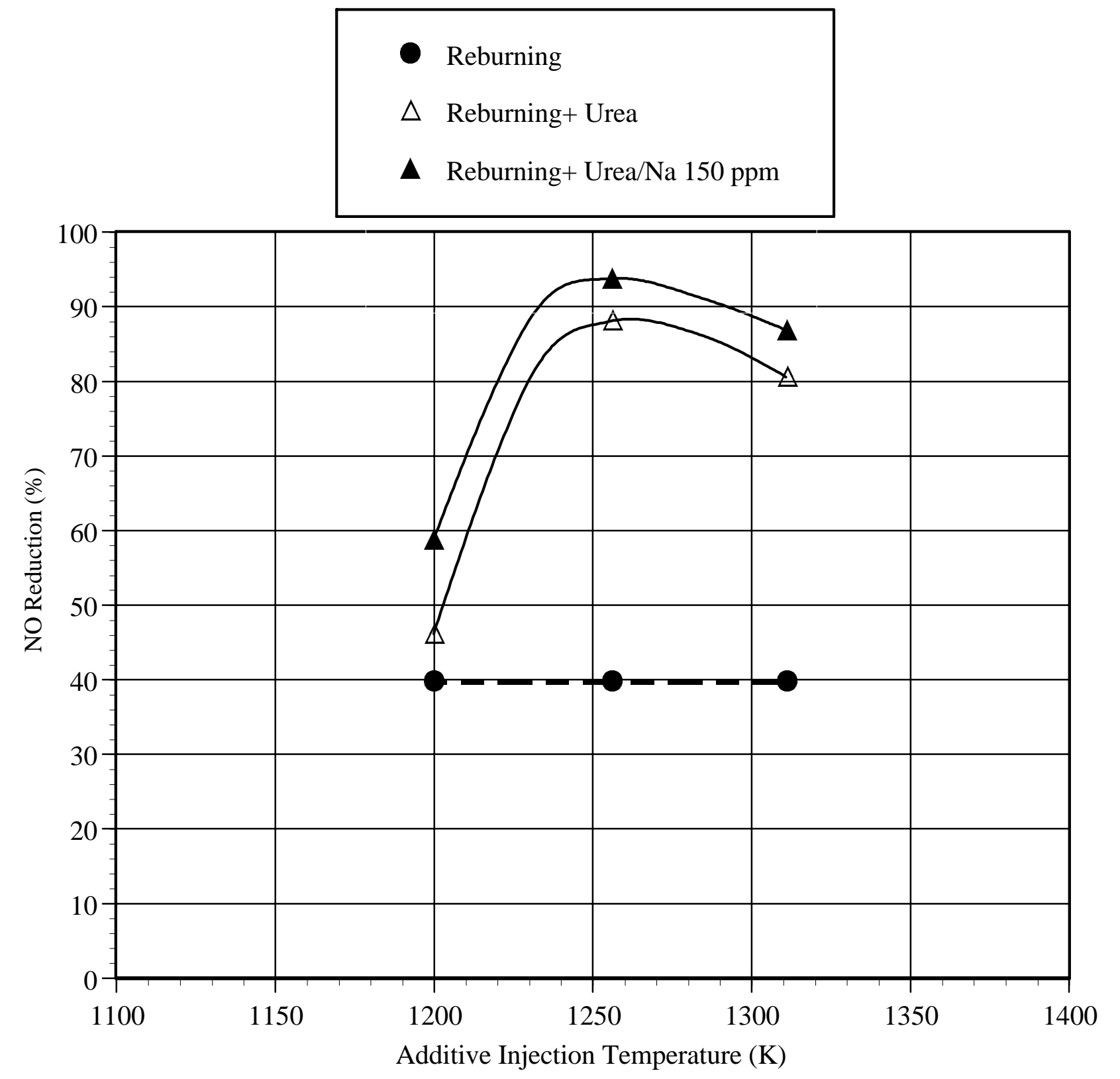

Figure 3.5. Reburning+SNCR tests: effect of additive injection temperature upon performance. 
Firing Rate: $705,000 \mathrm{Btu} / \mathrm{Hr}$

Main Fuel : Illinois Coal

9\% Nat.Gas Reburn

$\mathrm{SR} 1=1.10, \mathrm{SR} 2=0.99, \mathrm{SR} 3=1.15$

NOi: 1000 ppm @0\%O2 dry

First additive injected at $1590 \mathrm{~K}$

OFA injected at $1530 \mathrm{~K}$

$\mathrm{NSR}=1.5$

- Reburning

$\triangle$ Reburning + Agent $1+$ Agent 2

$\diamond$ Reburning +Agent1+Agent 2/Na $150 \mathrm{ppm}$

f Reburning +Agent1/Na 150 ppm+Agent 2

Reburning +Agent1/Na $150 \mathrm{ppm}+$ Agent 2/Na $150 \mathrm{ppm}$

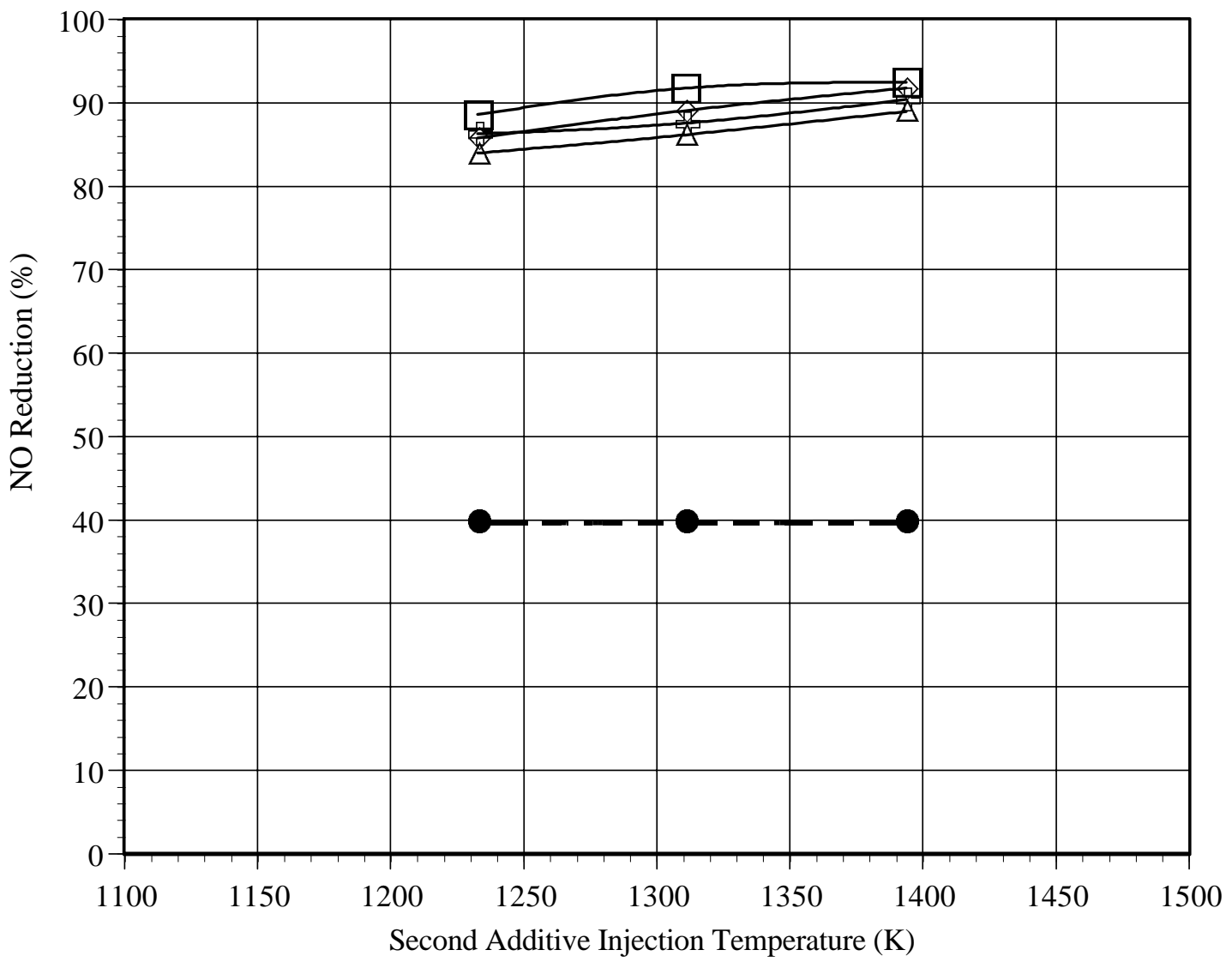

Figure 3.6. AR-Rich + SNCR tests: effect of second additive injection temperature upon performance. 


\subsection{MIAR Parametric Tests}

Multiple injection advanced reburning (MIAR) components include reburning, AR-Rich, and ARLean (both with and without promoters). Test variables at the BSF included reburn heat input, ARRich injection temperature, AR-Lean injection temperature, and sodium promoter concentration. Illinois coal was again used as the main fuel. Figure 3.7 shows NO reduction as a function of the AR-Rich injection temperature at reburn zone $\mathrm{SR}=0.90$ (i.e. $18 \%$ reburning). OFA was injected at 1900 F. Reburning alone gave 74\% NO reduction. Overall MIAR NO reduction was 80-82\%, and was nearly constant as additive injection temperature was varied from 2000 to $2300 \mathrm{~F}$. Addition of sodium promoter did not significantly impact performance. Because performance was relatively low, temperatures above $2300 \mathrm{~F}$ were not tested.

Similar tests were then conducted at reburn zone SR=0.99 (9\% reburning). Figure 3.8 shows performance as a function of AR-Rich additive injection temperature. Reburning alone gave $48 \%$ NO reduction. MIAR NO reduction increased with decreasing first additive injection temperature. Sodium promoter was added to each $\mathrm{N}$-agent individually and to both agents. Adding promoter to both $\mathrm{N}$-agents provided an incremental performance increase of about 5 percentage points at each temperature. Maximum NO reduction was $94 \%$, obtained with promoter added to both $\mathrm{N}$-agents at an AR-Rich injection temperature of $2000 \mathrm{~F}$. It is also noteworthy that performance remained relatively good at high injection temperatures. NO reductions above $80 \%$ were obtained at injection temperatures in excess of $2400 \mathrm{~F}$. This insensitivity can provide greater flexibility for application to boilers with limited furnace access for injectors.

MIAR tests were then conducted in which the AR-Lean additive injection temperature was varied, with the AR-Rich temperature fixed at $2150 \mathrm{~F}$. The AR-Lean additives were co-injected along with the OFA. Figure 3.9 shows results obtained at reburn zone $\mathrm{SR}=0.90$ (18.2\% reburning). Reburning alone gave $74 \%$ NO reduction. Overall MIAR NO reduction was 76-82\%, and was nearly constant as additive injection temperature was varied from 1700 to $2000 \mathrm{~F}$. Addition of sodium promoter to both $\mathrm{N}$-agents increased NO reduction by 5 percentage points at $1700 \mathrm{~F}$, but did not significantly impact performance at $2000 \mathrm{~F}$. 
Firing Rate: 705,000 Btu/Hr

Main Fuel : Illinois Coal

$18 \%$ Nat.Gas Reburn

$\mathrm{SR} 1=1.10, \mathrm{SR} 2=0.90, \mathrm{SR} 3=1.15$

NOi: 1000 ppm @0\%O2 dry

Second additive co-injected with OFA at $1310 \mathrm{~K}$

$\mathrm{NSR}=1.5$

- Reburning

$\triangle$ Reburning +Agent1+Agent 2

$\diamond$ Reburning +Agent $1+$ Agent 2/Na 150 ppm

\& Reburning + Agent1/Na 150 ppm+Agent 2

$\square$ Reburning +Agent1/Na $150 \mathrm{ppm}+$ Agent 2/Na $150 \mathrm{ppm}$

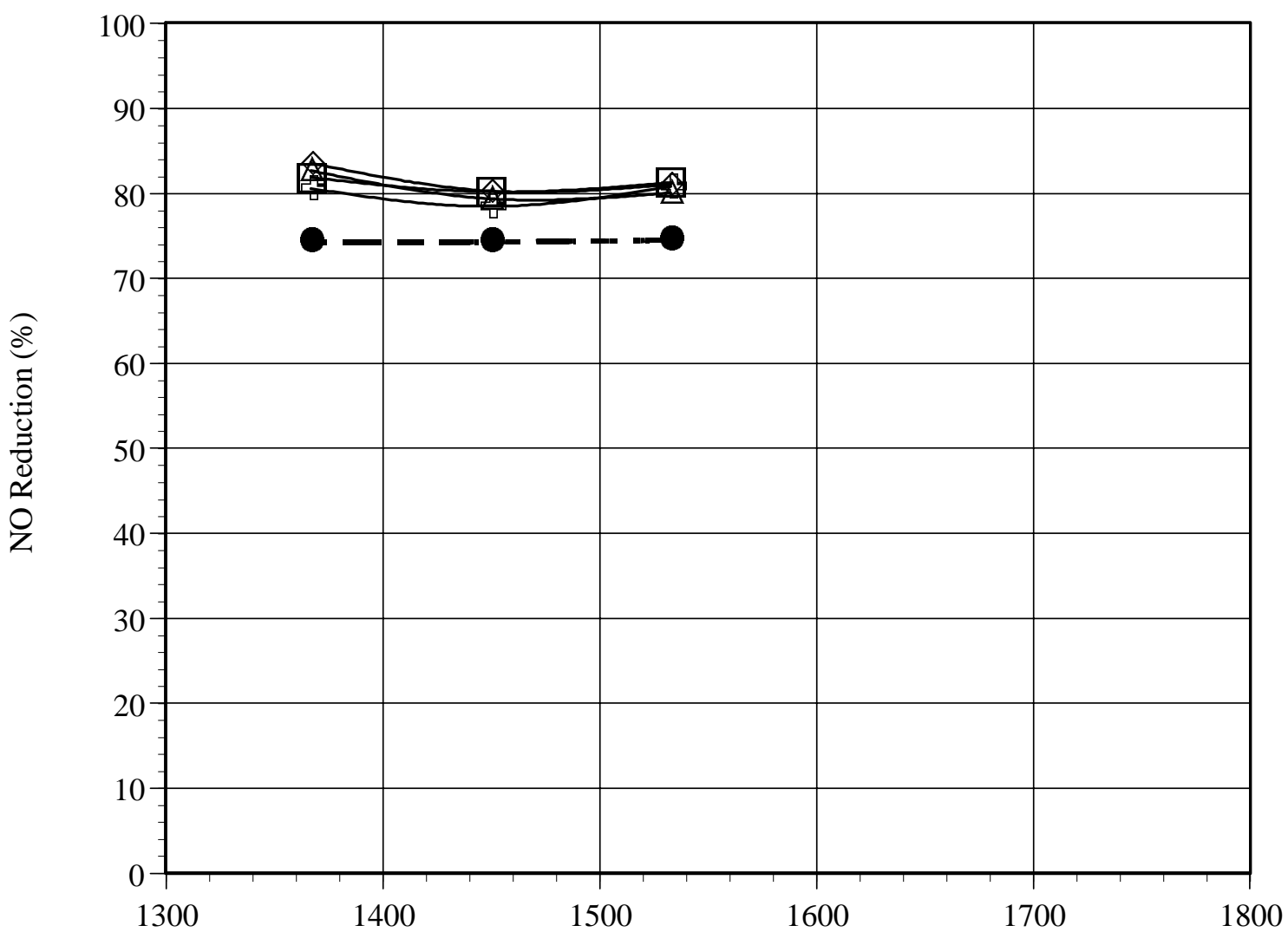

First Additive Injection Temperature (K)

Figure 3.7. MIAR tests: effect of first additive injection temperature upon performance at $18 \%$ reburning. 
Firing Rate: 705,000 Btu/Hr

Main Fuel : Illinois Coal

9\% Nat.Gas Reburn

$\mathrm{SR} 1=1.10, \mathrm{SR} 2=0.99, \mathrm{SR} 3=1.15$

NOi: 1000 ppm @0\%O2 dry

Second additive co-injected with OFA at $1310 \mathrm{~K}$

$\mathrm{NSR}=1.5$

- Reburning

$\triangle$ Reburning +Agent1+Agent 2

$\diamond$ Reburning +Agent $1+$ Agent 2/Na 150 ppm

\& Reburning +Agent 1/Na 150 ppm+Agent 2

$\square$ Reburning +Agent1/Na 150 ppm+Agent 2/Na 150 ppm

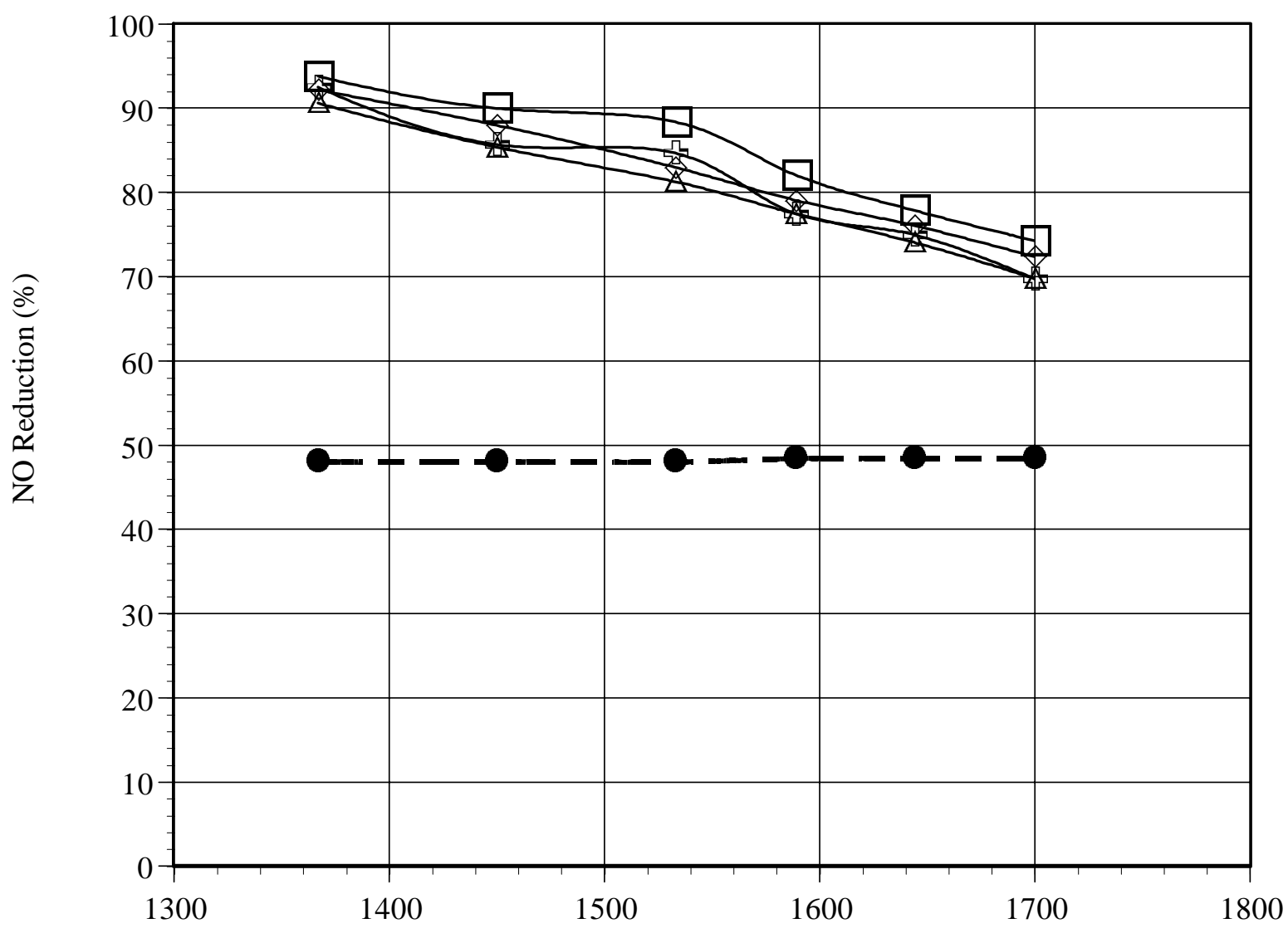

First Additive Injection Temperature (K)

Figure 3.8. MIAR tests: effect of first additive injection temperature upon performance at $9 \%$ reburning. 
Firing Rate: 705,000 Btu/Hr

Main Fuel : Illinois Coal

$18 \%$ Nat.Gas Reburn

$\mathrm{SR} 1=1.10, \mathrm{SR} 2=0.90, \mathrm{SR} 3=1.15$

NOi: 1000 ppm @0\%O2 dry

First additive injected at $1310 \mathrm{~K}$

Second additive co-injected with OFA

$\mathrm{NSR}=1.5$

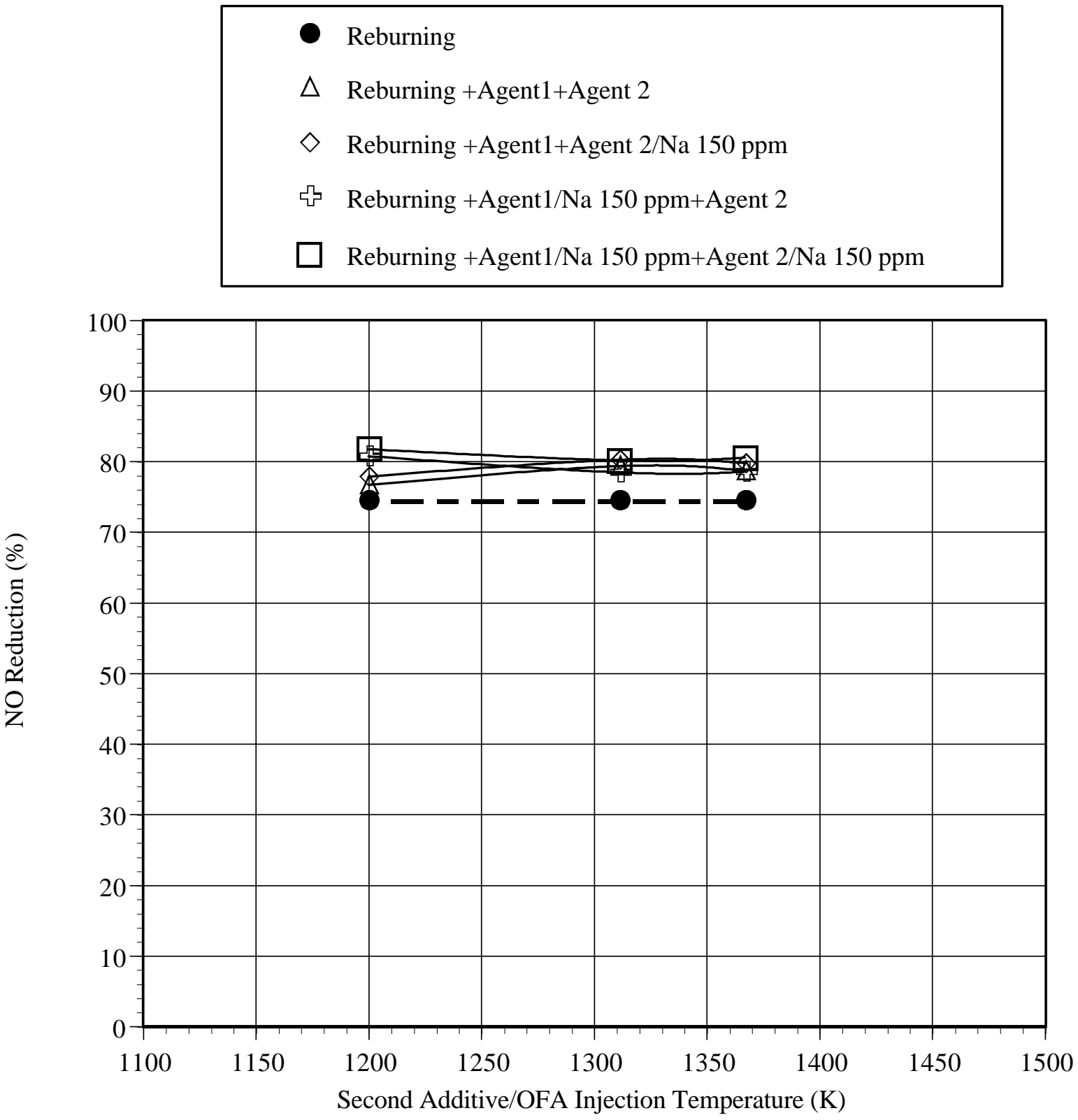

Figure 3.9. MIAR tests: effect of second additive injection temperature upon performance at $18 \%$ reburning. 
AR-Lean additive injection temperature was then varied at reburn zone $\mathrm{SR}=0.99$ (9\% reburning). As shown in Figure 3.10, reburning alone gave 48\% NO reduction. With two N-agents with no promoters, a maximum of $86 \%$ NO reduction was obtained. The optimum temperature was 1900 $\mathrm{F}$, and performance decreased as additive injection temperature increased to $2000 \mathrm{~F}$. However, with $150 \mathrm{ppm}$ sodium promoter added to the first $\mathrm{N}$-agent, performance increased with increasing temperature. Highest NO reduction was 95\%, obtained at an AR-Lean additive injection temperature of $2000 \mathrm{~F}$. It is theorized that adding sodium at with the first $\mathrm{N}$-agent at higher temperatures makes it available to promote reduction of $\mathrm{NO}$ by the second $\mathrm{N}$-agent.

In summary, the parametric tests showed that the AR technologies are able to provide effective NOx control for a high-sulfur coal fired combustor. Sodium was found to significantly promote performance when added at $150 \mathrm{ppm}$, which is a manageable level for most utility boilers. Maximum NO reductions achieved by the promoted AR technologies were $84 \%$ for AR-Lean, $93 \%$ for AR-Rich, $94 \%$ for reburning plus SNCR, and 95\% for MIAR.

\subsection{Byproduct Sampling Tests}

While the AR technologies have shown the ability for effective $\mathrm{NO}_{\mathrm{x}}$ control, another consideration is whether they generate any undesirable byproducts. Specifically, it was sought to determine whether the different variations of AR generate byproduct emissions greater than those of commercially accepted technologies such as SNCR and reburning. To answer this question, byproduct sampling tests were performed at the BSF. The following seven conditions were tested:

\footnotetext{
- $\quad$ Baseline coal firing

- $\quad$ SNCR

- Reburning

- AR-Rich

- $\quad$ AR-Lean

- $\quad$ Reburning plus SNCR

- $\quad$ MIAR
} 
Firing Rate: 705,000 Btu/Hr

Main Fuel : Illinois Coal

9\% Nat.Gas Reburn

$\mathrm{SR} 1=1.10, \mathrm{SR} 2=0.99, \mathrm{SR} 3=1.15$

NOi: 1000 ppm @0\%O2 dry

First additive injected at $1310 \mathrm{~K}$

Second additive co-injected with OFA

$\mathrm{NSR}=1.5$

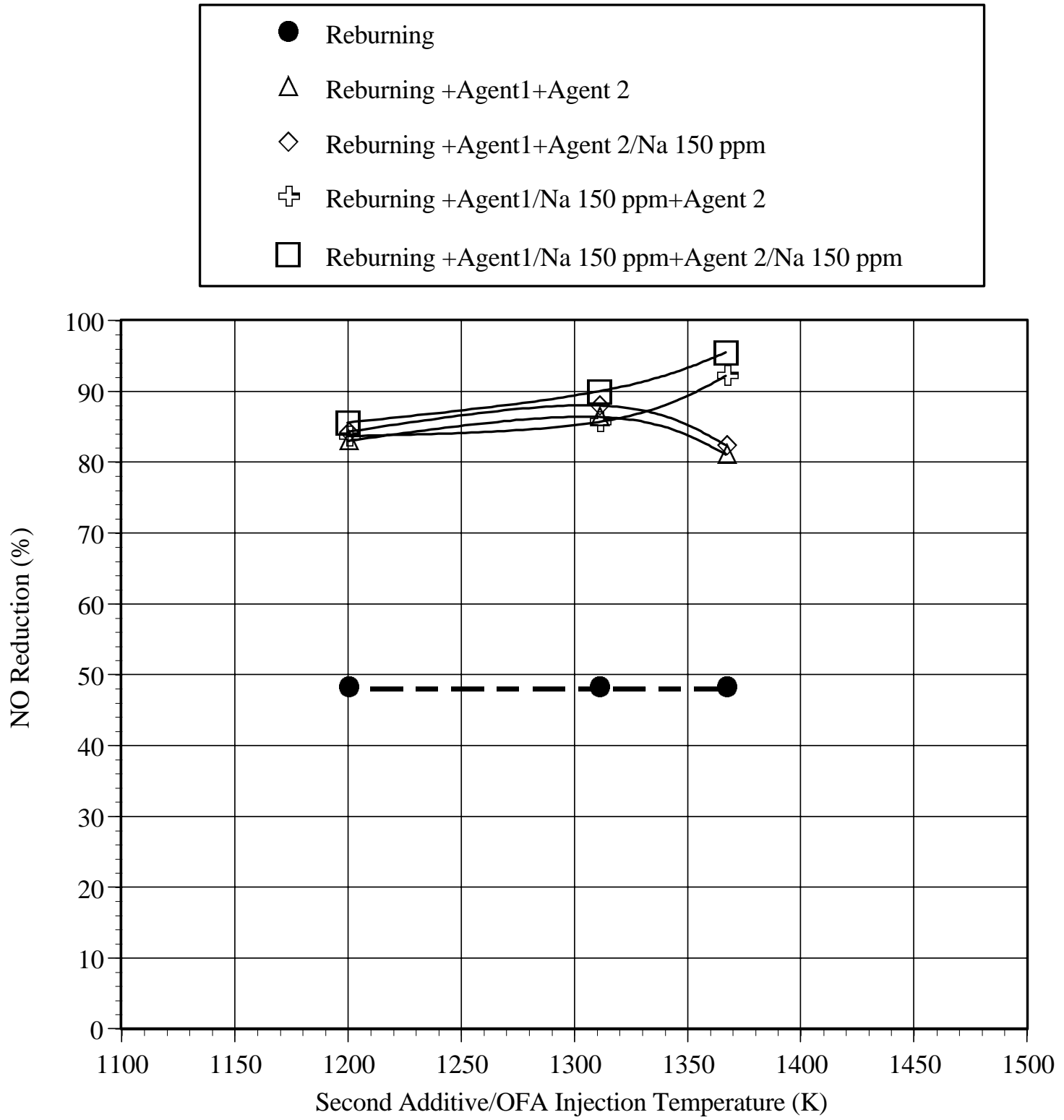

Figure 3.10. MIAR tests: effect of second additive injection temperature upon performance at $9 \%$ reburning. 
Test conditions, including reburn heat input, injection temperatures, promoter amounts and OFA temperatures, were selected as providing optimum performance while also being achievable in a typical utility boiler. For each condition, sampling included

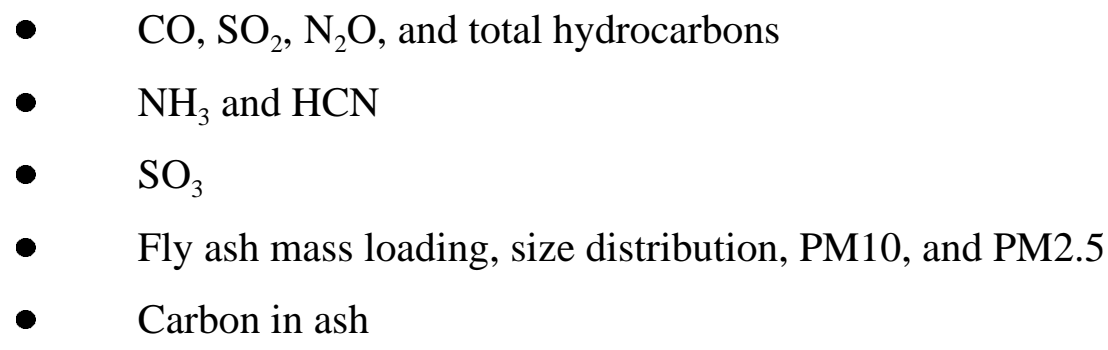

Test conditions and sampling data are summarized in Table 3.2. The byproducts were measured at conditions which were optimized for NOx control. Additional optimization tests on byproduct emissions can be conducted in Phase II. However, even without significant byproduct optimization efforts, the AR technologies do not generate more byproducts than reburning or SNCR. Results for each of the byproduct compounds tested are described below.

\section{CEMS Emissions}

A continuous emissions monitoring system (CEMS) was used to sample for $\mathrm{CO}, \mathrm{SO}_{2}, \mathrm{~N}_{2} \mathrm{O}$, and total hydrocarbons. $\mathrm{SO}_{2}$ concentrations were in the range of 3010 to 3140 ppm (@ 0\% $\mathrm{O}_{2}$ ) for each condition, and were not affected by the AR technologies. Total hydrocarbon emissions were $2 \mathrm{ppm}$ for each test condition. Figure 3.11 summarizes $\mathrm{CO}$ and $\mathrm{N}_{2} \mathrm{O}$ emissions for each of the seven test conditions. $\mathrm{CO}$ and $\mathrm{N}_{2} \mathrm{O}$ generally increased during application of the NOx control technologies relative to baseline coal firing. The largest increases were associated with the low temperature $\mathrm{N}$ agent injection technologies, i.e. SNCR and reburning + SNCR. For SNCR, CO increased from 58 to $120 \mathrm{ppm}$, and $\mathrm{N}_{2} \mathrm{O}$ increased from 1 to $73 \mathrm{ppm}$. OFA was injected at $1900 \mathrm{~F}$. Thus AR-Lean, ARRich, and MIAR generate lower concentrations of $\mathrm{CO}$ and $\mathrm{N}_{2} \mathrm{O}$ than does SNCR under similar conditions. It is believed that $\mathrm{CO}$ and $\mathrm{N}_{2} \mathrm{O}$ concentrations could be further reduced by injecting OFA at a higher temperature. 


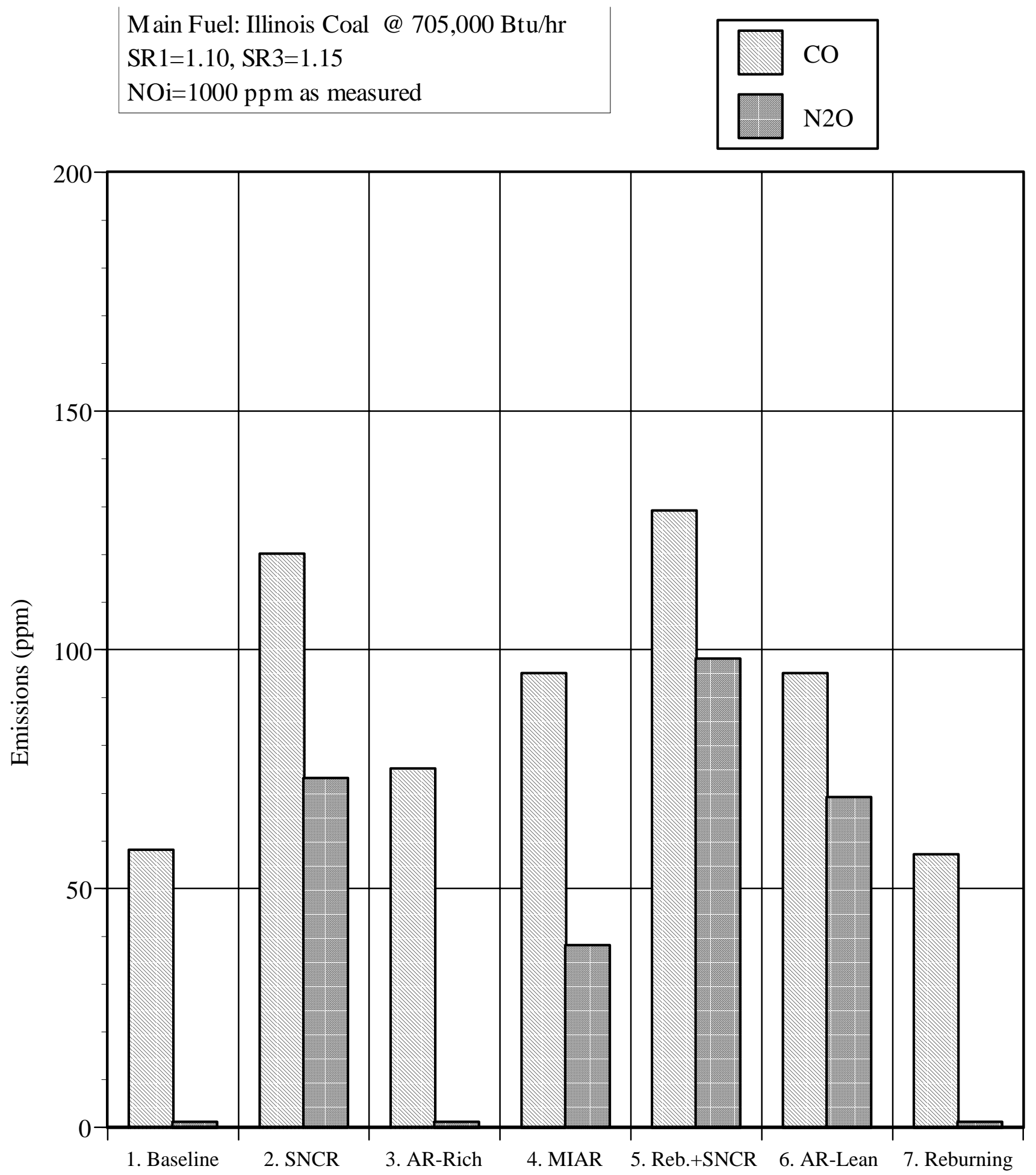

Figure 3.11. $\mathrm{CO}$ and $\mathrm{N}_{2} \mathrm{O}$ emissions for $\mathrm{AR}$ technologies. 
Table 3.2. Byproduct sampling conditions and results.

Baseline configuration: Illinois coal @ 705,000 Btu/hr

$\mathrm{NOi}=1000 \mathrm{ppm}$ as measured

$\mathrm{SR} 1=1.10, \mathrm{SR} 3=1.15$
Test conditions: NSR $=1.5$

$\mathrm{N}$-agent: Urea

$\mathrm{Na}$ promoter: $\mathrm{Na} 2 \mathrm{CO} 3$

\begin{tabular}{|c|c|c|c|c|c|c|c|}
\hline Parameter & 1. Baseline & 2. SNCR & 3. AR-Rich & $\begin{array}{r}\text { Test C } \\
\text { 4. MIAR }\end{array}$ & $\begin{array}{l}\text { ase } \\
\begin{array}{l}5 . \text { Reburning } \\
+ \text { SNCR }\end{array}\end{array}$ & 6. AR-Lean & 7. Reburning \\
\hline \multicolumn{8}{|l|}{ Test Conditions } \\
\hline Reburn NG heat input (\%), & None & None & $10 \%$ & $10 \%$ & $10 \%$ & $10 \%$ & $20 \%$ \\
\hline Rich side additive $\mathrm{T}(\mathrm{F})$ & None & None & 2100 & 2000 & None & None & None \\
\hline Rich side $\mathrm{Na}$ (ppm) & None & None & 150 & 150 & None & None & None \\
\hline OFA $\mathrm{T}(\mathrm{F})$ & None & None & 1900 & 1900 & 2300 & 1900 & 2300 \\
\hline Lean side additive $T(F)$ & None & 1900 & None & 1900 & 1900 & 1900 & None \\
\hline Lean side $\mathrm{Na}(\mathrm{ppm})$ & None & None & None & 0 & None & 150 & None \\
\hline \multicolumn{8}{|l|}{ Sampling Results } \\
\hline$\overline{\mathrm{CO}(\mathrm{ppm} @ 0 \% \text { O2) }}$ & 58 & 120 & 75 & 95 & 129 & 95 & 57 \\
\hline SO2 (ppm @0\% O2) & 3140 & 3011 & 3050 & 3012 & 3120 & 3045 & 3011 \\
\hline N2O(ppm@0\% O2) & 1 & 73 & 1 & 38 & 98 & 69 & 1 \\
\hline THC (ppm @0\% O2) & 2 & 2 & 2 & 2 & 2 & 2 & 2 \\
\hline NH3 (ppm @0\% O2) & 0.0 & 47.3 & 0.0 & 4.4 & 50.1 & 0.0 & 0.0 \\
\hline HCN (ppm@0\% O2) & 0.0 & 0.0 & 1.1 & 1.2 & 1.6 & 1.0 & 0.5 \\
\hline SO3 (ppm @0\% O2) & 2.0 & 0.8 & 1.3 & 1.1 & 1.7 & 2.8 & 1.2 \\
\hline Particulate loading (gr/dsc & 2.0 & 2.3 & 1.8 & 1.9 & 2.2 & 2.3 & 2.1 \\
\hline Fly ash MMD (microns) & 8.1 & 8.7 & 10.8 & 10.1 & 8.2 & 8.6 & 8.5 \\
\hline PM10 (\%) & 54.4 & 52.1 & 49.2 & 49.8 & 55.4 & 53.0 & 53.5 \\
\hline$(\mathrm{gr} / \mathrm{dscf})$ & 1.09 & 1.21 & 0.88 & 0.93 & 1.24 & 1.23 & 1.10 \\
\hline PM2.5 (\%) & 10.5 & 10.1 & 9.4 & 13.6 & 14.3 & 11.2 & 12.6 \\
\hline$(\mathrm{gr} / \mathrm{dscf})$ & 0.21 & 0.23 & 0.17 & 0.25 & 0.32 & 0.26 & 0.26 \\
\hline Carbon in ash (\%) & 0.08 & 0.03 & 0.17 & 0.26 & 0.07 & 0.10 & 0.08 \\
\hline
\end{tabular}

$\mathrm{NH}_{3}$ and $\mathrm{HCN}$ Emissions

$\mathrm{NH}_{3}$ and $\mathrm{HCN}$ emissions were measured by EPA Draft Method 206, using ion chromatography analysis. Results are shown in Figure 3.12. $\mathrm{NH}_{3}$ emissions were fairly high ( $>40 \mathrm{ppm}$ ) for the two SNCR conditions, but were below $5 \mathrm{ppm}$ for all other conditions (including MIAR). HCN emissions were below $2 \mathrm{ppm}$ for baseline coal and all AR test conditions. These results would appear to indicate that as long as the $\mathrm{N}$-agent(s) are added with or upstream of the OFA, $\mathrm{NH}_{3}$ and $\mathrm{HCN}$ emissions can be minimized. Thus AR-Lean, AR-Rich, and MIAR generate significantly lower $\mathrm{NH}_{3}$ emissions than does SNCR under similar conditions. For the SNCR cases, it is believed that a higher reagent injection temperature would also minimize $\mathrm{NH}_{3}$ emissions. 


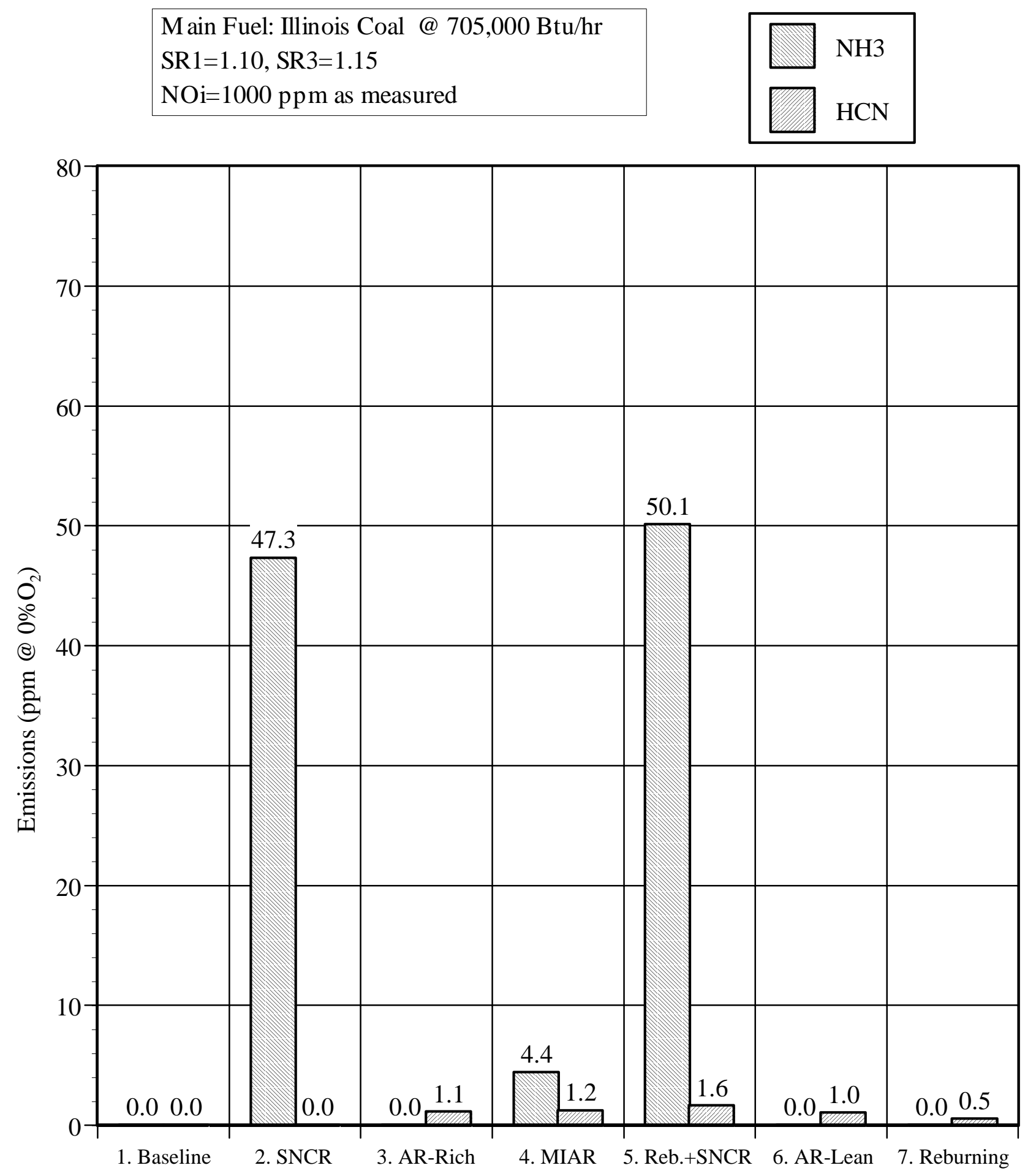

Figure 3.12. $\mathrm{NH}_{3}$ and $\mathrm{HCN}$ emissions for $\mathrm{AR}$ technologies. 
$\mathrm{SO}_{3}$ Emissions

$\mathrm{SO}_{3}$ emissions can impact electrostatic precipitator performance and, if present in high concentrations, can cause boiler corrosion problems. $\mathrm{SO}_{3}$ emissions were measured using the controlled condensation method, as detailed in the EPA's "Process Measurement Procedures Sulfuric Acid Emissions," 1977. The sample probe was operated at a temperature of $600^{\circ} \mathrm{F}$. Figure 3.13 shows $\mathrm{SO}_{3}$ test results. The $\mathrm{SO}_{3}$ concentration for baseline coal firing was about $2 \mathrm{ppm}$. For each of the NOx control technologies, $\mathrm{SO}_{3}$ remained below $3 \mathrm{ppm}$. It is concluded that none of the technologies cause a significant increase in $\mathrm{SO}_{3}$ emissions.

\section{Particulate Size Distribution}

Fly ash particle size can affect dust control equipment efficiency as well as causing respirability and health considerations. Particulate size distribution was measured using a cascade impactor. Figure 3.14 shows fly ash distributions for each of the seven test conditions. Fly ash mass mean diameter was between 8 and 11 microns for each condition. The AR technologies did not appear to significantly alter overall size distribution.

\section{Particulate Loading, PM10, and PM2.5}

PM10 and PM2.5 are defined as the fraction of fly ash material of diameter less than 10 and 2.5 microns, respectively. EPA Method 5 and cascade impactors were used to determine total particle loading, PM10, and PM2.5. Results are shown in Figure 3.15. Total particulate loading was 2.0 $\mathrm{gr} / \mathrm{dscf}$ for baseline coal firing, and ranged from 1.8 to $2.3 \mathrm{gr} / \mathrm{dscf}$ for the different NOx control technologies. PM10 was about $1.1 \mathrm{gr} / \mathrm{dscf}$ for baseline coal firing, and ranged from 0.9 to $1.2 \mathrm{gr} / \mathrm{dscf}$ for the different technologies. PM2.5 was about $0.21 \mathrm{gr} / \mathrm{dscf}$ for baseline coal firing, and ranged from 0.17 to $0.32 \mathrm{gr} / \mathrm{dscf}$ for the different technologies. These results would appear to indicate that the AR NOx control technologies do not significantly impact particulate loading, PM10, or PM2.5.

\section{Carbon in Ash}

Poor carbon burnout can adversely impact boiler thermal performance, along with the salability of collected fly ash. Ash samples were collected from the BSF convective pass using a volumetric sampler and were analyzed for carbon by a contract laboratory. Figure 3.16 shows 


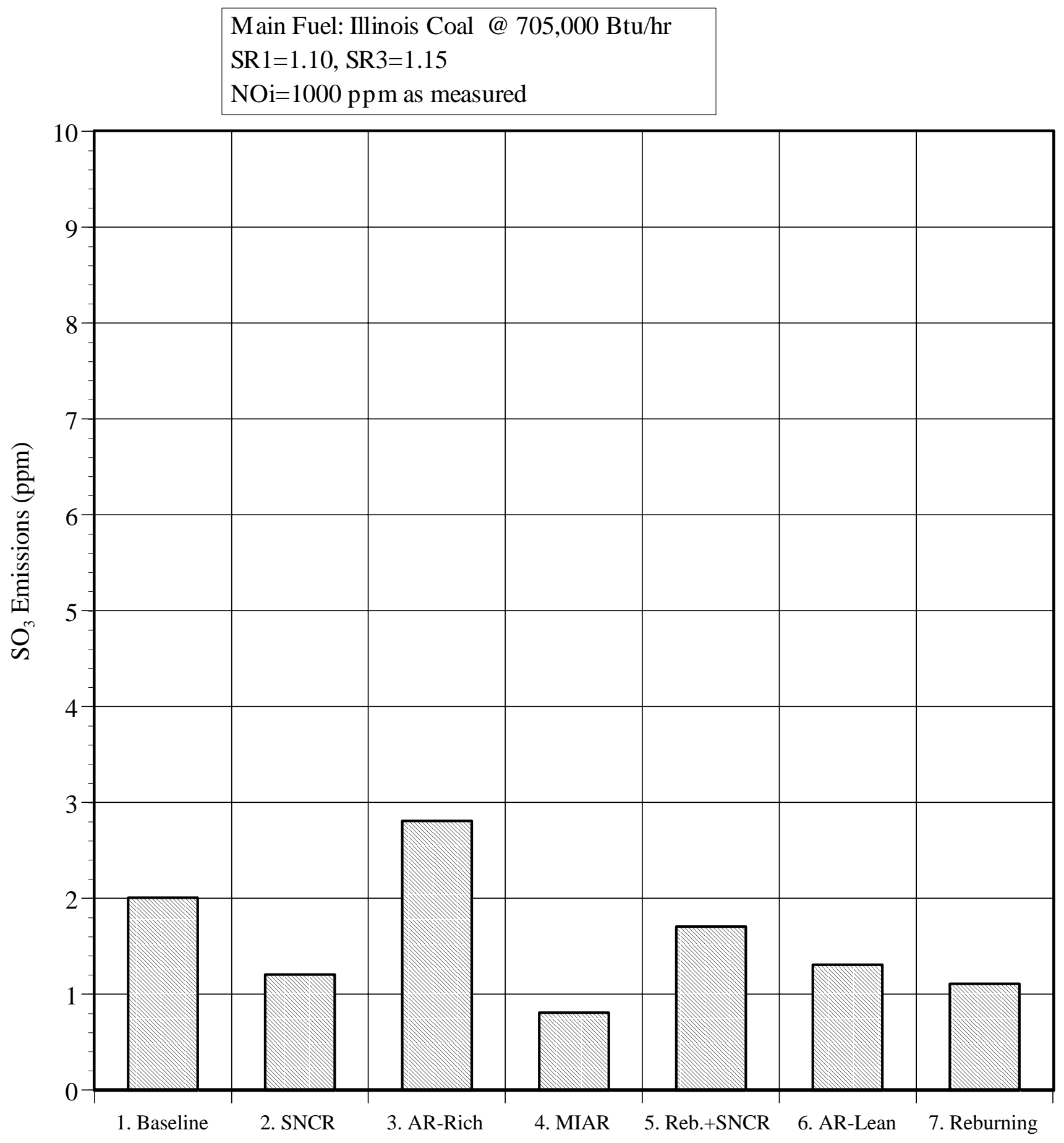

Figure 3.13. $\mathrm{SO}_{3}$ emissions for $\mathrm{AR}$ technologies. 


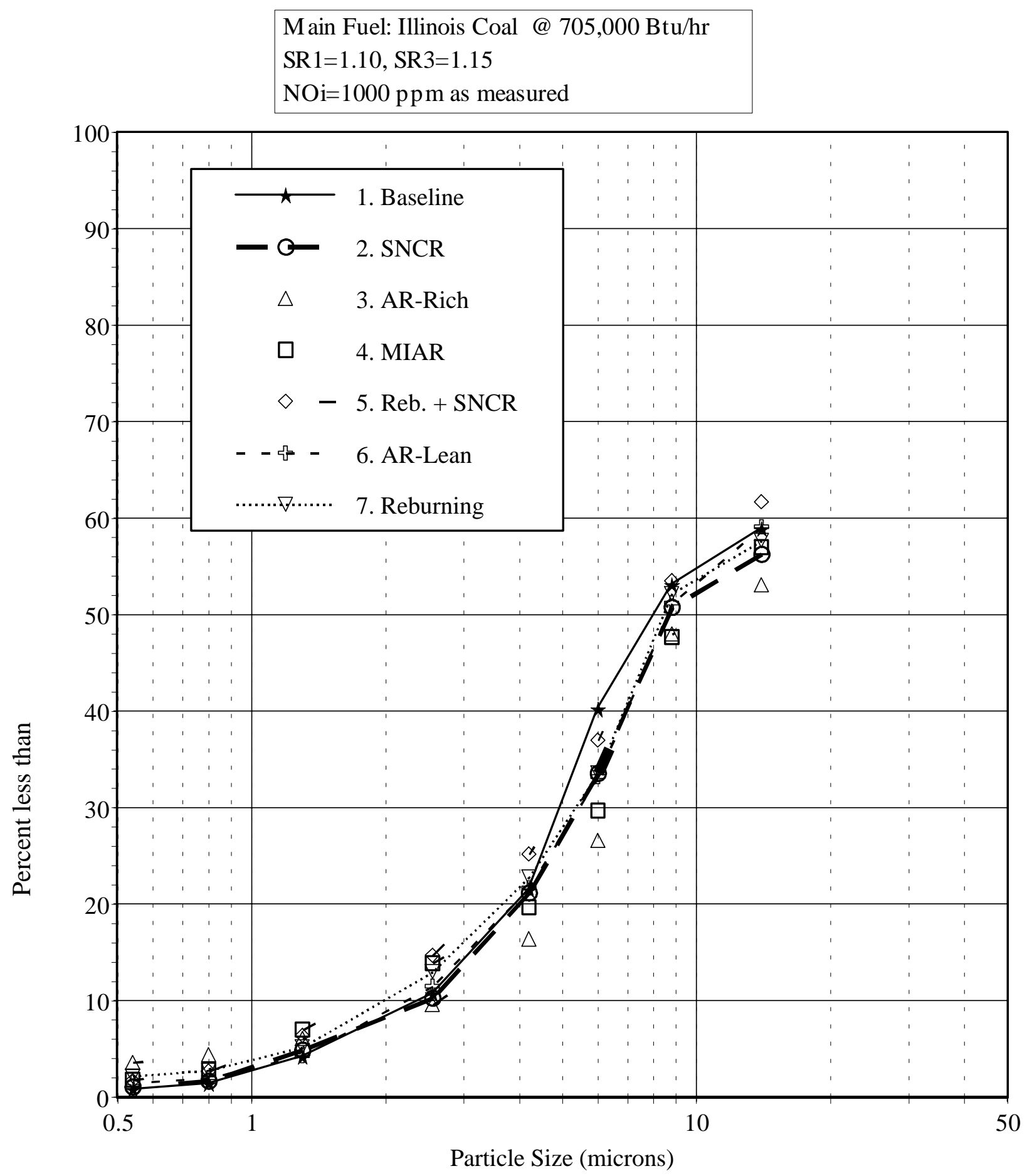

Figure 3.14. Fly ash size distributions. 


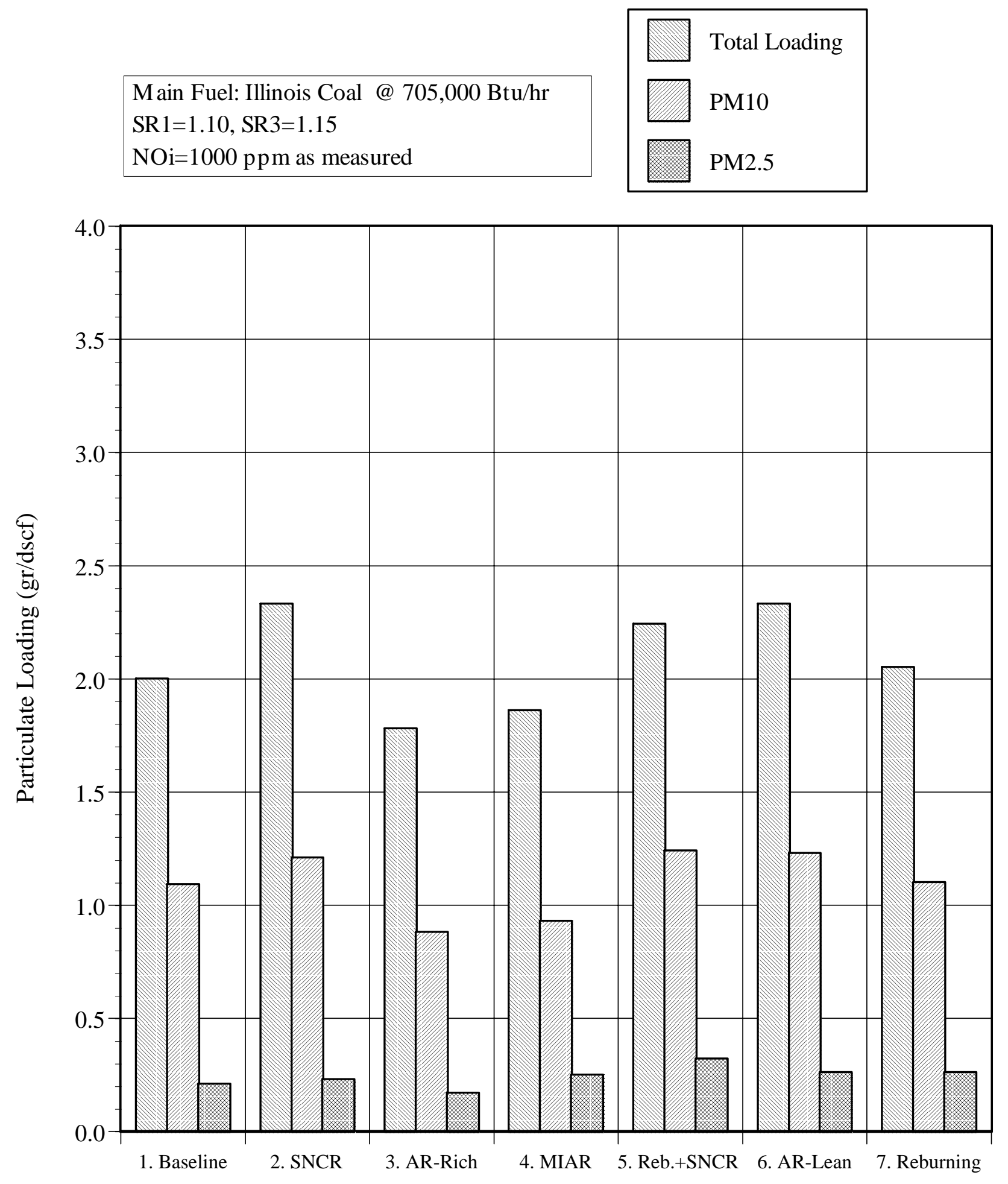

Figure 3.15. Fly ash total loading, PM10, and PM2.5. 


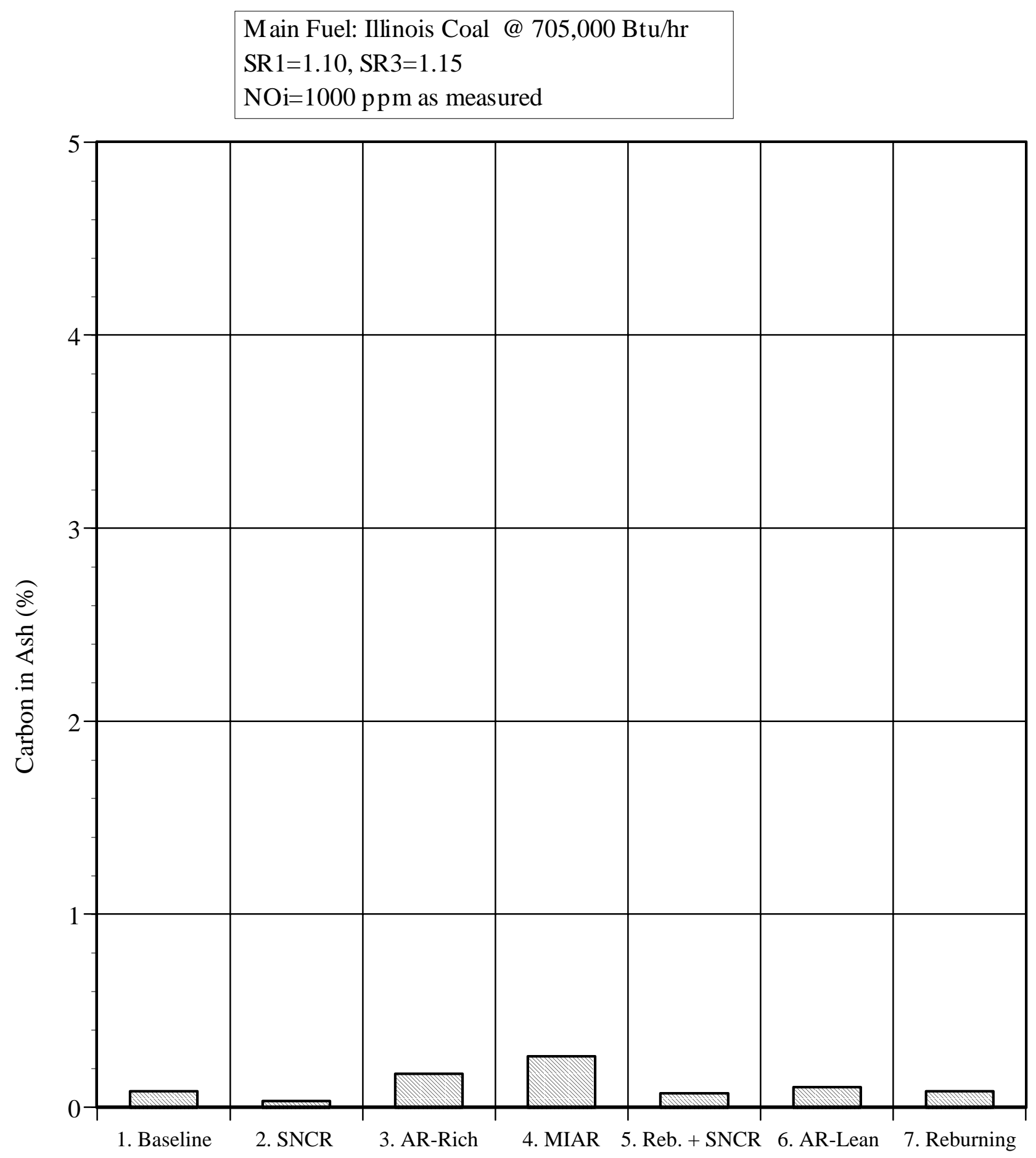

Figure 3.16. Carbon in ash results. 
carbon in ash results. For all conditions, carbon in ash was well below $1 \%$. Thus it is concluded that the AR technologies do not significantly decrease carbon burnout.

In summary, byproduct emissions were generally found to be low for the AR technologies. The only emissions which showed potential for significant increase were $\mathrm{CO}, \mathrm{N}_{2} \mathrm{O}$ and $\mathrm{NH}_{3}$, for $\mathrm{SNCR}$ conditions. However, these emissions can be minimized by adding the second $\mathrm{N}$-agent at higher temperature. 


\subsection{Modeling Studies}

The modeling studies of this report continue and extend those of the previous quarterly report. The model of Advanced Reburning has been used to better understand the effect of sodium promotion in AR-Rich.

\subsection{Evaluation of Advanced Reburning for $\mathrm{NSR}=1.0$}

The previous quarterly report (Zamansky, et. al., January 1997) included a study of the effect of mixing time on the kinetic behavior of advanced reburning, with the $\mathrm{N}$-agent $\left(\mathrm{NH}_{3}\right)$ injected into either the reburning zone (AR-Rich) or into the burnout zone (AR-Lean). This study employed a one dimensional chemical kinetics model (“ODF”) developed at EER. The model includes the capability to model plug flow reactors with external mass fluxes distributed along their length, to simulate the delayed mixing of reactants as occurs when process streams are injected via sprays or gaseous jets. Thus, mixing time was introduced as a variable, ranging from instantaneous mixing (to compare results with other models such as Chemkin, which employ this simplification), to mixing times of 30 ms (typical of bench and small pilot scale systems) and $300 \mathrm{~ms}$ (typical of large pilot-scale and fullscale industrial combustion systems). Thus the mixing time parameter is one indication of the effect of scale on AR performance.

In addition to mixing time, the studies in the previous report varied other process parameters, including the reburning zone stoichiometry and the locations/temperatures at which $\mathrm{N}$-agent and overfire air (OFA) were injected. The primary and burnout zone stoichiometric ratios were about 1.10 and 1.15, respectively, for all cases. A representative temperature profile of $-300 \mathrm{~K} / \mathrm{s}$ was used, from a reburn fuel injection temperature of $1700 \mathrm{~K}$. The $\mathrm{N}$-agent injection location was characterized in terms of it's position relative to reburn fuel or overfire air injection, as the overlap or delay between reactant streams significantly impacts the emissions performance.

Another significant parameter in AR performance is the amount of $\mathrm{N}$-agent added relative to the amount of NO present in the system. This is characterized as the Nitrogen Stoichiometric Ratio (NSR), which is defined as the molar ratio of moles of $\mathrm{N}$ atom added with the $\mathrm{N}$-agent to the moles 
of NO in the combustion products at the point of injection. Under ideal mixing and temperature conditions, N-agent added to an NSR of 1.0 would be sufficient to destroy most of the NO. In most practical systems, a higher NSR is used to overcome non-ideal aspects such as non-uniform mixing, temperature variations, and wall effects.

The specification of NO at the point of injection as the reference value in the definition of NSR is a significant issue, particularly in technologies such as AR with multiple, distributed reactant streams. In such systems, the concentration of NO may change rapidly as it interacts with each reactant stream. As a result, a quantity of $\mathrm{N}$-agent which is optimal at one location could be excessive at another, with the possible risk of the additional N-agent escaping unreacted, or itself forming NO or other fixed nitrogen products thus diminishing the effectiveness of the system. This presents an operating challenge since it is often impractical to measure the NO at the exact point of injection. As an alternative, most working systems employ monitoring and control techniques which optimize the rate of $\mathrm{N}$-agent injection based on readily measurable parameters such as the stack NO concentration.

In the mixing model studies of the previous quarterly report, the $\mathrm{N}$-agent (ammonia) was injected with a consistent concentration of $600 \mathrm{ppm}$ for all cases, matching the NO concentration entering the reburning zone. This simplification allowed an initial screening of the effect of various process parameters, but the resulting NSR based on NO at the point of injection varied for all conditions except for the case in which $\mathrm{N}$-agent was co-injected with the reburning fuel.

To characterize AR performance in terms of a consistent $\mathrm{N}$-agent stoichiometry, the cases discussed in the previous report were rerun with the NSR adjusted to 1.0 at the point of injection. The figures which present overall performance (Figures 4.2.7 through 4.2.10 of the January Report) have been updated to show the results for NSR=1.0, as shown in Figures 4.1 through 4.4. Figures 4.1 and 4.2 show the performance of AR-Rich (and conventional reburn without N-agent) for reburn zone stoichiometries of 0.90 and 0.99 , respectively, for different $\mathrm{N}$-agent injection locations. Figure 4.3 shows the results of AR-Lean at different OFA injection temperatures when $\mathrm{N}$-agent is co-injected with the OFA. Figure 4.4 shows the corresponding AR-Lean cases when N-agent is injected $0.1 \mathrm{~s}$ after the OFA. 
In these figures, performance is defined as $\mathrm{XN} / \mathrm{NO}_{\mathrm{i}}$, where $\mathrm{XN}$ is the mole fraction of $\mathrm{NO}$ or Total Fixed Nitrogen (TFN) after burnout, and $\mathrm{NO}_{\mathrm{i}}$ is the initial mole fraction of $\mathrm{NO}$, prior to the addition of reburning fuel (not the $\mathrm{NO}$ at the point of $\mathrm{N}$-agent injection). The results are plotted as a function of the characteristic mixing time (which is the same for all added streams), for different operating conditions.

The trends shown in Figures 4.1 through 4.4 are similar to those with the higher NSR levels shown in the previous report. When NSR is trimmed to 1.0, however, NO reduction is better for cases which previously performed poorly, particularly for rapid injection rates. This may be interpreted as a reduction in excess $\mathrm{N}$-agent which can contribute to reaction pathways which generate new NO. However, there are cases which previously showed very good NO reduction and demonstrate degraded performance at $\mathrm{NSR}=1.0$. For example, the AR-Lean case injecting OFA at $1400 \mathrm{~K}, \mathrm{NH}_{3}$ delayed by $0.1 \mathrm{~s}$, and $300 \mathrm{~ms}$ mixing (see Figure 4.4) now shows $102 \mathrm{ppm}$ NO at the exit for NSR=1, as opposed to $25 \mathrm{ppm}$ NO for NSR=2. This is because at near optimal conditions, additional N-agent improves NO destruction and at the same time any excess N-agent is destroyed under a favorable reaction environment.

As might be expected, the reduction in NSR leads to a reduction in $\mathrm{NH}_{3}$ emissions (known as "ammonia slip"). However, most cases which exhibited significant ammonia slip previously still have it at NSR=1.0. This is because when conditions allow significant $\mathrm{NH}_{3}$ to escape (typically at temperatures lower than optimal), even moderate quantities of $\mathrm{N}$-agent can result in a significant unreacted fraction. However, in the optimum temperature window the ammonia slip can be effectively eliminated by adjustment of the NSR. For example, the case mentioned above (AR-Lean, $1400 \mathrm{~K}$ OFA, $0.1 \mathrm{~s} \mathrm{NH}_{3}$ injection delay, $300 \mathrm{~ms}$ mixing) effectively eliminated about $12 \mathrm{ppm}$ of ammonia slip by adjusting the NSR from 2 to 1 .

Whether additional $\mathrm{N}$-agent helps or hurts depends on the specific conditions at which it reacts, with optimum performance usually confined to a finite range of injection temperatures. This is analogous to the behavior of the basic thermal $\mathrm{DeNO}_{\mathrm{x}}$ process $\left(\mathrm{NH}_{3}\right.$ injection alone under fuel-lean conditions), which has been extensively studied and characterized. 


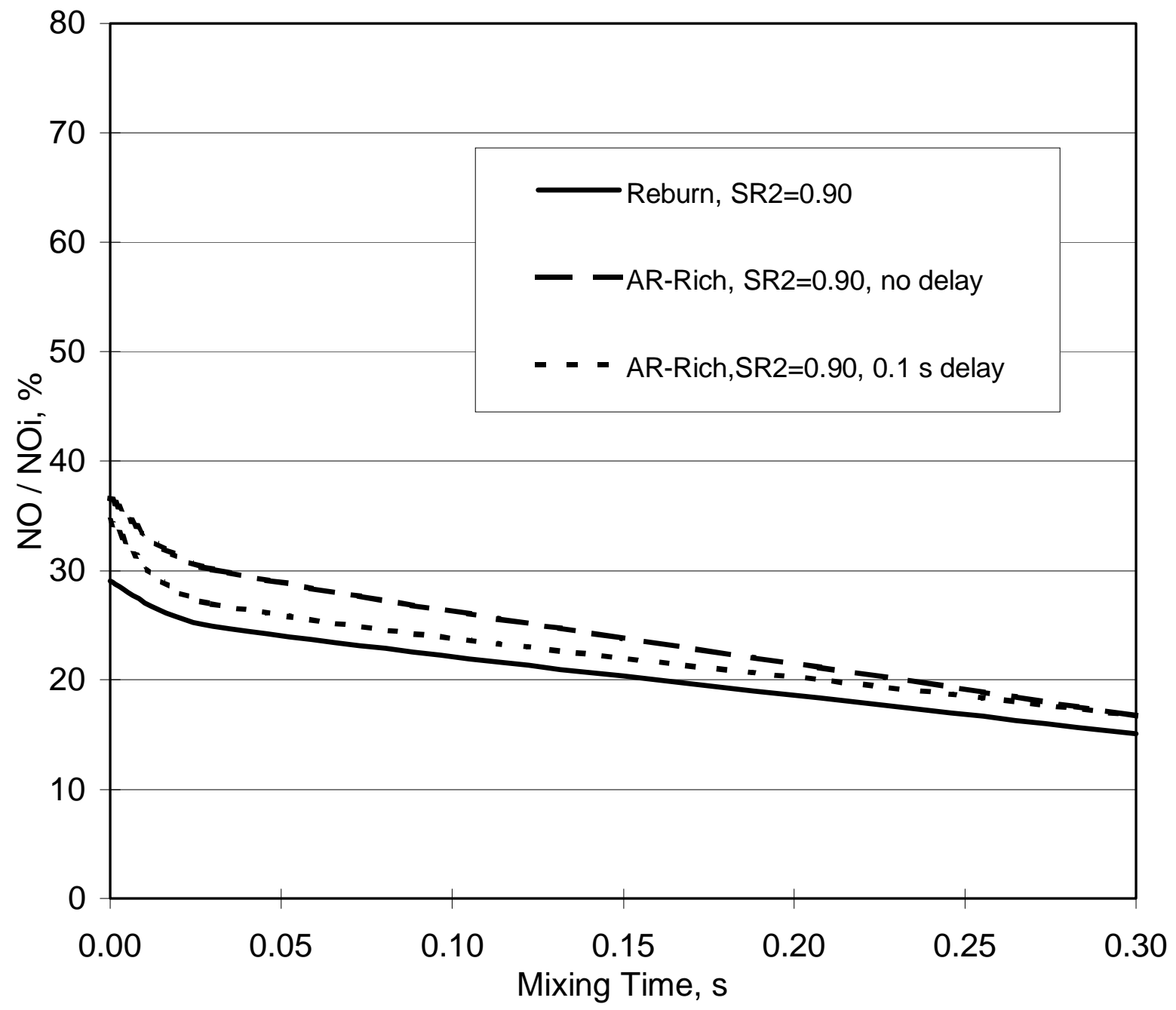

Figure 4.1. AR-Rich $\mathrm{NO}$ emissions, for $\mathrm{SR}_{2}=0.90$ and $\mathrm{NH}_{3}$ added to $\mathrm{NSR}=1$ at the point of injection. 


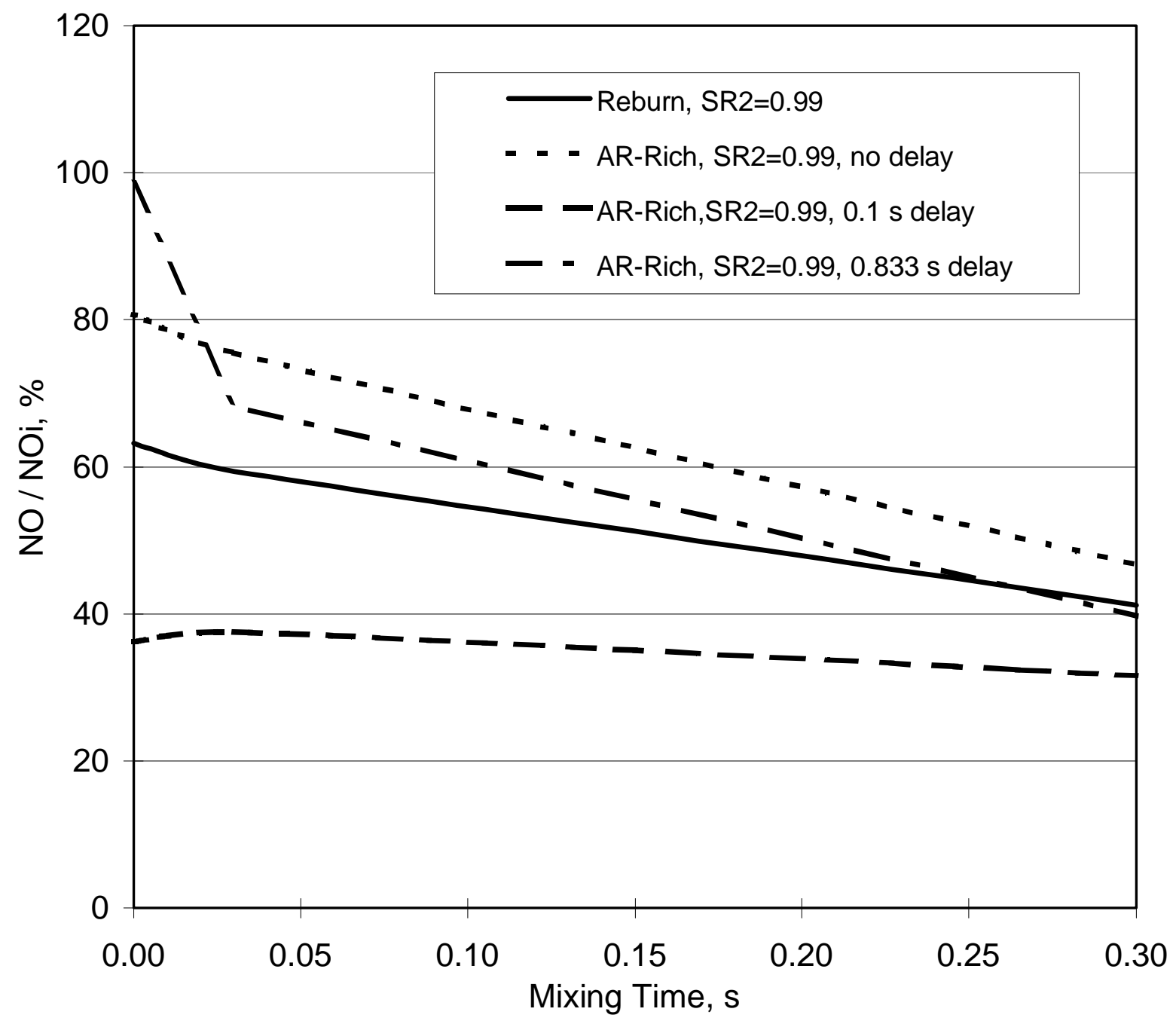

Figure 4.2. AR-Rich $\mathrm{NO}$ emissions, for $\mathrm{SR}_{2}=0.99$ and $\mathrm{NH}_{3}$ added to $\mathrm{NSR}=1$ at the point of injection. 


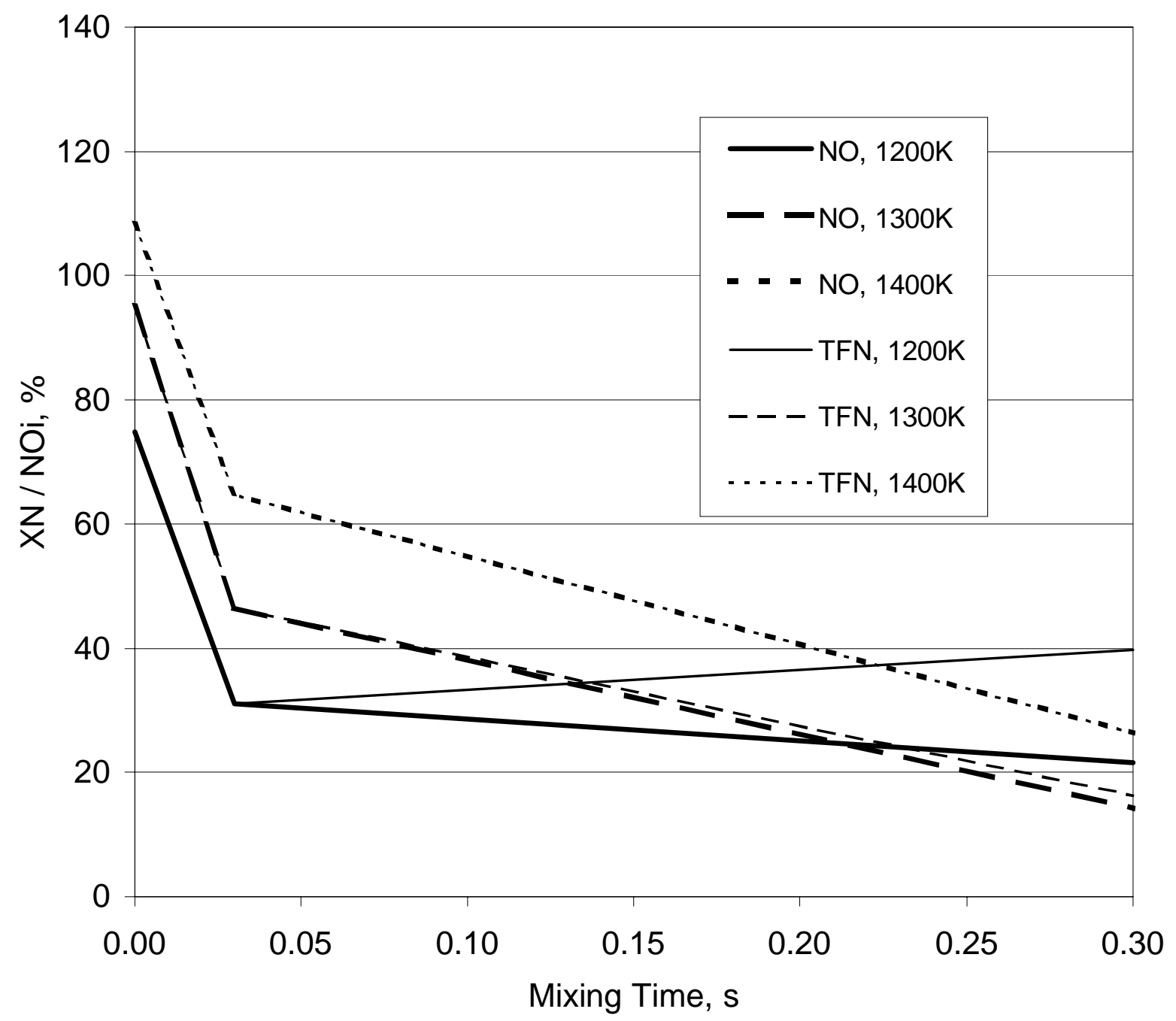

Figure 4.3. AR-Lean $\mathrm{NO}$ emissions, for $\mathrm{SR}_{2}=0.99$ and $\mathrm{NH}_{3}$ added at the same time as burnout air, to NSR=1 at the point of injection. 


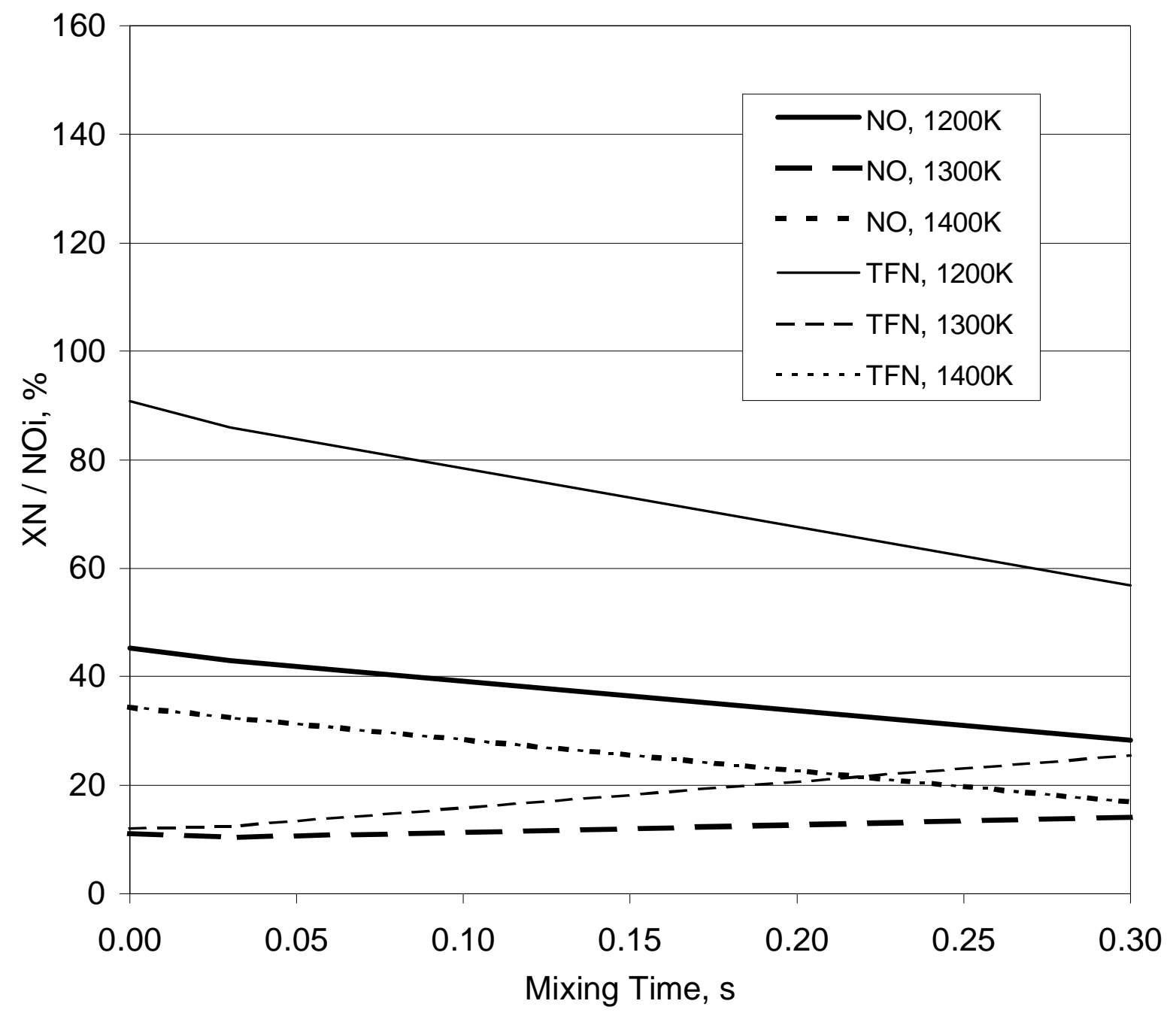

Figure 4.4. AR-Lean $\mathrm{NO}$ emissions, for $\mathrm{SR}_{2}=0.99$ and $\mathrm{NH}_{3}$ added $0.1 \mathrm{~s}$ after burnout air, to $\mathrm{NSR}=1$ at the point of injection. 


\subsection{Effect of Sodium Promotion in AR-Rich}

The continued refinement of the reactor model of the basic Advanced Reburning system lends confidence for extending the model to more complex Second-Generation Advanced Reburning (SGAR) processes. Of immediate interest is gas-fired AR with sodium promotion, for which measurements are being gathered in the experimental portion of this program.

The University of Texas subcontract for this program is providing experimental data which will enhance our fundamental understanding of sodium chemistry under conditions of interest for SGAR. In the previous report (Zamansky et al., January 1997) a preliminary sodium mechanism has been added to the chemical mechanism for combustion and nitrogen chemistry. The reactions and rates have been estimated based on the current literature and understanding of these processes. Using the same methodology, additional reactions have been included for other elements, including sulfur and chlorine, which are not present in a gas fired system but which may be significant in a system fired with coal or waste fuels. In this report, the mechanism was updated to include reactions of sodium carbonate (2.5-2.7) discussed in Section 2.0.

The initial cases considered here are for AR-Rich conditions based on the model described in Section 4.1 above. The stoichiometric ratios are nominally 1.10 in the primary zone, 0.99 in the reburn zone, and 1.15 in the burnout zone. Reburn fuel is injected at $1700 \mathrm{~K}$, after which the gas cools at a constant rate of $300 \mathrm{~K} / \mathrm{s}$. N-agent and sodium promoter, if any, are co-injected at $0.1 \mathrm{~s}$ after the beginning of reburn fuel injection (this condition selected as it showed promise in the earlier AR-Rich studies, as shown in Figure 4.2). The results presented here are for the AR-Rich reburn zone only. Calculations are in progress for promoted AR-Lean and for the AR-Rich burnout zone. The work being reported here focuses on the chemistry of the AR-Rich reburning zone, with or without a sodium promoter. When included, the sodium promoter is $50 \mathrm{ppm}$ of $\mathrm{Na}_{2} \mathrm{CO}_{3}$.

Figures 4.5 through 4.10 show the kinetic curves for the AR-Rich reburning zone with and without promotion, for NSR=1.0. The curves start at the point at which the injection of reburn fuel begins $(1700 \mathrm{~K})$, and continues for $1.0 \mathrm{~s}$ of reactor time (to a temperature of $1400 \mathrm{~K}$ ). 
Figures 4.5 and 4.6 are the kinetic curves with and without sodium promoter, respectively, for the reactor with instantaneous mixing. The discontinuity at $0.1 \mathrm{~s}$ is due to the sudden premixing of the additives at that location. For these conditions, there is little net impact of sodium promotion. The greatest change is that $\mathrm{O}_{2}$ disappears more rapidly in the presence of the promoter. Correspondingly, the radicals $\mathrm{H}$ and $\mathrm{OH}$ also decrease more quickly for the case with sodium. The net impact is that the final concentrations of $\mathrm{NO}$ and $\mathrm{NH}_{3}$ are actually somewhat lower in the case without promoter. However, the differences are relatively small.

Figures 4.7 and 4.8 show the corresponding behavior for $30 \mathrm{~ms}$ mixing. The kinetic curves are similar to those for instantaneous mixing, again with promotion causing a more rapid decline in $\mathrm{O}_{2}, \mathrm{OH}$, and H. With the distributed mixing, however, the sudden change in concentrations at the addition points is smoothed over the mixing time. $30 \mathrm{~ms}$ is relatively fast in terms of the overall reaction time, but at the given conditions the chemical reactions are faster. Therefore, the distributed mixing does change the shape of the curves and affect the downstream composition. In this case the net effect of the sodium promoter is a slight decrease in the NO concentrations near the end of the zone shown, accompanied by a slight increase in $\mathrm{NH}_{3}$.

Figures 4.9 and 4.10 show the kinetic curves for $300 \mathrm{~ms}$ mixing, with and without promoter. Here the mixing is distributed over such a long time that the chemistry is definitely affected. The long mixing times result in slow progression though a range of stoichiometries and local NSR's as the reburn fuel, N-agent, and overfire air are slowly introduced. Since the mixing time is longer than the delay between reburn fuel and $\mathrm{N}$-agent addition, these two mixing zones actually overlap. Interestingly, there is still an appearance of a step change in the unpromoted profile in Figure 4.10, but now it is at the end of staging (for reburn fuel, at $0.3 \mathrm{~s}$ ) rather than at the start of injection. At 0.3 s, the supply of reburn fuel is out and the pool of radicals and unburned fuel that it helps to sustain now begins to disappear, changing the direction of the kinetic curves at that point. With sodium promotion, even this transition is spread out, suggesting that in this case the sodium promoter helps to sustain the radical pool. In this case, the sodium promoter has a definite beneficial effect on NO and TFN emissions. 


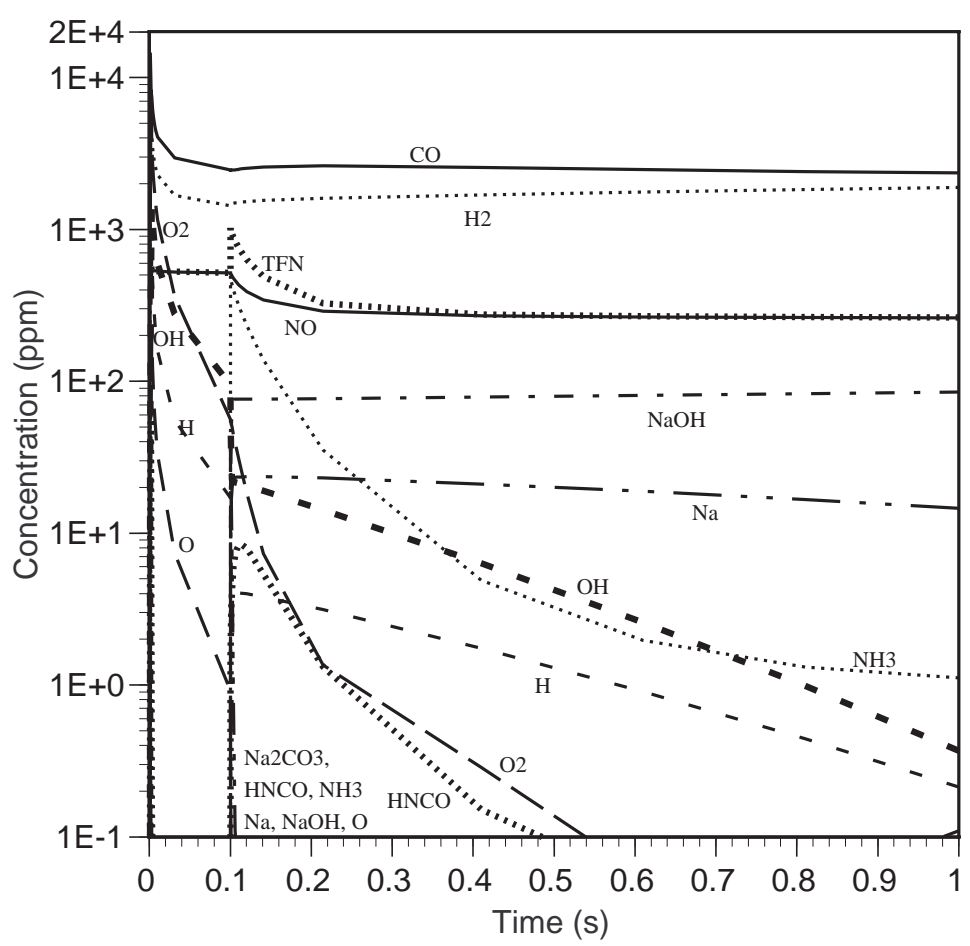

Figure 4.5. Promoted AR-Rich kinetic curves from the point of $\mathrm{NH}_{3}(\mathrm{NSR}=1)$ and $50 \mathrm{ppm}$ $\mathrm{Na}_{2} \mathrm{CO}_{3}$ injection (100 ms after reburn fuel), with instantaneous mixing.

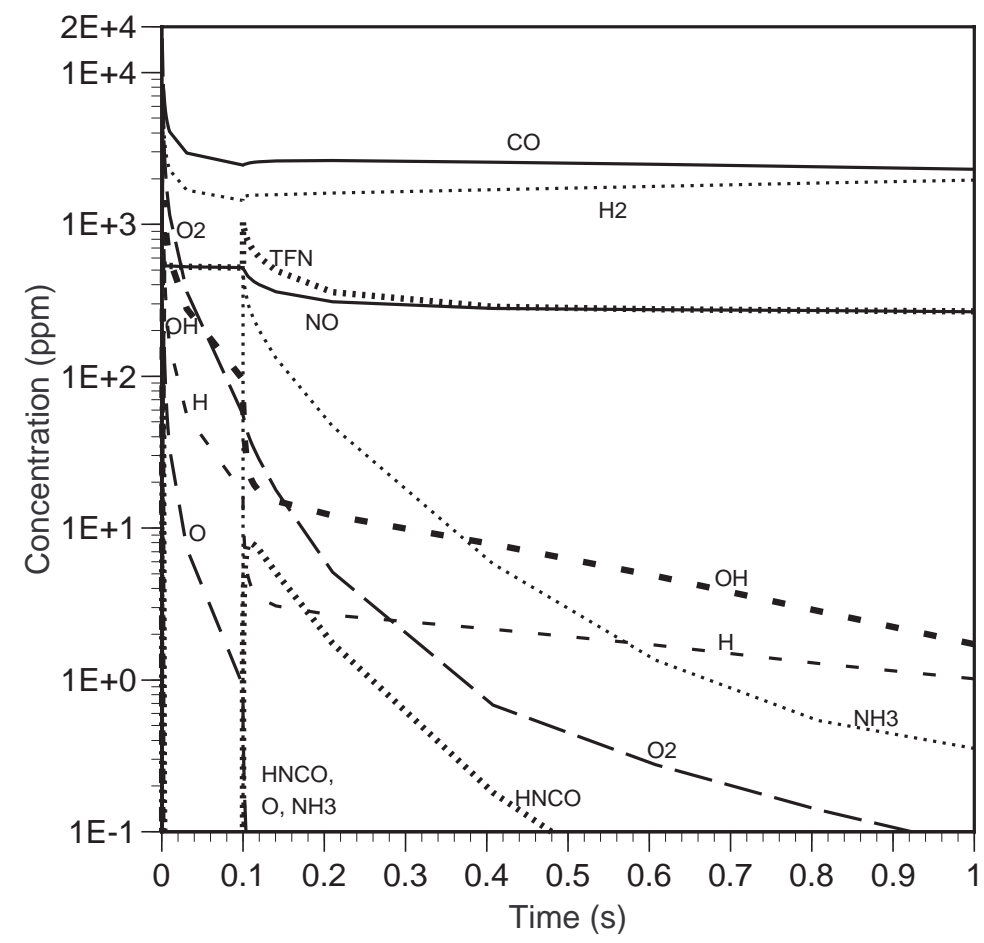

Figure 4.6. Unpromoted AR-Rich kinetic curves from the point of $\mathrm{NH}_{3}(\mathrm{NSR}=1)$ injection (100 ms after reburn fuel), with instantaneous mixing. 


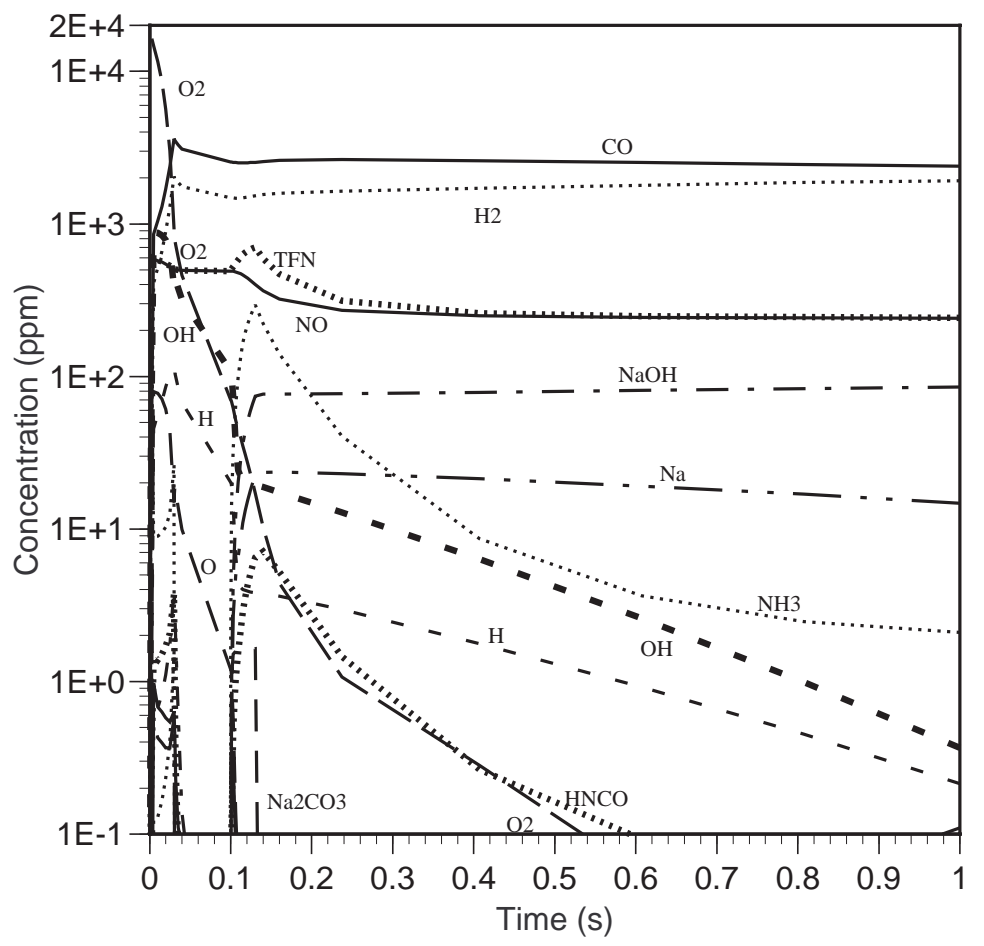

Figure 4.7. Promoted AR-Rich kinetic curves from the point of $\mathrm{NH}_{3}(\mathrm{NSR}=1)$ and $50 \mathrm{ppm}$ $\mathrm{Na}_{2} \mathrm{CO}_{3}$ injection (100 ms after reburn fuel), with $30 \mathrm{~ms}$ mixing.

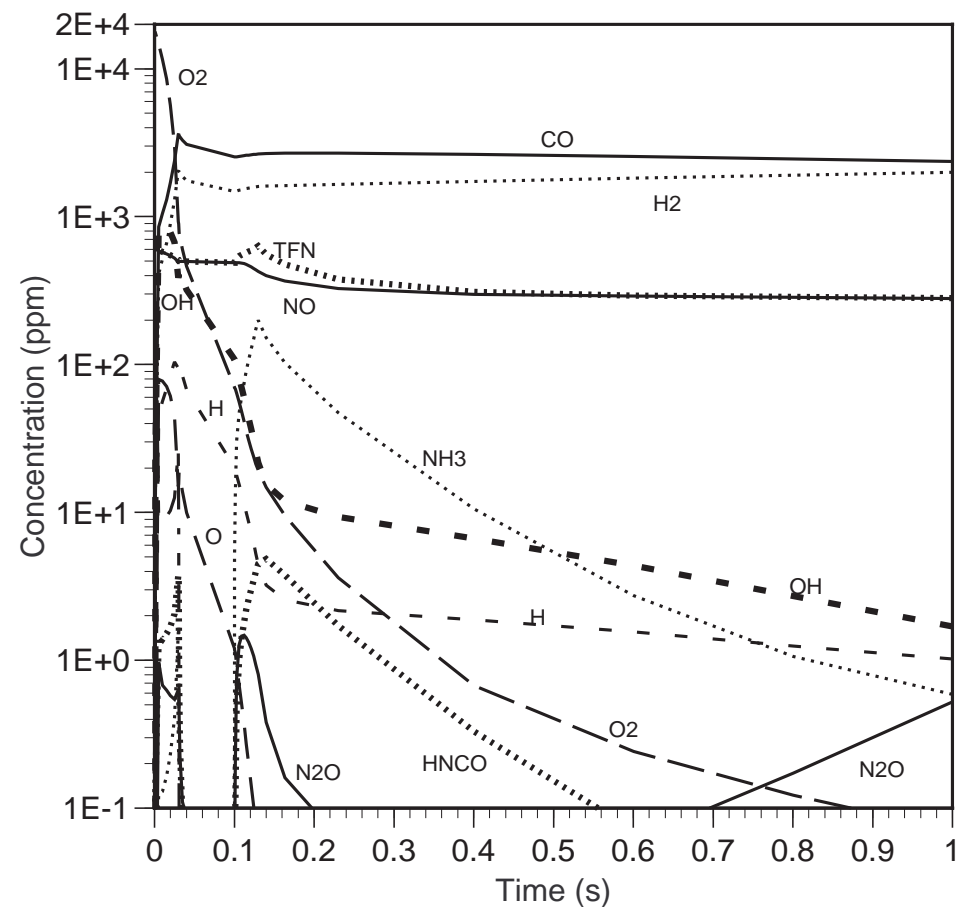

Figure 4.8. Unpromoted AR-Rich kinetic curves from the point of $\mathrm{NH}_{3}(\mathrm{NSR}=1)$ injection (100 ms after reburn fuel), with $30 \mathrm{~ms}$ mixing. 


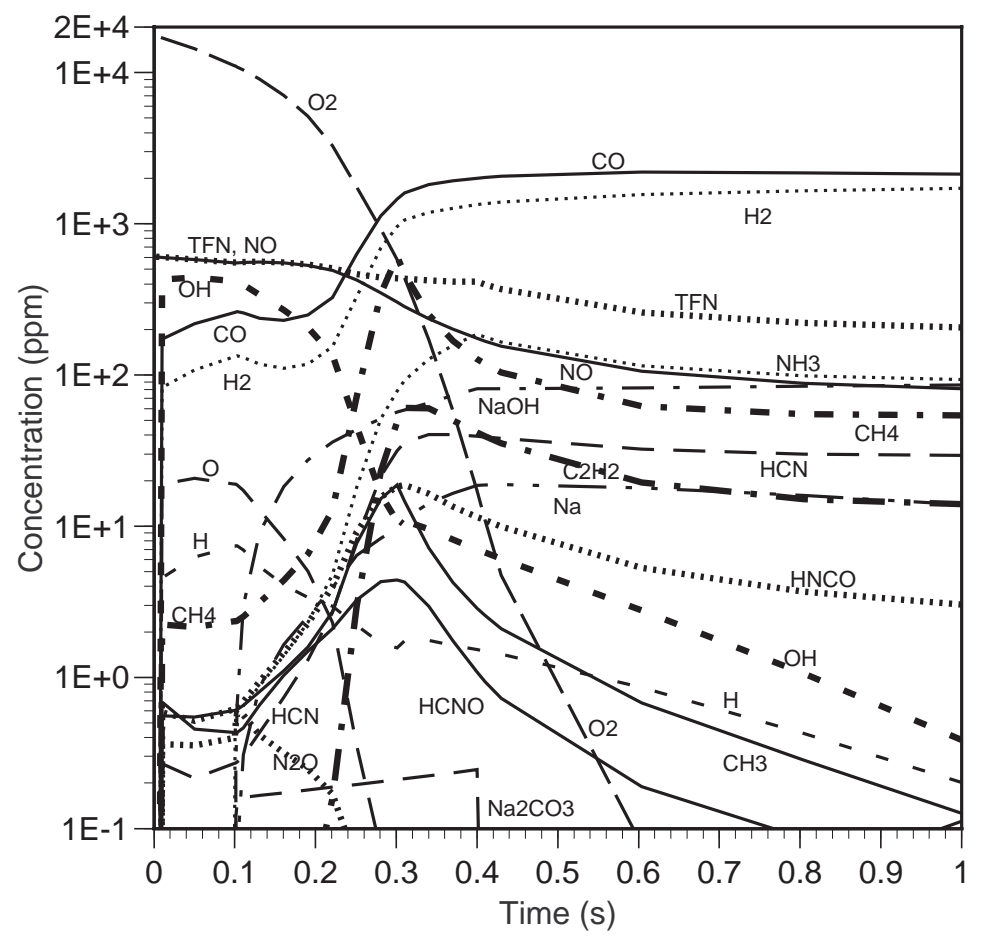

Figure 4.9. Promoted AR-Rich kinetic curves from the point of $\mathrm{NH}_{3}(\mathrm{NSR}=1)$ and $50 \mathrm{ppm}$ $\mathrm{Na}_{2} \mathrm{CO}_{3}$ injection (100 ms after reburn fuel), with $300 \mathrm{~ms}$ mixing.

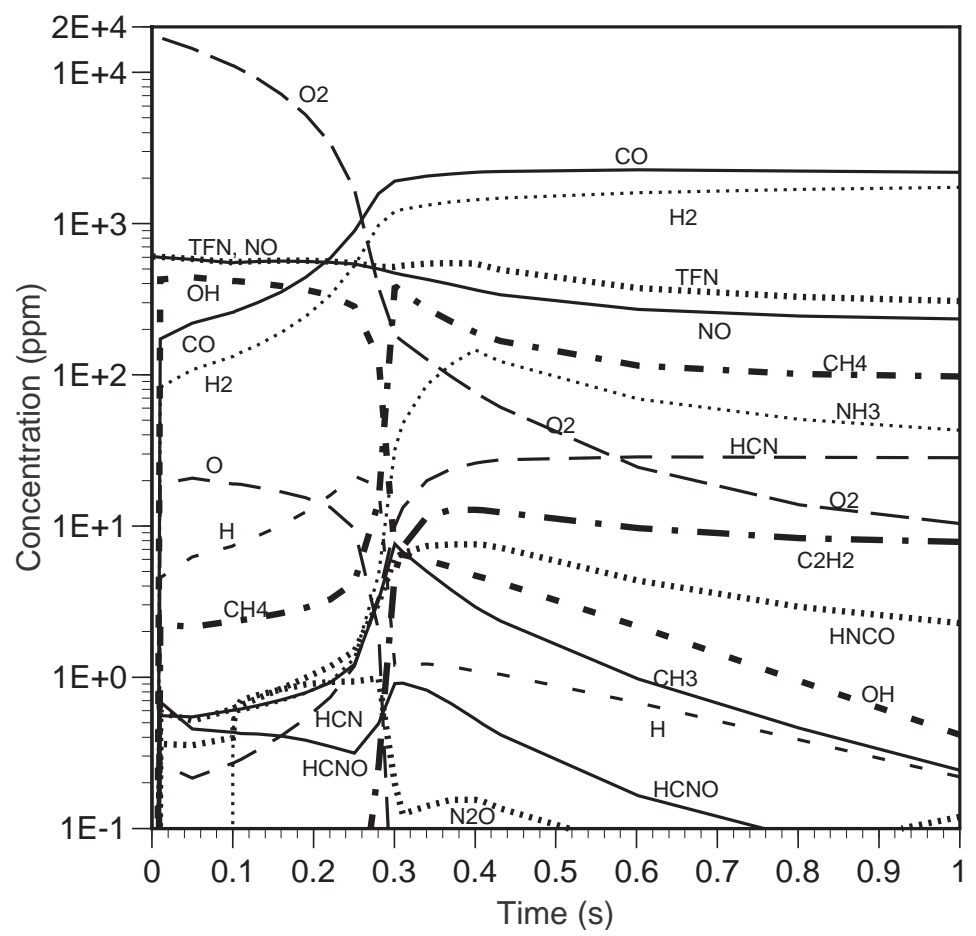

Figure 4.10. Unpromoted AR-Rich kinetic curves from the point of $\mathrm{NH}_{3}(\mathrm{NSR}=1)$ injection (100 ms after reburn fuel), with 300 ms mixing. 
The net impact of promotion is illustrated in Figure 4.11, which shows the concentration of NO and TFN in the reburn zone at $1300 \mathrm{~K}$ (1.33 s after the start of reburn fuel injection), with and without sodium promotion. At instantaneous mixing, the promoter has a very slight negative effect on emissions. However, for mixing times as short as $30 \mathrm{~ms}$, promotion begins to show a beneficial effect. For longer mixing times representative of industrial installations, the effect is quite pronounced. Longer mixing times also show very large TFN concentrations aside from NO, but it should be remembered that this is before burnout.

As discussed before, the quantity of $\mathrm{N}$-agent can have a significant impact on system performance. To illustrate this, Figure 4-12 shows the results of AR-Rich calculations with the same conditions as for Figure 4-11, except that the injected N-agent is $800 \mathrm{ppm}$ in all cases. This guarantees an NSR greater than 1 since the initial NO is $600 \mathrm{ppm}$. The actual NSR is approximately 1.5 based on NO at the point of injection. As would be expected, the NO concentration decreases as more $\mathrm{N}$-agent is added, but note that the effect is non-linear. For instant mixing, the adverse effect of the sodium promoter within the reburning zone increases, but systems with finite mixing times still perform better with sodium promotion. The TFN also changes non-linearly as NSR increases. Most notably, at 30 ms mixing the inclusion of sodium promoter results in better NO removal with little additional TFN, but without promoter the additional $\mathrm{N}$-agent results in considerable ammonia slip which is reflected in the high TFN. The differences in the effect of promotion at different mixing times reflect the difference in kinetic behavior with mixing time, as illustrated in Figures 4.5 through 4.10. These changes in characteristic behavior are due to the effect of distributing mass addition, and at long mixing times the shift in temperature due to gas cooling also has an impact. Figures 4.11 and 4.12 demonstrate the potential improvement in NO and TFN reduction due to the inclusion of a promoter at finite mixing times characteristic of real combustion systems.

\subsection{Summary of Modeling Studies}

The chemical kinetic modeling studies this quarter focussed on the impact of the quantity of N-agent and on the impact of sodium promotion in AR-rich. It should be noted that: 


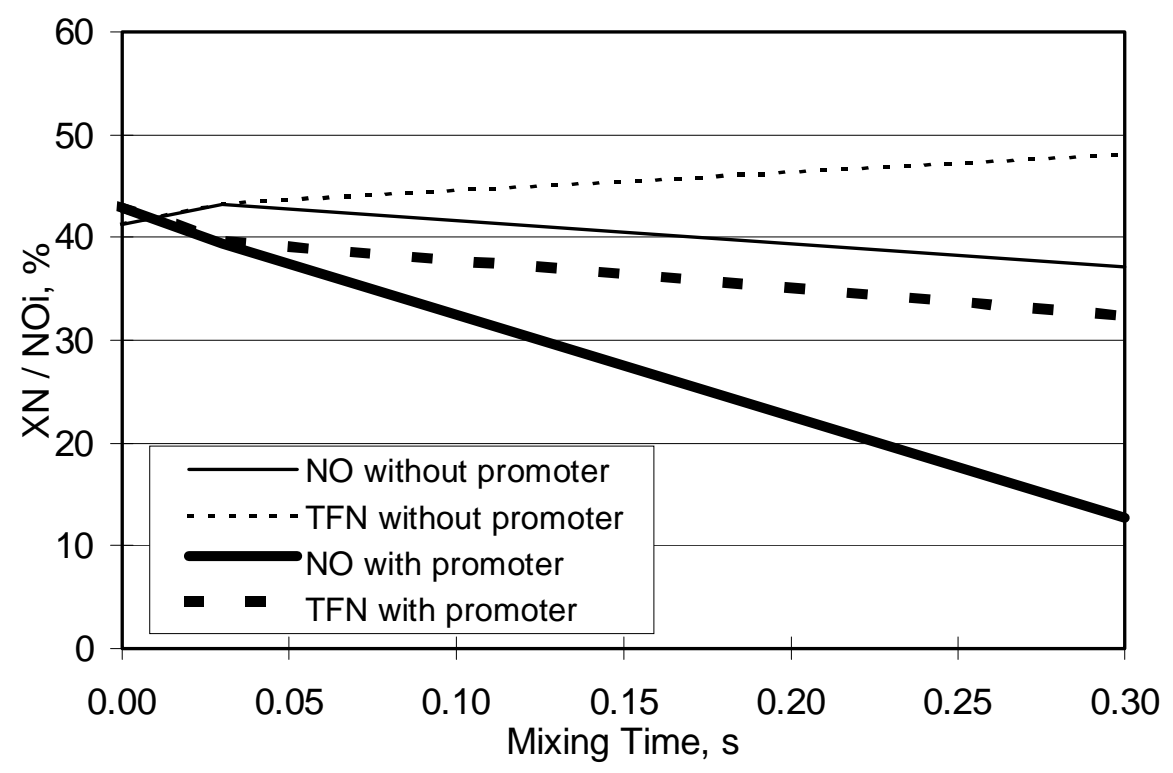

Figure 4.11. $\mathrm{NO}$ and Total Fixed Nitrogen before burnout for AR-Rich, $\mathrm{NH}_{3}$ added to $\mathrm{NSR}=1.0$ at the point of injection, with and without $50 \mathrm{ppm} \mathrm{Na}_{2} \mathrm{CO}_{3}$ promoter.

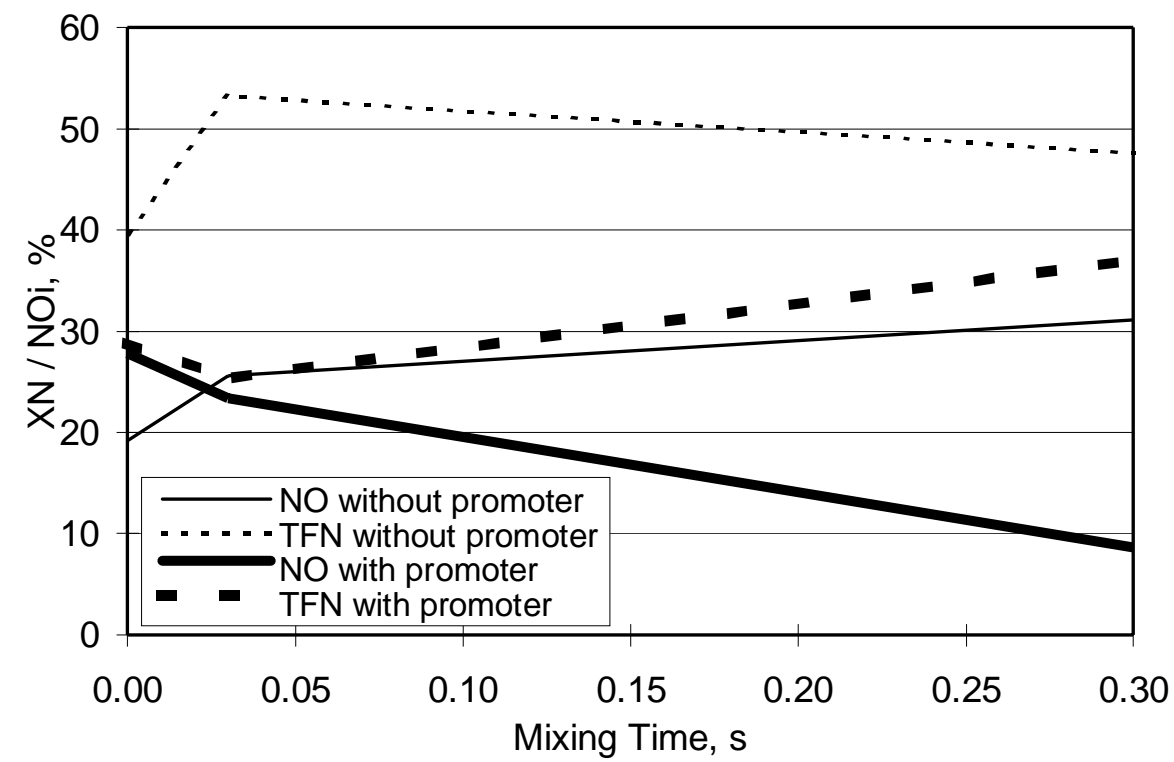

Figure 4.12. NO and Total Fixed Nitrogen before burnout for AR-Rich, $800 \mathrm{ppm} \mathrm{NH}_{3}$ added (NSR approximately 1.5), with and without $50 \mathrm{ppm} \mathrm{Na}_{2} \mathrm{CO}_{3}$ promoter. 
- Optimization of the amount of $\mathrm{N}$-agent is important to system performance. The quantity must be adequate for the degree of NO reduction but more is not necessarily better. Designing the injection system to promote uniform mixing should help minimize the quantity of $\mathrm{N}$-agent needed but the performance also depends on the characteristic time of mixing. The NSR and mixing time both affect the net NO reduction as well as the net concentration of other TFN species.

- Sodium promotion can improve AR-Rich performance by sustaining the radical pool when it is needed. This effect is most pronounced in systems with long characteristic mixing times, as is typical in full-scale industrial applications. Therefore, promoted advanced reburning continues to show promise for commercial implementation. 


\subsection{Design Methodology and Application}

The primary objectives of this task are to update EER's basic methodology for design and scale up of advanced reburning to utility boilers to include the second generation advanced reburning (SGAR) process developed in this project and to prepare a preliminary design for application of the most promising variation of the SGAR process to a typical utility boiler. This design will include sufficient information to permit the capital and operating costs and full scale $\mathrm{NO}_{\mathrm{x}}$ removal performance of the process to be defined. These costs can then be used to assess the economic effectiveness of the process in comparison to other $\mathrm{NO}_{\mathrm{x}}$ control technologies.

EER's general methodology for application of reburning and advanced reburning to utility boilers is shown in Figure 5.1. The design methodology uses various experimental and analytical tools to develop the injector specifications and operating characteristics of the reburning/advanced reburning system with the objective of meeting specific process requirements for optimum emissions control performance while maintaining boiler operation and performance at normal levels. The primary elements of the methodology consist of:

- Collection of system design and operating data to quantify the characteristics of the full-scale system, and to obtain data for use in model set up and calibration. This information should include the range of typical operation, specific unit limitations that should be taken into account in the design, and emissions controls requirements.

- Heat transfer modelling of the unit to predict the boiler's thermal characteristics as functions of various input and operational variables. This analysis is focussed on studying the impacts of the reburning process on boiler performance, and on identification of possible remedies for any adverse impacts which are expected to occur. 


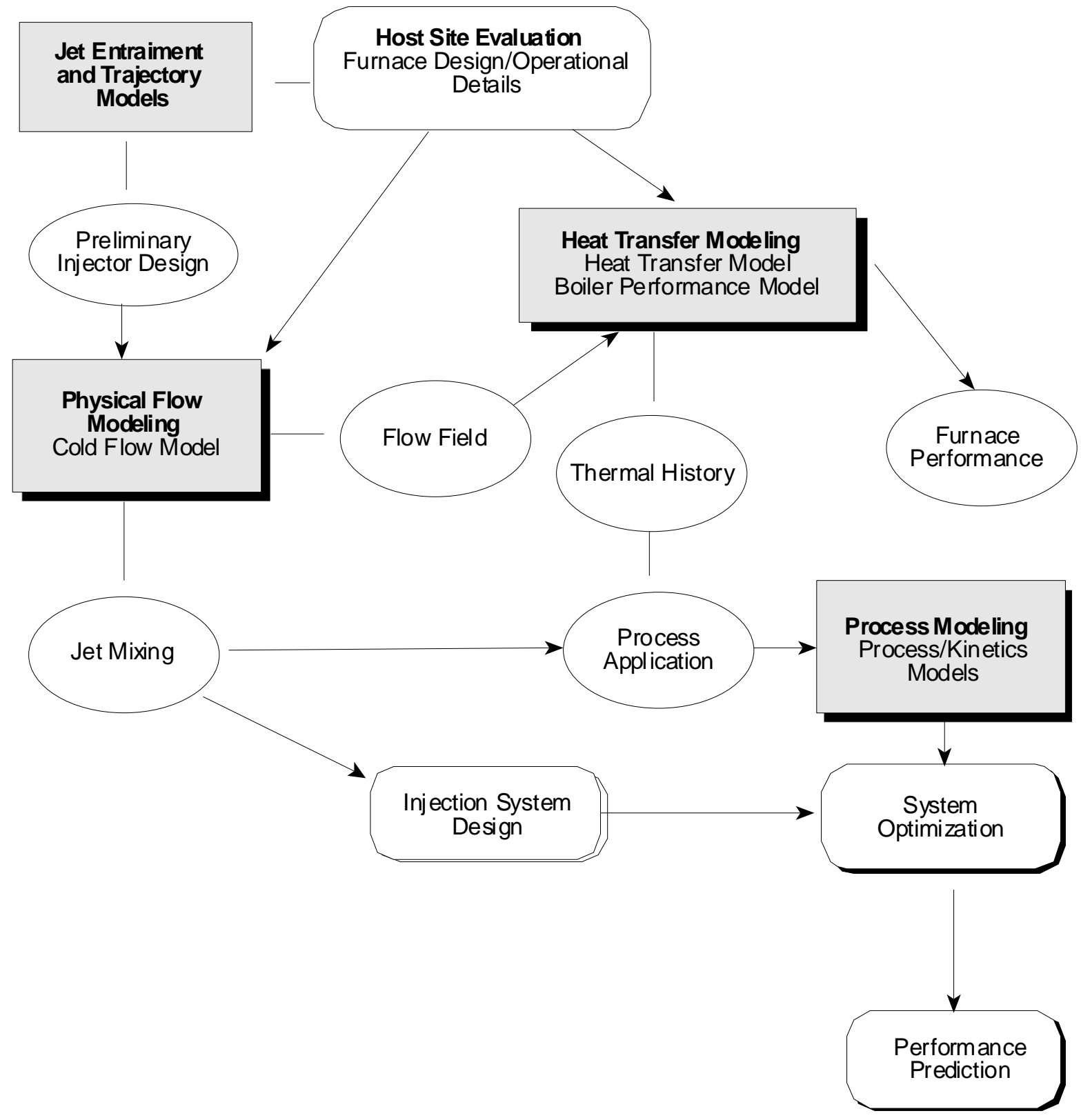

Figure 5.1. EER's general methodology for application of reburning and advanced reburning to utility boilers. 
- Isothermal flow modelling of the unit to simulate the full-scale furnace flow field, and to optimize the injection parameters of the reburning/advance reburning systems. A key objective of the flow model studies is to develop injection systems which provide rapid and uniform mixing of the reburning fuel, overfire air, and $\mathrm{N}$-agent.

- Development of performance predictions for full-scale applications of the reburning process using process and kinetic models developed from the results of subscale tests and the fundamental chemistry involved in the process. Model predictions under ideal mixing conditions are used in conjunction with the results of isothermal model mixing studies to assess the impacts of mixing on reburning/advanced reburning performance.

This design methodology has been used to scale up and apply reburning and advanced reburning technologies to utility boilers. In this task of the project, EER will update this methodology to take into account the specific requirements of the SGAR process. To demonstrate the applicability of the final methodology, EER will apply it to a typical full-scale utility boiler to develop a design for the most promising of the SGAR process variation.

During this reporting period, work was focussed on reviewing the results of the pilot scale tests conducted to date and on developing a plan for modification of the methodology. The results of the small scale studies show that the SGAR process could be implemented at full scale in a number of different configurations. Each of these configurations is expected to have its own specific requirements for optimum full-scale implementation. In comparing the SGAR processes to conventional advanced reburning (AR-Lean), the key difference between the processes appears to be the need for multiple injection locations for reagent and/or rich side additive. Incorporating multiple injection stages into the design methodology raises the following questions:

- Can injection systems be designed to rapidly mix one stage of agent or additive prior to injection of a second stage of reagent within the optimum temperature windows implied by the results of small-scale tests? 
- What is the impact of the three-dimensionality of the flow and temperature field in the temperature regions of interest on the effectiveness of the process and on the design of an optimum injection system?

- Can process/kinetic models be developed to account properly for process chemistry and mixing effects?

The scope of work performed in this task will focus on addressing these issues. First, an existing physical model of a large utility boiler will be set up to study injection systems for potential implementations of the SGAR process. Mixing studies will be performed to evaluate the requirements for applying the process to a full-scale boiler. The results of this study will provide information on the number and characteristics of wall or lance injectors needed to achieve uniform distribution of reagent or additive within a narrow window. Second, a three dimensional heat transfer model of the boiler will be set up to predict the temperature field in the upper furnace with emphasis on the regions of interest. The temperature field will be used to evaluate the ability of the proposed injection schemes to distribute the reagent into the regions of interest. Combination of the results of the flow model and heat transfer model studies will provide information on the time-temperature profiles associated with the injected materials and will permit prediction of full-scale performance. Third, process/kinetic models will be developed based upon the results of the small scale and kinetic model studies to predict the performance of the SGAR process. These models will be applied to the results of the previous studies to predict the potential performance for the process which can be archived at full scale.

Evaluation of the effectiveness of the different AR variants and their potential impacts on the boiler performance and operation will lead to selection of one configuration which has the highest potential for successful full-scale implementation. Preliminary costs estimates for application of this configuration to the subject boiler will be developed and used for comparison of the cost effectiveness of the SGAR process to other technologies. 


\section{0 Summary and Conclusions}

1. Kinetic study of $\mathrm{Na}_{2} \mathrm{CO}_{3}$ reactions shows that decomposition of $\mathrm{Na}_{2} \mathrm{CO}_{3}$ from 900 to 1190 K can be described in terms of two irreversible (2.5) and (2.6) and one reversible (2.7) chemical reactions. The necessary rate coefficients were adjusted to describe the measured rate of $\mathrm{Na}_{2} \mathrm{CO}_{3}$ decomposition, while the rate coefficient of reaction (2.7) was estimated from kinetic data for the similar reaction of $\mathrm{CaO}$.

2. Mass spectrometric analysis of products of $\mathrm{Na}_{2} \mathrm{CO}_{3}$ decomposition confirms that the primary gas-phase products of decomposition are $\mathrm{Na}, \mathrm{NaOH}$ and $\mathrm{CO}_{2}$. Experiments with temperature control show formation of $\mathrm{Na}$ atoms at temperature $1235 \mathrm{~K}$.

3. The BSF parametric pilot scale tests with Illinois coal firing demonstrated that the AR technologies are able to provide effective $\mathrm{NO}_{\mathrm{x}}$ control for a high-sulfur coal fired combustor. Sodium was found to significantly promote performance when added at $150 \mathrm{ppm}$, which can be a manageable level for most utility boilers. Maximum NO reductions achieved by the promoted AR technologies were $84 \%$ for AR-Lean, $93 \%$ for AR-Rich, $94 \%$ for reburning plus SNCR, and $95 \%$ for MIAR.

4. AR technologies do not generate significant byproduct emissions in comparison with basic reburning and SNCR processes under similar conditions. In most cases, byproduct emissions were found to be lower for the AR technologies.

5. Modeling demonstrated that optimization of the amount of $\mathrm{N}$-agent is important to $\mathrm{AR}$ system performance. The quantity must be adequate for the degree of NO reduction but more is not necessarily better. The NSR and mixing time both affect the net NO reduction.

6. Modeling predicts that sodium promotion can improve AR-Rich performance by sustaining the radical pool when it is needed. This effect is most pronounced in systems with long characteristic mixing times, as is typical in full-scale industrial applications. Therefore, promoted advanced reburning shows promise for commercial implementation.

7. A detailed plan was prepared for updating EER's basic methodology for design and scale up of AR to utility boilers to include the second generation improvements. 


\subsection{Future Plans}

The main activities of the next quarter will include continuation of the modeling study on identification of sodium promotion mechanisms under reburning and burnout conditions. The experimental program at the University of Texas will also be continued with the goal to develop and confirm the sodium promotion mechanism. A flow system study on reactions of $\mathrm{Na}_{2} \mathrm{CO}_{3}$ with components of flue gas will be conducted. Modeling will include reaction kinetics of $\mathrm{Na}$ atoms and Na-containing species, under conditions relevant to $\mathrm{NO}_{\mathrm{x}}$ reduction, in particular their interactions with $\mathrm{NO}_{\mathrm{x}}$ and $\mathrm{SO}_{\mathrm{x}}$ chemistry. Main results on developing engineering design methodology of the second generation AR processes will be obtained, including economic and market analysis of controlling NO emissions. Results of these and previous project activities will be summarized in a comprehensive draft final report to be submitted to FETC by July 31, 1997. Simultaneously, a Phase II proposal on project continuation for the next three years will be submitted. 


\subsection{References}

Cotton, D.H. and Jenkins, D.R., Trans. Faraday Soc. 67, 730, 1971.

Feitelberg, A.S., CET89 for the Macintosh: A Chemical Equilibrium and Transport Properties Calculator. General Electric Company, 1994.

Kee, R.J., Rupley, F.M. and Miller, J.A., Chemkin II: a Fortran Chemical Kinetics Package for the Analysis of Gas Phase Chemical Kinetics, Sandia National Laboratories, Report SAND89-8009, 1992.

McBride, B.J., Gordon, S. and Reno, M.A., Coefficients for Calculating Thermodynamic and Transport Properties of Individual Species, NASA Technical Memorandum 4513, October, 1993.

Zamansky, V.M. and Maly, P.M., Second Generation Advanced Reburning for High Efficiency NOx Control, EER 4th Quarterly Report, DOE Contract No. DE-AC22-95PC95251, October, 1996.

Zamansky, V.M., Maly, P.M. and Sheldon, M. S. Second Generation Advanced Reburning for High Efficiency NOx Control, EER 5th Quarterly Report, DOE Contract No. DEAC22-95PC95251, January, 1997. 